University of Rhode Island

DigitalCommons@URI

Open Access Dissertations

1997

\title{
Individual Differences in Timing Measures: Continuation Tapping, Relaxation Time, Reaction Time, and Critical Flicker Fusion
}

Anna S. Klevak

University of Rhode Island

Follow this and additional works at: https://digitalcommons.uri.edu/oa_diss

\section{Recommended Citation}

Klevak, Anna S., "Individual Differences in Timing Measures: Continuation Tapping, Relaxation Time, Reaction Time, and Critical Flicker Fusion" (1997). Open Access Dissertations. Paper 989. https://digitalcommons.uri.edu/oa_diss/989

This Dissertation is brought to you for free and open access by DigitalCommons@URI. It has been accepted for inclusion in Open Access Dissertations by an authorized administrator of DigitalCommons@URI. For more information, please contact digitalcommons-group@uri.edu. 
INDIVIDUAL DIFFERENCES IN TIMING MEASURES: CONTINUATION TAPPING, REIAXATION TIME, REACTION TIME, AND CRITICAL

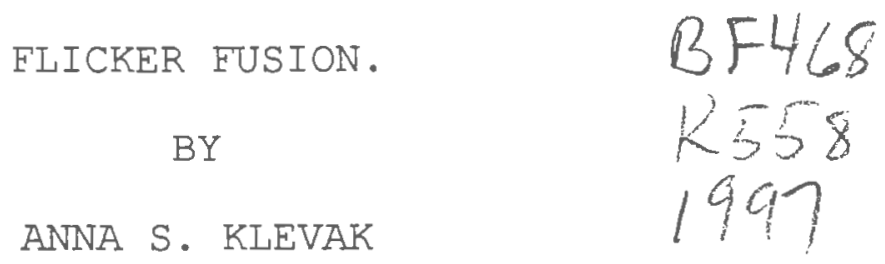

A DISSERTATION SUBMITTED IN PARTIAL FULFILLMENT OF THE REQUIREMENTS FOR THE DEGREE OF DOCTOR OF PHILOSOPHY

IN

PSYCHOLOGY

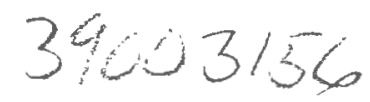

UNIVERSITY OF RHODE ISLAND 


\section{ABSTRACT}

In order to investigate human time sense individual differences in timing were studied in a sample of 39 healthy adults at rest. Fast Muscular Relaxation Time, Preferred. Muscular Relaxation Time, Critical Flicker Fusion Threshold, Continuation Tapping, and Simple and Choice Reaction Times were examined with the aim of determining both linear and non-linear relationships among the measures. Several significant linear relationships among the variables were obtained. Subjects with higher Critical Flicker Fusion threshold exhibited significantly less overall variability in timing, $(\mathrm{p}<0.001)$ and showed a slower increase in variability with increasing interstimulus interval. The Simple Reaction Time was positively correlated with the Fast Relaxation time $(p<0.05)$. The finding of a positive association between Choice Reaction time and Simple Reaction time $(p<0.001)$ was replicated in the present research. Subjects whose scores were located in the middle of the Preferred Muscular Relaxation Time (PMRT) distribution of scores exhibited less overall variability in continuation Tapping $(\mathrm{p}<0.05)$ in comparison with subjects who were located at both ends of the PMRT distribution of scores. The effect was attributed to the mechanism of a biological clock. 
Some evidence for a relationship between the continuation tapping task and the single-response tasks was found. There was a tendency for Fast Muscular Relaxation Time, Preferred Muscular Relaxation Time, and Choice Reaction Time, to fall at time intervals where there are local maxima or minima in the function relating bias in continuation tapping to interstimulus interval. Overall, these relationships support the theory of multiple oscillators and the pattern of data suggests a rather strong possibility that the studied temporal characteristics are regulated by a common oscillatory timing mechanism. 


\section{ACKNOWLEDGMENT}

This research represents a pinnacle of my interest of many years in the study of individual differences in temporal characteristics. Naturally, I have accrued indebtedness to many people over the years of these studies. I would like to express my deepest gratitude to my Professor at the Leningrad University, Joseph Paley, who greatly influenced my thinking in psychology and my choice of subject matter. Despite the fact that I was his student during the end of the $1970^{\prime} \mathrm{s}$, I still utilize some of his creative ideas.

Since I undertook these studies in the United States, my work has been enriched by many special people. First and foremost, I would like to thank my advisor, Professor Charles Collyer, who has always been a rich source of knowledge for me and who has provided support during these years. When we first met, it was sometimes difficult for us to understand each other, being from different cultural backgrounds. However, he was always very patient with me and willing to make sense of my English.

My gratitude also extends to the members of my committee for their efforts in assisting me through the process of my graduate experience: Professor Mark Rowinski at the Physical Therapy Department for his exceptional help 
in providing me with the equipment for this research and for his useful comments on the project. To Professor Paul Florin, who has been always willing to help me in any way and especially for providing me with the opportunity to work with subjects for the pilot study. Professor Nelson Smith, who was always ready to help with the equipment and to discuss any problems and questions that arose. It gives me pleasure to also thank Professor James Agostinucci, at the Physical Therapy Department, who while not a committee member, had given me his lab which I had occupied for almost three years and had never heard a word of complaint.

My deepest gratitude goes to my friend Julian Butler, who during these years was close by, helping me in every aspect of technical support and for writing several excellent software programs for this research. I am also thankful to my friends Alexander Zaslavsky, and Leonid Sheftelevich for their help on this project.

I owe a tremendous debt to my long suffering husband Eugene who during these years has been a source of immeasurable support; and to my brother Dmitry, who always has been willing to help me with any problems that arose; and to my mother Galina who took care of my family during these years and for her love and encouragement that has so enriched my life. 


\section{DEDICATION}

To two wonderful boys Andrew and Mitchell who bring joy and sense of purpose into my life. 


\section{TABLE OF CONTENTS}

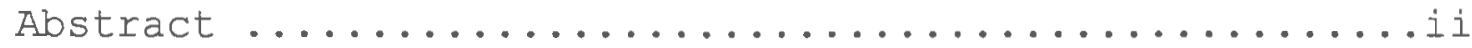

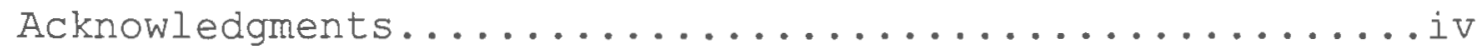

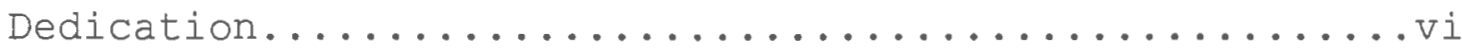

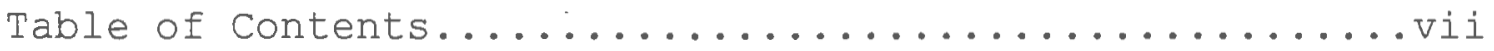

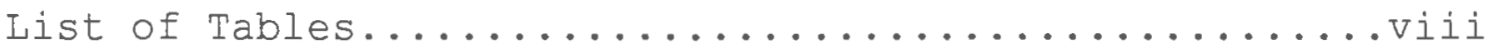

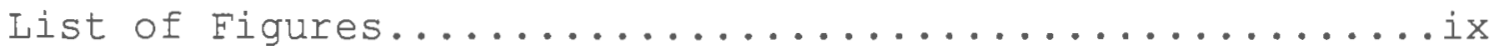

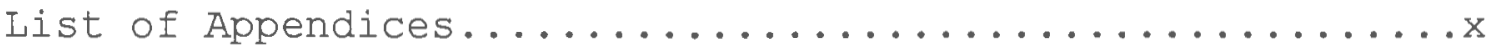

Introduction $\ldots \ldots \ldots \ldots \ldots \ldots \ldots \ldots \ldots \ldots \ldots \ldots \ldots \ldots \ldots \ldots \ldots \ldots \ldots$

Research on Individual Time sense.................

Research in Skeletal Muscular Relaxation .............

Research in Critical Flicker Fusion Threshold..........14

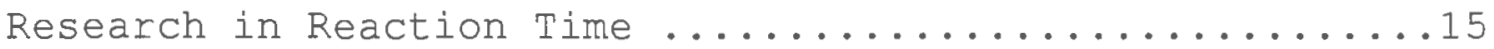

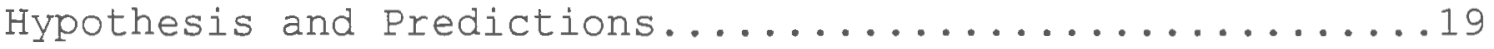

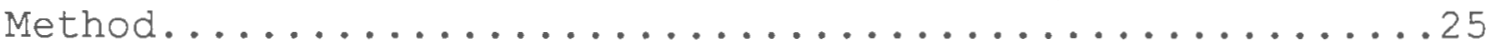

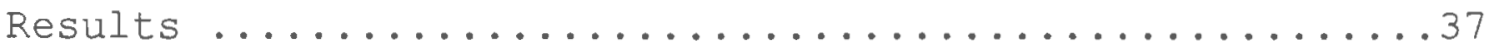

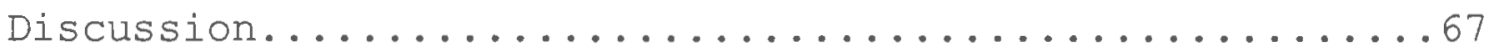

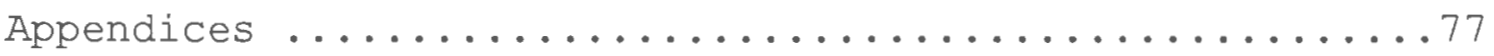

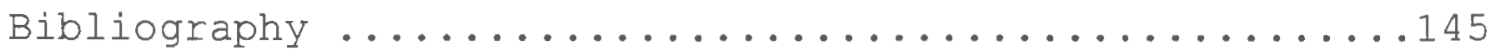




\section{LIST OF TABLES}

TABLE I ------- Mean values for Fast Muscular Relaxation Time (FMRT), Simple Reaction Time (SRT), Choice Reaction Time (CRT) in Experiment 1. (p.39).

TABLE II

Mean values for Critical Flicker Fusion

Time(CFFT), Fast Muscular Relaxation

Time(FMRT), Preferred Muscular

Relaxation Time(PMRT), Simple Reaction

Time(SRT), SRT Button Time(SRTBT),

Choice Reaction Time(CRT), CRT Button

Time (CRTBT). (p. 41).

Table III. ------ Correlations Among the Variables. $(\mathrm{p} .44)$.

Table IV.-------- Regression Coefficients for Standard Deviation of ISI. (P. 54). 


\section{IIST OF FIGURES}

Figure 1

Figure 2.

Figure
Scattergram: SIQR/ISI and CFFT. (p.45).

Scattergram: Slope of Standard Deviation vs ISI Function and CFFT. (p.46).

Figure $3 a$.

An Example of Low Temporal Resolution. (p.47).

Figure $3 b$.

An Example of High Temporal Resolution. (p.47).

Figure 4.

Comparative Bar Diagram for Preferred Muscular Relaxation Time (PMRT) and Accuracy in Manual Timing Performance (AMTP). (p. 50).

Figure 5

Temporal Resolution in Groups with short, Intermediate, and Long PMRT. (P.51).

Figure 6

IRI as a Function of ISI. (p.52).

Figure

Residual Plot for Linear Regression IRI vs ISI. (p.53).

Figure 8. Average Standard Deviation $(n=38)$ vs ISI. (p. 55).

Figure 9 Oscillator Signature, Experiment1. (p.57). 
Figure 10.

Figure 11.

Figure 12.

Figure 13.

Figure 14.

Figure 15.
Oscillator Signature (Subject 41). (p. 59).

Oscillator Signature (Subject 41). (p. 60).

Oscillator Signature (Subject 36). (p. 61).

Distributions of the First Derivatives of random Points. (p.63).

Distributions of the First Derivatives for one Random Point and for the Temporal Measures (p.64).

Average Oscillator Signature. $(\mathrm{p} .65)$. 


\section{LIST OF APPENDICES}

Appendix

I $\quad \ldots \ldots \ldots$ Consent Form....................

II ........ Subject Protocol.................79

III ......PRB (Experiment 1) .............

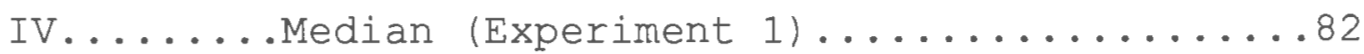

V....Values of First Derivatives for PMRT, FMRT, CRT

......... and SRT Measures................84

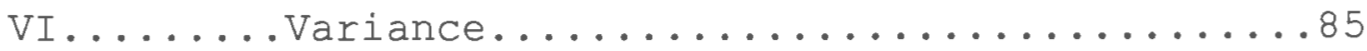

VII........standard Deviation...............87

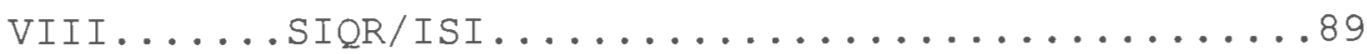

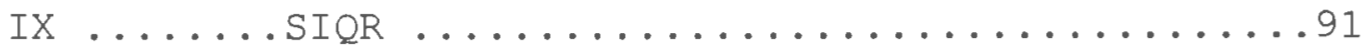

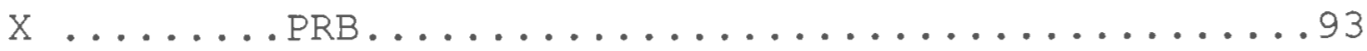

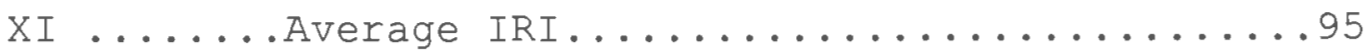

XII ......Median...........................

XIII......Timing Test Reliability.............999

XIV ........ Individual Oscillator Signatures.......101 XV...Averaged First Derivatives for Each Subject Using $\ldots \ldots 1,3,6,9$, and 15 random points...........139 XVI..... Variability of Raw Data for Preferred .........Muscular Relaxation Time Test....... 140 XVII. .... Variability of Raw Data for Fast...... .Muscular Relaxation Time Test........ 141 XVIII. Variability of Raw Data for Critical Fusion ..........licker Threshold Test........... 142 XIX.. An example of data acquisition function for .......Fast Muscular Relaxation Time...........143 XX... An example of data acquisition function for .......Preferred Muscular Relaxation Time........144 
INTRODUCTION

\section{PURPOSE OF THE RESEARCH}

Time sense is a "somewhat loose term denoting our direct experience of the lapse of time, based, however, on the very definite impression we have of a time interval within the sensory or specious present."

The Penguin Dictionary of Psychology 1983, p.299.

The purpose of the present research was to analyze the interrelation of temporal performance measures from different tasks. A number of research questions were addressed in this study inasmuch as the investigation of the problem stated required such an approach.

The intriguing problem of the brain's control of subjective time has been a subject of numerous investigations in different scientific disciplines. The study of "time sense" in timing research originated over a hundred years ago in Stevens' (1886) experiment. When the subjects tapped at a rate specified by a metronome, retrieving the interstimulus intervals from memory, stevens reported an apparent "zig-zag" in the duration of the adjacent interresponse intervals. Interresponse intervals of short duration were followed by interresponse intervals 
of long duration. He concluded that the subjects were adjusting the lengths of subsequent interresponse intervals based upon the accuracy of previously produced IRIs due to a central monitor that compensated for timing errors in successive IRI's in order to keep the mean interval close to the target $(p .401)$.

Significant development in timing research emerged when Wing and Kristofferson, (1973) proposed a model to account for these results. It was suggested that the length of any IRI can be attributed to the effects of an internal timekeeper and the durations of the starting and ending motor delays. The motor-delay is the time between the trigger of a response and execution of the response, and the timekeeper delay is the time between the trigger for one response and the trigger for the next. The model predicts that successive IRIs will be negatively correlated with the covariance of consecutive intervals equaling the variance of the motor delays in its negative form. Wing argues that "even if no active correction process is assumed, this model predicts statistical dependence among IRIs" (Wing, 1980, p. 471$)$

An important implication of this research is that the variability of the interresponse interval should increase with increasing ISIs. Wing had noted that the linear relation between timekeeper variance and the size of the 
interval produced "is consistent with a stochastic count basis for the 'internal clock' in which elapsed time is judged in relation to how many of a pool of neural events fire in that time" (1980, p.479).

If this statement is correct, one might expect that significant individual differences exist regarding the extent to which the variability of interresponse intervals grows with increasing ISI in different individuals. Apparently, if the elapsed time in Wing's 'internal clock' is judged according to the number of neural events that fire during the time interval, then an overall increase in variability may not be strictly accounted for merely by the size of the interval presented. Using Wing's terminology, one might speculate that a slower increase in variability with the increasing of the size of the interval may occur if a proper number of neural events relative to the interval are fired. Further, if the number of neural events per interval varies randomly, a faster increase in variability should occur.

There is a rather general agreement among those studying individual differences that manifestation of human temporal characteristics is secondary to the features of central nervous functioning. In the Nebylitsyn and Gray "Biological Bases of Individual Behavior", Gray has stated: "This theory assumes as its leading postulate the existence 
in the highly organized nervous system of a number of properties (parameters, traits, dimensions) which characterize the dynamics of operation of the nervous processes of excitation and inhibition and which form in their combinations the neurophysiological basis of various forms of behavior together with individual differences in these forms of behavior." (Nebylisyn and Gray, 1972). The concept of lability of the nervous system (which is very close to the problem of physiological arousal), that was developed within this conceptual framework appears to be very meaningful for the purposes of the present investigation. Physiological lability was defined as a property associated with higher speed of alternation and with faster removal of stagnant centers of excitation or inhibition in the nervous substrate (Teplov, 1963; Nebylitsyn and Gray, 1972). Critical Flicker Fusion Threshold that is used in the present study, among the set of other highly intercorrelated indices, defined a separate factor called lability.

One of the problems explored in the present research was whether there existed linear relationships between individual variations in timing accuracy and such temporal measures as Fast Muscular Relaxation Time, Preferred Muscular Relaxation Time, Critical Flicker Fusion Threshold, and Simple and Choice Reaction Time, as well as among all of 
the measures. A search of the literature has not revealed any studies examining such potentially intriguing problems, not to mention, that "...in America [there is] an almost complete neglect of individual differences...", as Cattell comments, (Nebylitsyn and Gray, 1972, p.141). There are distinct individual differences in manual time interval production (Keele, 1987; Keele and Ivry, 1987) and regardless of the timing tasks, there are subjects who reliably demonstrate better temporal resolution and/or more accurate time perception (Keele, 1985; Moiseeva, 1985). However, the results of such studies are often contradictory and reasonably high correlations between motor tasks, Rosenbaum argues (Rosenbaum, 1991, p. 366), may be obtained when the temporal tasks share a common set of abilities or a common variance.

Another question examined was whether there exist nonlinear relationships among the measures. Wing and Kristofferson's two-process model of timing stimulated a vast amount of research regarding the possible existence of a timekeeper located within the central nervous system. While one line of evidence suggests that there is a single timekeeper or clock (Wing and Kristofferson, 1973; Gibbon, 1977; Gibbon and Church, 1984), other research implies possible existence of many such timekeepers within the central nervous system (Collyer, Broadbent and Church, 1992; 
1994; Gallistel, 1993).

There is one line of evidence that seems to be of considerable use in understanding the structure of the relationship in human temporal characteristics. Collyer (Collyer, et al, 1990), conducted an experiment in which subjects tapped at ISIs ranging from $175 \mathrm{msec}$ to $825 \mathrm{msec}$ in steps of $25 \mathrm{msec}$. It was reported that subjects reproduced some rates too slowly and some rates too quickly; subjects were also able to very accurately reproduce ISIs of certain durations $(300,600,1200 \mathrm{msec})$. The observed alternation between positive and negative bias at different ISI durations was thought to be the reflection of a subjects' oscillator or clock and was termed the oscillator signature. Further, it was proposed that "the pattern of relatively slow and relatively fast rates supported a categorical timing hypothesis, in which time production is controlled by a set of oscillatory processes, each with a natural rate of its own," (Collyer et al., 1994, p.443). The authors provided evidence that the influence of the proposed oscillatory process could be found in different timing tasks.

The present research examined the possibility that the influence of oscillators can be found across diverse temporal tasks. The question pursued was whether the individual variations in oscillator signature were related 
to the individual differences in simple Reaction Time, Fast Relaxation Time, Preferred Relaxation Time, and Choice Reaction Time. Except for the Critical Flicker Fusion threshold which was measured in $\mathrm{Hz}$, the values for the rest of our temporal measures were acquired in real time (ms), which enabled us to perform an explicit comparison between the timing task and the other temporal measures.

The present study is an attempt to integrate existing knowledge from disparate areas of psychology: differential psychology, psychophysiology, and general psychology (control of timing). It is also an effort to add a significant piece of knowledge regarding individual differences in human temporal characteristics and their interrelation, to the field of psychology.

This study also offers a substantive modification of the Muscular Relaxation speed method (Vysotchin, 1978). Originally, the method utilized merely the Fast Muscular Relaxation time acquisition, the assessment of which employed only a quick type of response. For the purposes of the present investigation a new measure termed Preferred Relaxation Time was developed. The goal was to assess an unconstrained measure from subject's rapidity of individual variations in muscular relaxation time. As far as we know the present research appears to be one of the first efforts to utilize the method in the area of psychology, and it is 
the first attempt to relate Muscular Relaxation Time to diverse human temporal characteristics.

\section{RESEARCH ON INDIVIDUAL TIME SENSE}

Since the concept of a biological clock was first formulated, a number of theories aiming to discover the factors influencing and/or determining individuals' time sense have been proposed. One of the first attempts to study individual variations in time was the study done by Hoagland (Hoagland, 1933), where he demonstrated that a subjectively judged minute was shorter at higher body temperatures than at lower ones. Additional evidence for the existence of body-time relationships was suggested by O'Hanlon's experiment (1974), in which it was shown that temporal acuity increases as a function of increasing body temperature. These early investigators suggested the existence of an inner clock, or pacemaker that is controlled by the speed of the brain's metabolism.

Contemporary timing research often ignores such important psychological matters as neurophysiological determinants of human temporal characteristics. However, the analysis of behavioral outcomes such as individual variations in timing accuracy and its correlates may contribute to our understanding of the mechanisms involved 
in subjective time. In fact, it is reasonable to think that subjects with an accurate time sense possess neurophysiological mechanisms that control a range of individual temporal characteristics differently from those of non-accurate subjects.

Available literature and our own previous data suggest that there are distinct individual differences in manual time interval production and time perception. Regardless of the timing tasks, there are subjects who reliably demonstrate better temporal resolution and/or more accurate time perception. For example, it was shown that subjects with low variability in finger tapping were also likely to exhibit low variability in foot tapping (Keele, 1987; Keele and Ivry, 1987). Other research has shown that there is a positive relationship between the accuracy in motor timing and perceptual judgment: individuals good at perceptual timing are also good at motor timing and/or sensorimotor reactions (Keele, 1985; Moiseeva, 1985).

Additional support has been provided by collyer, Broadbent and Church (1992). The authors have found consistent individual differences in the degree of nonlinearity in the production of time intervals. They have named these effects the oscillator signature.

Wing, Keele \& Margolin (1984), performed a study on a patient with early asymmetrical Parkinson's disease. The 
patient showed an increased timing variance when the hand contralateral to the diseased hemisphere was used, but normal timing variance when the hand contralateral to the normal hemisphere was used. The motor delay variance remained constant and normal for both hands. The authors concluded that the parkinsonism affected the timekeeper intervals rather than the motor delays.

Additional support for the central timekeeper mechanism came from the experiment by Collyer, Broadbent and Church (1990). Subjects were given the task to tap at a preferred rate with either their wrist restrained or with their fingers restrained. The results showed that regardless of the condition, subjects reliably selected the same preferred rate.

These experiments suggest the possibility of a general neurophysiological mechanism associated with the internal clock or individual time sense.

RESEARCH IN SKELETAL MUSCULAR RELAXATION.

Skeletal muscular relaxation and/or tension has been the subject of a substantial amount of research in the health psychology and related areas (Wilson and Housberger, 1975; Patel, 1975; Jacob and Chesney, 1984; Kleinman and Goldman, 1977; Woolfolk, 1975; Benson, 1989; 1990). 
Elevated muscular tension levels are known to be stress related and emotionally disturbed groups were shown to exhibit significantly higher levels of muscle tension (Goldstain 1964a, 1964b; Shipman 1964). On the other hand the development of specific stress related physical symptoms was suggested to be determined by individual differences in the type of reactivity. Some individuals who were exposed to stress were shown to develop muscle contraction headaches as a symptom (Glueck and stroebel, 1975), while others, who responded to stress with their cardiovascular system were shown to develop hypertension and cardiovascular disease (Jacob and Chesney, 1984). Unfortunately, the results of such studies are often contradictory and despite the considerable recent progress in the understanding of the relaxation-tension relationship with regard to health outcomes, further clarification of the problem is needed. A number of questions regarding individual and intraindividual differences in skeletal muscle relaxation at rest and the correlates remain to be answered. Several studies have investigated the effects of various relaxation treatments on different psychophysiological measures.

The most commonly examined question was whether some of the techniques were more effective than others in treating different illnesses, as well as the psychological and physiological changes associated with relaxation in general. 
However, an equally interesting problem which has received less attention is the extent to which skeletal muscular relaxation varies from one individual to the next, and from one situation to the other independently of responses to a particular intervention.

A major part of this problem is due to the fact that there were just a few early investigations of individual differences in relaxation at rest (Goldstain, 1964; Shipman 1964; Sainsbury and Gibson, 1954; Wenger, 1938, 1943). Yet, the measure that has been claimed to be a predictor of muscular relaxation was muscular tension. The assumption made was that in states of complete relaxation there would be no tension. Although this could be true, the major problem which arises is that there are many definitions of muscle tension as well as many methods. There is very little agreement in the literature on this matter, and it appears likely that different methods may give diverse results. Further, the rationale for using muscular tension as an indirect measure of relaxation can be found in the relative accessibility of muscular tension assessment, yet there are some technical difficulties which arise while attempting to measure the muscular relaxation variable. Skeletal Muscular Relaxation Time as a psycho-physiological measure is not yet well recognized in psychology, presumably because the method was originally utilized in a different 
field (Vysochin, 1978). It was demonstrated (Azhichenko and Vysochin, 1985), that the time taken for a muscle to return to a completely relaxed state from the maximum tensed state could be used as a meaningful and informative index associated with professional performance in athletes. Other research has shown that shorter time of muscular relaxation was related to reduced tension in cardiovascular, endocrine, and metabolic systems in athletes (Kusnetsova and Ostoumova, 1987).

Further research (Klevak and Boldirev, 1987) suggested that skeletal muscular relaxation time was also associated with certain individual temporal characteristics. The authors have shown that subjects with shorter time of muscular relaxation exhibited a different pattern of temporal response (as measured by the $t$-test) in Tapping Test, Target Tracking Task, Critical Flicker Fusion Threshold values, and Short Time Estimation Task, than subjects with longer time of muscular relaxation. Specifically, subjects with shorter time of muscular relaxation had higher values of Critical Flicker Fusion Threshold, higher Tempo of Voluntary Movements in Tapping Test, tended to underestimate the minute duration, and exhibited more accurate performance in the Target Tracking Task in comparison with subjects with longer time of relaxation. 


\section{RESEARCH IN CRITICAL FLICKER FUSION THRESHOLD}

A review of literature suggests that for years there has been a discussion regarding the nature of CFFT. The effects of CFFT have been attributed to physical variables affecting retinal mechanisms. It was firmly established that retinal mechanismis such as for example, the intensity of the flickering light, the position of the light on the retina, the wavelength of the light, the waveform of the flicker, and the illumination of the surrounding field affect the fusion threshold (James, 1948; Crozier and Wolf, 1941; Verigna, 1963; Kelly, 1978).

During the past three decades much work has been directed towards elaborating new evidence for an additional role played by the brain in the nature of flicker fusion. There is enormous and growing literature that provides strong evidence for a central mechanism in CFFT. CFF threshold has been considered a rather stable psychophysiological measure, but at the same time it was shown to vary over time as a function of certain psychophysiological changes in the organism such as body temperature (O'Hanlon, 1974), and the degree of mental arousal (Payne, 1982; Weber, 1980; Baschera, 1979); moreover, CFFT was shown to exhibit a pattern of circadian variations (Musumeci and Misiak, 1974), and to be affected 
by fasting and fatigue conditions (Ali, 1989; Volle, 1979; 1980; Urgelles, 1982) ); it was shown to reflect the differences in the cortical hemispheric activity (Powel, 1983), and to vary as a function of cardiovascular reactivity, significantly decreasing with the decreasing of the heart rate (Lagergren, 1975).

Clearly, these data suggest a pattern of body-temporal relationship in the nature of CFFT. Some neurophysiological explanations of the nature of CFFT reiterated the long-held view of a balance between central inhibitory and excitatory states (Bartley, 1976). According to Bartley, a high degree of unbalance results in relatively lower individual threshold values. Russian physiologists Nebylitsyn and Teplov attributed individual variations in CEFT to a physiological quality in the central nervous system which they called the lability function. Higher lability is associated with higher speed of alternation and with faster turnover of focal excitation and inhibition in the brain (Teplov, 1972; Nebylitsyn, 1972).

\section{RESEARCH IN REACTION TIME}

The speed with which a person reacts to different stimuli is a widely used measure in contemporary psychology and psychophysiology. The empirical analysis of the 
reaction time goes back to Donders (1869) and Woodworth (1938). Computerization has made it possible to measure reaction time with great precision and accuracy.

Changes in Reaction time reflect alternations in information processing and in the state of the subject (Debus and Borgens, 1988); in the nature of the stimulus, and in the nature of the response, as well as in the relations among these factors (Boff, et al., 1986). A literature review suggests that the simple reaction times of the dominant and nondominant hands as well as the simple reaction times for different fingers differ very little (Woodworth, 1938). Reaction time was shown to change as a function of age, namely, it substantially slows at a younger age with a very moderate slowing afterwards (Woodworth \& Schlosberg, 1954).

Since long ago it was known that simple reaction time is in the order of 200-300 $\mathrm{msec}$, though it depends on stimulus modality. Choice reaction time varies with a number of factors such as the probability of an event and the number of choices. Meyer has shown that choice reaction times were generally longer than simple reaction times and that there is a positive correlation between simple and choice reaction times (Meyer, et al., 1990). Hick (1952), discovered that the mean choice reaction time increases as a linear function of the logarithm of the number of choices. 
Brand (Brand and Jolles, 1985), has shown that while button time increases with the task complexity, the movement time is stable across different conditions.

Reaction time has been extensively studied in relation to the state of the subject. It has been shown that neurological, Parkinson disease and demented patients exhibited slower reaction times than healthy controls (Brand, et al, 1990; Evarts, et al, 1981). Psychiatric patients diagnosed with depression, schizophrenia, anxiety disorders, and obsessive compulsive patients were shown to exhibit slowness of reaction time (Byrne, 1976; Frewer and Hindmarch, 1988; Swantantra, 1981). Frewer attributed slowness in reaction time in such subjects to a higher level of arousal and suggested that performance impairment in such groups may be explained by the application of the YerkesDodson curve (Frewer and Hindmarch, 1988).

Since Spearman (1927) has put forth the theorem of the indifference of the indicator, extensive research has been done in the study of human intelligence. During the last three decades much attention has been directed to the low level theories (which view human behavior as resulting from features of central nervous system functioning) of intelligence. Following this new approach researchers have used such measures as reaction time and evoked potentials in order to study their relation to intelligence. The aim has 
been to observe correlations between simple measures like reaction time and evoked potentials that do not depend on education and IQ, in order to avoid problems pertaining to purely psychometric strategy. For example, Eysenck's mental speed hypothesis attributes individual differences in intelligence to a speed of cognitive processing, e.g. subjects with shorter reaction time exhibit higher values of IQ in both timed and untimed conditions (Eysenck, 1990). In summarizing the results of the research in the area Jensen (Jensen, 1987), refers to Donders who attributed the difference between mean choice reaction time and mean simple reaction time to the time required for a mental process of discrimination and choice decision. The more intelligent subject showed a slower increase in reaction time with an increase of the number of choices than the less intelligent subject. Additional support was provided by Schafer (Schafer \& Marcus, 1973), who has shown that subjects with higher neural adaptability exhibit cortical evoked potentials with larger amplitude to unexpected stimulus and with smaller amplitude to stimulus that they can predict. Brighter subjects generally show larger difference in amplitude to this type of stimulation.

In spite of numerous investigations, however, this area is not without contradictions. Some serious drawbacks of this approach, as Eysenck argues, (Eysenck, 1987), are great 
variability of the results reported as well as relatively low test-retest reliability of the reaction time measure.

\section{HYPOTHESES AND PREDICTIONS}

The above research suggests the existence of stable individual variations in human temporal characteristics such as Manual Time Production and Perception, Critical Flicker Fusion Threshold, Reaction Time and Skeletal Muscular Relaxation Time. Furthermore, a number of studies have suggested that stable individual variations in human temporal characteristics exhibit a certain pattern of temporal responses correlated with each other to a certain degree. If people differ significantly and consistently in their perceptual and motor abilities with regard to time, investigation of corresponding differences in their neural mechanisms of behavior appears to be a logical sequence of research. Some progress has been made recently regarding stability in individual variations of human temporal characteristics. However, besides stability, there is a basic question of neuropsychological determinants of individual temporal characteristics that has yet to be addressed.

The empirical roots of this study are drawn from the broad conceptual framework of biological determinants of 
human behavior developed early on by Eysenck, Teplov and Nebylitsyn. Within this conceptual framework "... individual psychological differences may be explained by the dynamics of internal neuropsychological factors whose aggregate action in the organism forms the biological foundation of the individual mode of behavior" (Nebylitsyn, 1972, preface). The specific study will measure individual variations in Timing, in Time of Skeletal Muscular Relaxation, in Critical Flicker Fusion Threshold, and Simple and Choice Reaction Times.

Among the findings reported by Wing and Kristofferson (1973), there is one that appears to be interesting in terms of individual differences in the Accuracy of Manual Time Production. In addition to the general support for a central timekeeper mechanism provided by this research, there is one important finding which would be useful for the purposes of our investigation. It is the finding that the timekeeper variance generally increases with the increasing of the mean of ISI while the motor-delay variance remains constant.

The question that arises is to what extent the variance of the clock grows with the ISI in subjects with shorter and longer Time of Skeletal Muscular Relaxation and in subjects with higher and lower Critical Flicker Fusion Threshold.

A large number of studies have proposed a central mechanism in the Flicker Fusion Threshold. As discussed 
above, such a role has been suggested by extensive research in the area (Payne, 1982; Weber, 1980, Baschera, 1979; O'Hanlon, 1974; Volle, 1979, 1980; Lorie, 1982, Ali and Amir, 1989; MacNab, 1985; Pathy, 1986; Musumeci and Misiak, 1974).

It has long been known that CFFT for the same individual may vary over time even when physical conditions are unchanged. These variations are not random, however, and several ideas were presented to account for the variations. It was suggested that $C F F T$ reflects the degree of mental arousal (Payne, 1982). Bartley (1976) and Nebylitsyn (1972) have arrived at the conclusion that basic neurophysiological factors such as excitation and inhibition play an important role in individual variations of CFFT and thus, variability in CFFT may be accounted for by a balanceimbalance relationship between central inhibitory and excitatory states.

There is one type of experiment that provides support for Bartley's and Nebylitsyn's interpretations. If balanceimbalance relationship in excitation and inhibition results in individual variations of CFFT, then we might expect that under inhibitory stimulation the threshold will decrease, while under excitatory stimulation the threshold will increase. In fact, Critical Flicker was shown to be very sensitive to drug effects. It has been recommended as a 
possible standardization procedure for the operational definition of drug effects (Leigh, 1982). Numerous studies have shown that stimulants increased CFFT, while hypnotics decreased it. For example, doxepin, diazepam, amitriptyline, imipramine, and nitrazepam were shown to decrease CFF threshold (Warrington, 1986; King, 1991; Hindmarch, 1983, 1991; Kleinknecht, 1975; Grundstrom, 1978; Weber, 1975; Ogura, 1987; MacNab, 1985), while amphetamine and marijuana caused an increase in CFF threshold (MacNab, 1985; Schwin, 1974).

Further elaboration of these findings have led researchers to examine whether behavioral sensorimotor output such as tempo of voluntary movements and preciseness of sensorimotor reactions is affected by the balanceimbalance relationship within the individual. Research findings suggest that subjects with higher values of CFFT exhibit a pattern of faster and more efficient sensorimotor reactions (Akimova, 1974; Klevak and Boldirev, 1987). Further, an assumption can be made that sensorimotor rigidity arises from a highest degree of excitationinhibition imbalance, while the increase in precision of sensorimotor output may be accounted for by equilibration between central excitatory and inhibitory states.

In our research we will examine correlations (using Pearson's r) between Timing Accuracy and Critical Flicker 
Fusion Threshold, critical Flicker Fusion Threshold and Relaxation Time, and Timing Accuracy and Relaxation Time. We will also examine correlations of Relaxation Time and Reaction Time and of Reaction Time and Timing Accuracy.

The first question that will be addressed is to what extent the variability of the clock grows with the ISI in subjects with lower and higher critical Flicker Fusion Threshold. We predict that CFFT and Accuracy in Manual Timing Performance will be negatively correlated. Further, subjects with a higher Critical Flicker Fusion Threshold will exhibit a slower increase in variability with the increasing of the ISI, while subjects with lower Critical Flicker Fusion Threshold will exhibit a faster increase in variability with increasing of the ISI.

We next hypothesize that the Accuracy in Manual Timing Performance (AMRT) and Preferred Muscular Relaxation Time (PMRT) will be positively related. With the increasing of timing variability there will be a significant increase in Preferred Muscular Relaxation Time and vice versa, with the decreasing of PMRT value there will be a significant decrease in AMTR value. Yet, another possibility that we hold for the AMRT and SMRT relationship is that there will be a non-linear relationship between the measures, i.e. subjects who are more accurate in Manual Timing Performance will reside in the middle of Skeletal Muscular Relaxation 
Time distribution of scores, while the less accurate subjects will reside at both ends of SMRT distribution of scores.

We hypothesize that CFFT and Simple and Choice Reaction Times (SRT and CRT) will be negatively related. With the increasing of the CFF threshold value there will be a significant decrease in SRT and CRT values.

We also predict that Fast Muscular Relaxation Time (EMRT) and SRT and CRT will be positively related. With the increasing of Skeletal Muscular Relaxation Time there will be a significant increase in SRT and CRT.

It is logical to suppose that the reaction time measures will be positively interrelated. With the increasing of SRT values there will be an increase in CRT values.

Finally, we will examine non-linear relationships among the variables. The specific question will address whether the individual variations in oscillator signature are related to the individual differences in simple Reaction Time, Fast Relaxation Time, Preferred Relaxation Time, and Choice Reaction Time. 


\section{TAPPING TASK}

\section{Apparatus}

The experiment was controlled by an IBM 386 AT computer. Stimuli and responses were timed by a MetraByte CTM-05 five channel counter-timer board. Auditory stimuli (50 ms $1 \mathrm{KHz}$ tones) were generated by a MED Associates signal generator (ANL-916). The generator produced a series of tones separated by an interstimulus interval (ISI) under synchronous control from counter \#1 of the CTM-05 board. The counter \#1 counted $1 \mathrm{msec}$ pulses from programmable divider output of the board in order to generate the frequency required to produce the ISI series. Counter \#2 constantly counted $1 \mathrm{msec}$ clock pulses from the programmable divider output and the software read it periodically. Every output pulse of the Counter \#1 also generated an interrupt for the software. The interrupt routine read the current value of counter \#2 and stored it in the PC's memory. The subject tapped on a General Controls Snap Action Microswitch which was connected to the interrupt line of the CTM-05 card. Every time the switch was closed an interrupt was generated. The interrupt service routine read counter \#2 current value once more and stored the value in the PC's 
memory. The software calculated the difference between the two values and the difference represents the interresponse interval (time elapsed between the two events).

The RC based Latch circuit was used to eliminate a response time calculation error due to Microswitch contact bouncing while closing and opening. Multiple pulses that may occur on the contact transition may generate multiple interrupts on one event which may cause multiple software readings of the counter \#2. The Switch was tested and showed a very low bouncing time interval of about $1.5 \mathrm{msec}$. The RC Latch was designed to eliminate multiple interrupt pulses due to bouncing of the switch. The counter \#2 counted 1 millisecond clock pulses until the switch was closed by a subject's response.

Timing Task Reliability

It is desirable to attain precision within $1 \mathrm{msec}$ in tasks measuring timing responses and reaction times. In this experiment the routine achieved one millisecond time resolution by means of a very precise on-board crystal oscillator and a programmable divider on the CTM-05 MetraByte board.

We conducted an experiment in order to test the software error utilized for measuring subjects responses in 
timing and reaction time tasks. A $486 \mathrm{AT}$ computer was wired together with a $386 \mathrm{AT}$ computer. The $486 \mathrm{AT}$ computer was set up to generate series of 20 ISI's ranging from 250 to $950 \mathrm{msec}$ in steps of $50 \mathrm{msec}$. The signals of those durations were sent to the other computer and were recorded by means of the software used in the experiment. The output of the experiment edited in an Excel spreadsheet is presented in Appendix XIII. As can be seen from the Appendix, the standard deviation of the output signals ranged from zero to $0.39 \mathrm{msec}$. There were only 7 outputs out of the 300 inputs that deviated from the target ISI by one msec, therefore, the overall precision was within one millisecond.

\section{Design and Procedure}

A tapping trial consisted of 20 synchronization taps and 30 continuation taps. During the synchronization phase of a trial, a train of 50-msec auditory tones (pacer sounds) at some constant ISI was heard over the headphones. The subject's task was to tap in synchrony with these sounds. After 20 synchronization taps, there were no further pacer sounds. The subjects task was to continue tapping at the same rate. The trial ended after 30 of these taps in the continuation phase without pacer sounds. In Experiment 1 
eleven values of ISI ranging from 250 to $750 \mathrm{msec}$ in steps of $50 \mathrm{msec}$ were presented. In Experiment 2 fifteen values of ISI were presented in steps of $50 \mathrm{msec}$ ranging from 250 msec to $950 \mathrm{msec}$. A block of 3 trials was run at each ISI. There was one session per subject. Each subject had a different random permutation of the ISI values. The subjects were tested individually in a quiet room while seated at a table and wearing earphones. Tapping was performed with the index finger of the dominant hand.

Analysis of Data

Median IRI and Semiinterquartile range (SIQR) on each trial were averaged over 3 trials at each ISI. Additionally, the seminterquartile range was divided by a corresponding ISI resulting in a value of SIQR/ISI for each ISI. Variance (accuracy in manual timing production, AMTP) and standard deviation on each trial were averaged over 3 trials at each ISI. Raw Bias was estimated as the difference between median IRI and ISI. Further, the Raw Bias was expressed as a percent of ISI for all ISIs (Percent Residual Bias (PRB); = (Median IRI-ISI)/ISI) $\times 100)$ ).

occasionally an interresponse interval of about two times the presented duration occured because of a missed tap. Such IRIs were replaced by an average IRI for 
corresponding ISI. Although the RC based Latch circuit was used to eliminate a response time calculation error due to Microswitch contact bouncing, infrequently an IRI of about $35 \mathrm{msec}$ was found. We attributed such cases to the problem of multiple pulses in the Microswitch. These values were added to the nearest preceding IRI. Additionally, in order to minimize the influence of very large or very small values we used the seminterquartile range as a measure of variability because it is less sensitive to outliers.

\section{CRITICAL FLICKER FUSION THRESHOLD}

The method of limits was used in this study. Ascending (8) and descending (8) series of flickering light were presented alternately. The ascending series began at a frequency below the fusion threshold and increased the frequency until a no-flicker response was given. Descending series began at a higher than threshold frequency and decreased the frequency until a flicker response was given. Each subjects was given a training session of 5 ascending and 5 descending series.

The subjects were tested individually in a quiet room while seated at a table. A strobe light was placed at a distance of 30 inches from the subject. Subjects were given the following instructions: "In front of you is the source 
of flickering light. Please do not move and try to focus constantly on the source of light. I will be increasing the frequency of the flicker and at some point the light will look steady for you (you will see no more flicker) and your task will be to let me know when that happens. Please reply only when you are completely sure that you do not see the flicker any more. Now, I will be decreasing the frequency of the flicker, please let me know when you start seeing the flicker again. We will repeat these series 8 times each". Apparatus

The instrument used in this experiment is a stroboscope-tachometer with the range of 100 to 12,000 flashes per minute. The instrument has an independent power source $(12 \mathrm{v}$ battery) and a manual control of frequency. The instrument was installed on a vertical support 12" high. The final measure was the average of the crossover frequencies (threshold estimates) for both series.

Variability of Raw data for CFFT.

Critical Flicker Fusion test raw data (either ascending or a descending series were used) for each subject was analyzed in order to study the influence of random error. The data is presented in Appendix XVIII. As can be seen 
from the Appendix, the mean and median for every subject's raw data is very close indicating the symmetry of the analyzed distributions. The standard deviation ranged from 19.4 to 73.2. Percent error ranged from $0 \%$ to $3 \%$

TIME OF SKELETAL MUSCULAR RELAXATION

\section{Apparatus}

The experiment was controlled by a 486 IBM AT computer with Electronic Chart Recorder software. Data acquisition features include simultaneous signal monitoring and recording to hard disk. A load cell was mounted on a wooden frame attached to a belt wrapped tightly around three quarters of the subject's forearm. With the bending and subsequent unbending of the forearm the belt tension generated mv signal that was displayed on a screen in the form of an X:Y plot where the $X$ axis was real time in milliseconds. In our experiment we used one millisecond time resolution. The EMG sensor was applied to the biceps. The signal from the sensor was recorded and displayed on the screen simultaneously with the strain signal. Each subject's data was stored on a diskette in a form of an ASCII data file. 


\section{Design and Procedure}

The method used a synchronized graphic registration of the bioelectrical activity (electric myogram, and dynogram) of the biceps muscle during its maximal voluntary tension and relaxation in the isometric regime. The subject was placed in a comfortable chair and his/her forearm was wrapped tightly with a belt. The belt was applied exactly on three quarters of the length of the forearm. The position of the forearm was 90 degrees relative to the arm. The subject was instructed to exclude any movements during the testing trials other than those required for the testing. For the Fast Muscular Relaxation Time acquisition, upon hearing a signal, the subject was asked to bend the arm in the fastest manner possible against belt tension. The subject was then asked to continue the effort while the signal was on (for $2 \mathrm{sec}$ ), and to completely relax the working muscle after the signal was turned off. An example of the data acquisition function for Fast Muscular Relaxation Time is provided in Appendix XIX. Each subject performed 3 training trials and 5 testing trials.

For the Preferred Muscular Relaxation Time acquisition the instruction was different. The subject was given a signal to start to regularly bend and unbend the arm against the belt in a preferred manner and with a preferred speed. 
Subjects provided successive tension and relaxation (with approximately 60 percent of maximal force) in a manner that was mostly comfortable for the subject in terms of the speed of alternations between tension and relaxation, as well as in terms of the time elapsed between the start and the end of a single attempt. Although there was no specific instruction as to how long a single attempt should last and that it depended on a subject's preference, it was explained to the subject that there was no need to keep an effort for too long after he or she had achieved 60 percent of their maximal force. One training trial of 4 successive attempts was given to each subject. An example of the data acquisition function for Preferred Muscular Relaxation Time is provided in Appendix XX. After the subject had provided a block of 5 consecutive tensions and relaxations, a signal to stop was given. The dynogram waveform provided the new data, and relaxation times were read from the record.

\section{Measure}

The time (in milliseconds) required for a muscle to return to a completely relaxed state from a tensed state was used as the measure of muscular relaxation time for both Fast Relaxation Time and Preferred Relaxation Time. In both measures we used an average relaxation time over 5 testing trials. 
Variability of Raw Data for Muscular Relaxation Time test.

Raw data for both Fast Muscular Relaxation and Preferred Muscular Relaxation Time was examined in order to estimate the influence of random error on test results. Appendices XVI and XVII present the mean, median, standard deviation and percent error for each subject's raw data for both Fast Relaxation and Preferred Relaxation time. As can be seen from the Appendices the mean and median in every case are very close indicating the symmetry of the analyzed distributions. The standard deviation ranged from 0.014 to 0.13 in both the Fast and Preferred Relaxation Time tests. Average percent error in both tests was equal $9 \%$. Additionally, two subjects provided 10 and 18 attempts on Fast Relaxation Time. The mean, median and standard deviation for the first subject $(n=18)$, was 353, 352, and $0.013 \mathrm{msec}$ correspondingly, with percent error of $3.5 \%$. For the second subject $(n=10)$, the mean, median and standard deviation was 329, 336, and 0.015 correspondingly with percent error of $4.5 \%$.

SIMPLE AND CHOICE REACTION TIMES

Apparatus, Design and Procedure

Classical versions of SRT and CRT (with 3 choices) were 
used. The experiment was controlled by an IBM $386 \mathrm{AT}$ computer. The subject was seated in a comfortable chair in front of a response box. The box had four buttons: Ready button, Right button, Left button and a Center button. The instruction on the computer screen prompted the subject to press the Ready button. Next, another screen appeared that displayed four different letters placed in the four corners of a screen. The bottom left letter changed with a random time delay to either "L", "R", or "C". In the simple Reaction Experiment the letter always changed to "R" (right). As soon as it changed, the subject was required to release the Ready button and to press the Right button as soon as possible. In the Choice Reaction Time experiment the bottom left corner letter changed with a random time delay to either "L", "R", or "C". The subject was required to release the ready button and to press the corresponding button on the panel in the fastest manner possible. If a wrong button was pressed accidentally, the screen on the computer would prompt the subject to try again ("wrong button, please try again"). Each subject first performed a training trial for both SRT and CRT. The Button times in both Simple and Choice Reaction time experiments were measured as the period of time from the moment when the letter in the bottom left corner changed and the moment when the ready button was released. The simple and Choice 
reaction times were the times from the moment when the Ready button was released until the moment the corresponding button was pressed. There were 15 SRT and 21 CRT trials (with 7 random presentations for each choice). The reaction times were measured in milliseconds. The number of errors were recorded but error $\mathrm{RT}^{\prime} \mathrm{s}$ were not counted in calculating average reaction times.

Occasional outliers were found in raw SRT and CRT data files. The values that were four standard deviations above the mean were replaced by a subject's average reaction time.

All testings occured during a single session. The order of presentation of the tasks was the same for each subject. The time of day was not the same, however. Subjects were scheduled for testing every two hours from 9:30 in the morning till 4:30 in the afternoon, thus the testing time for subjects varied from morning till late afternoon. 
RESULTS

Demographic Characteristics.

There were 2 separate experiments in this research. During the first experiment 7 volunteers were tested. Six subjects in this group were undergraduate URI students with mean age 24 and standard deviation 7.09 years, one of subjects was 40 years old and was a professional. Among the group there were 3 males and 4 females. All subjects were White and right handed. All subjects were in good health and were not taking any medication by the time of testing. Thirty nine subjects participated in the second experiment. Nineteen females and 20 males were tested. Subjects ranged in age from 18 to 50 with a mean age of 29.6 and a standard deviation of 8.4. Subjects were paid $\$ 10$ for one hour and a half participation in the experiment. There were 17 graduate students, 16 undergraduate students and 6 professionals. Ethnic/racial composition was 89.7\% White, with African American and Asian subjects comprising the remaining $10.3 \%$ of the sample. Almost all subjects were predominantly right handed, of 39 subjects, 2 were left handed and one subject was ambidextrous. Thirty subjects were in good health and were not taking any medication at the time of testing. Nine subjects were on medication for different reasons. Two subjects were on medication for 
depression, three subjects were taking medication

for high blood pressure, one subject was taking medication for an ulcer, and three subjects were taking medication for mild asthma and allergy. None of the subjects refused to provide this information.

In Experiment 1 seven volunteers were tested while in Experiment 2 thirty nine subjects were tested who were paid for their participation. In Experiment 2 both Fast and Preferred Muscular Relaxation Times were assessed, while in Experiment 1 only Fast Muscular Relaxation Time was assessed. No correlational analysis was utilized for Experiment 1. We used, however, the data from this sample for descriptive purposes.

Experiment 1 .

In Tapping Experiment 1 there were 3 trials per ISI. The ISIs ranged from 250 to $750 \mathrm{msec}$ in steps of $50 \mathrm{msec}$. Each trial provided 30 continuation taps from which a median IRI was computed. Further, the 3 medians were averaged at each ISI and used as a measure of IRI in the analysis. Raw Bias was estimated as the difference between median IRI and ISI. Further, the Raw Bias was expressed as a percent of ISI for all ISIs (Percent Residual Bias (PRB); = (Median IRI-ISI)/ISI) $\times 100)$ ). The mean and median of the IRI's 
across different ISI's were very close indicating the symmetry of the distributions of the analyzed IRI's. Appendix III and IV contains estimated PRB and Median for the timing test in Experiment 1. Fast Relaxation Time and Simple Reaction Time and Choice Reaction Time were obtained for each subject. The means for the variables used for the analyses are listed in Table 1. The scores are listed as follows: FMRT (Fast Muscular Relaxation Time), SRT (Simple Reaction Time), CRT (Choice Reaction Time), all scores are listed in milliseconds.

Table 1

Mean values for Fast Muscular Relaxation Time(EMRT), Simple Reaction Time(SRT), Choice Reaction Time(CRT) in Experiment 1

Subject

EMRT

SRT

CRT

ID

1

2

3

4

5

6

7
348.00

360.00

371.00

265.00

358.00

268.00

460.00
504.27

753.10

584.13

737.62

464.73

653.81

495.07

821.43

530.73

807.86

475.13

618.05

491.27 
Experiment 2 .

In Continuation Tapping test 215 ISIs ranging from 250 msec to $950 \mathrm{msec}$ were presented. There were 3 trials per ISI. Each trial provided 30 continuation taps from which a median IRI, a standard deviation, a variance, and a seminterquartile range were computed. Further, the 3 medians, 3 standard deviations, 3 variances, and the 3 semiinterquartile ranges were averaged at each ISI. Additionally, we used the value of seminterquartile range divided by the corresponding ISI. The mean and median of IRI's across different ISI's were very close indicating the symmetry of the distributions of the analyzed IRI's.

The means for the variables used for the analyses are listed in Table 2. The scores are listed as follows: Critical Flicker Fusion Threshold (CFFT), FMRT (Fast Muscular Relaxation Time), PMRT (Preferred Muscular Relaxation time), SRT (Simple Reaction Time), SRTBT (Simple Reaction Button Time), CRT (Choice Reaction Time), CRTBT (Choice Reaction Button Time). Except for CFFT scores listed in $\mathrm{HZ}$, the rest of the scores are listed in milliseconds.

Appendix VI-XII lists the variables for the timing task as follows: Accuracy in Manual Timing Production expressed as a variance for each of 15 ISIs ranging from 250 to 950 in steps of $50 \mathrm{msec}$ (AMTP); Standard deviation for each of 15 
ISIs ranging from 250 to 950 in steps of $50 \mathrm{msec}$ (stdev);

Table 2

Mean values for Critical Flicker Fusion Time(CFFT), Fast

Muscular Relaxation Time(EMRT), Preferred Muscular

Relaxation Time(PMRT), Simple Reaction Time(SRT), SRT Button

Time(SRTBT), Choice Reaction Time(CRT), CRT Button

Time (CRTBT).

$\begin{array}{lllllll}\text { Subject CFFT FMRT PMRT SRT SRTBT } & \text { CRT } & \text { CRTBT }\end{array}$

ID

$\begin{array}{lclllllll}10 & 39.02 & 352.00 & 636.00 & 412.20 & 256.60 & 686.71 & 405.00 \\ 11 & 33.81 & 373.00 & 608.00 & 587.27 & 278.27 & 676.65 & 412.65 \\ 12 & 39.26 & 376.00 & 606.00 & 701.53 & 406.33 & 873.67 & 524.33 \\ 13 & 37.43 & 318.00 & 422.00 & 469.43 & 273.43 & 746.62 & 476.10 \\ 15 & 32.15 & 308.00 & 405.00 & 654.67 & 282.73 & 704.05 & 406.00 \\ 16 & 37.90 & 301.00 & 334.00 & 398.87 & 249.80 & 755.68 & 423.43 \\ 17 & 35.84 & 386.00 & 659.00 & 568.60 & 260.87 & 805.95 & 418.81 \\ 18 & 36.75 & 258.00 & 300.00 & 600.47 & 308.47 & 790.05 & 474.67 \\ 19 & 35.27 & 408.00 & 701.00 & 520.53 & 248.47 & 675.71 & 351.86 \\ 20 & 36.42 & 310.00 & 442.00 & 346.87 & 236.07 & 610.05 & 414.65 \\ 21 & 34.73 & 348.00 & 442.00 & 405.20 & 239.53 & 702.70 & 419.71 \\ 22 & 39.27 & 382.00 & 516.00 & 583.50 & 249.07 & 739.90 & 352.52 \\ 23 & 36.04 & 372.00 & 432.00 & 600.40 & 293.33 & 808.24 & 485.33 \\ 24 & 34.10 & 536.00 & 526.00 & 769.07 & 378.85 & 788.67 & 429.95 \\ 25 & 38.44 & 314.00 & 544.00 & 766.60 & 378.20 & 948.57 & 486.95 \\ 26 & 35.69 & 350.00 & 624.00 & 559.33 & 272.40 & 659.48 & 381.43 \\ 27 & 38.18 & 494.00 & 680.00 & 615.87 & 310.20 & 738.52 & 415.10 \\ 28 & 38.28 & 430.00 & 496.00 & 700.27 & 297.87 & 942.19 & 439.76 \\ 29 & 36.60 & 432.00 & 614.00 & 548.93 & 271.67 & 706.00 & 430.57 \\ 30 & -\star & 504.00 & 794.00 & 788.07 & 402.21 & 859.77 & 449.33\end{array}$

Note. -* represents missing data 


\begin{tabular}{lccccccc}
$\begin{array}{l}\text { Subject } \\
\text { ID }\end{array}$ & CFFT & FMRT & PMRT & SRT & SRTBT & CRT & CRTBT \\
\hline 31 & & & & & & & \\
32 & 38.27 & 315.00 & 471.00 & 741.40 & 369.20 & 834.70 & 540.40 \\
33 & 36.03 & 498.00 & 748.00 & 566.80 & 230.47 & 639.71 & 301.60 \\
34 & 36.33 & 560.00 & 647.00 & 778.86 & 301.43 & 831.62 & 445.38 \\
35 & 38.98 & 360.00 & 720.00 & 428.00 & 260.70 & 718.50 & 462.70 \\
36 & 39.23 & 406.00 & 556.00 & 583.20 & 291.67 & 841.41 & 441.86 \\
37 & 38.84 & 429.00 & 715.00 & 519.13 & 214.13 & 755.29 & 367.90 \\
38 & 38.86 & 424.00 & 678.00 & 705.73 & 414.27 & 714.48 & 455.52 \\
39 & 39.16 & 396.00 & 472.00 & 547.33 & 314.40 & 779.86 & 496.20 \\
40 & $-\star$ & 656.00 & $-\star$ & 524.71 & 211.84 & 818.00 & 354.00 \\
41 & 35.57 & 379.00 & 681.00 & 679.60 & 194.87 & 821.52 & 359.29 \\
42 & 37.84 & 388.00 & 585.00 & 787.67 & 361.07 & 872.81 & 450.48 \\
43 & 37.52 & 448.00 & 559.00 & 781.80 & 415.87 & 739.67 & 444.38 \\
44 & 38.24 & 394.00 & 560.00 & 658.27 & 237.00 & 778.25 & 330.00 \\
45 & 36.75 & 402.00 & 559.00 & 592.40 & 237.93 & 782.95 & 380.52 \\
46 & 36.73 & 545.00 & 407.20 & 626.76 & 271.38 & 852.95 & 444.05 \\
47 & 35.09 & 504.00 & 580.00 & 665.80 & 350.00 & 836.40 & 435.50 \\
48 & 34.83 & 378.00 & 534.00 & 534.71 & 275.36 & 752.42 & 421.10 \\
49 & 37.70 & 491.00 & $-\star$ & 804.77 & 297.85 & 835.35 & 364.50
\end{tabular}

Note. ** represents missing data

averaged over 3 trials seminterquartile range divided by corresponding ISI for each of the 15 conditions (SIQR/ISI); averaged over 3 trials seminterquartile range for each of the 15 ISI'S(SIQR); Percent Residual Bias for each ISI condition (PRB), average IRI for each ISI condition; averaged median (over 3 trials) for each of the ISI conditions.

All scores were obtained for each subject with the following exceptions: subjects \#30, 31, and 40 were not 
tested on Critical Flicker Fusion Threshold either because of the history of seizures or due to their reaction to the flickering light. The scores for subjects \# 40 and 49 on Preferred Muscular Relaxation Time task deviated by more than 4 standard deviations above the group mean and were excluded from the analysis.

Tapping data for subject \# 46 was accidentally lost. It was overwritten during the experiment by data from subject \# 47 who mistakenly was assigned the same ID number. Subject \# 14 had to repeat the tapping task 2 times. The subject was assigned the ID numbers 14 and 15, and for that reason in the tables \#14 is missing.

CORRELATION ANALYSIS.

Across-task correlations

We performed correlation analysis $(n=39)$, on all pairs of variables using Pearson's $r$. The results are shown in Table 3.

We will discuss the correlations that attained significance at the 0.05 level. As seen from the Table there is a negative association between CFFT and SIQR/ISI ( $r=-0.436$, $p<0.001$; see Figure 1), and between CFFT and AMTP ( $r=-0.566$, $p<0.001)$. While the value of $S I Q R / I S I$ refers to subject's 
random error, AMTP represents both random and systematic error. With the increase of the CFF threshold both the variability and random error decrease. In Figure 2 one can observe this tendency: there is a negative association between the CFF threshold and the slope of standard deviation vS ISI function indicating that subjects with higher CFFT exhibit a better temporal resolution resulting in a slower increase of variability with increasing duration.

Figure $3 a$ provides an example of the standard deviation of IRI Vs ISI for a subject with low CFFT. Figure $3 \mathrm{~b}$ gives an example of the SIQR VS ISI for a subject with high CFFT.

Table 3.Correlations Among the Variables

\begin{tabular}{lrrrrrrr} 
& \multicolumn{1}{c}{ CFFT } & \multicolumn{1}{c}{ FMRT } & PMRT & SRT & CRT & AMTP & SIQR/ISI \\
CFFT & 1 & & & & & & \\
FMRT & 0.002 & 1 & & & & & \\
PMRT & 0.150 & 0.606 & 1 & & & & \\
SRT & -0.022 & 0.351 & 0.217 & 1 & & & \\
CRT & 0.235 & 0.190 & 0.015 & 0.620 & 1 & & \\
AMTP & -0.566 & -0.040 & -0.161 & 0.052 & -0.129 & 1 & \\
SIQR/ISI & -0.436 & 0.070 & -0.162 & 0.112 & -0.056 & 0.783 & 1
\end{tabular}

Where $r=0.264, p<0.05$ and $r=0.367, p<0.01$ 


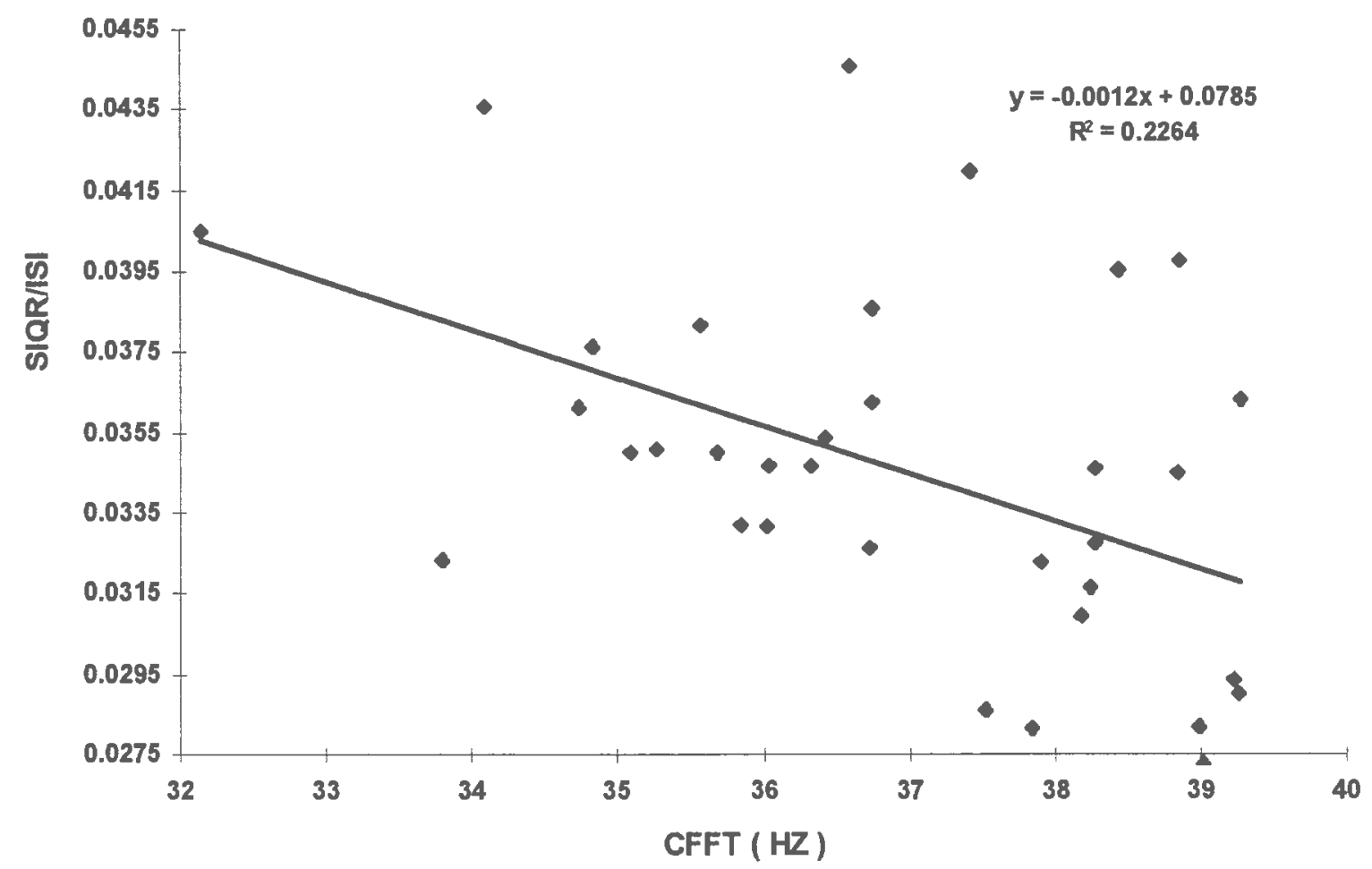

Figure 1. Scattergram: SIQR/ISI and CFFT

CFFT - Critical Flicker Fusion Threshold, Hz

SIQR/ISI - semiinterquartile Range divided by ISI 


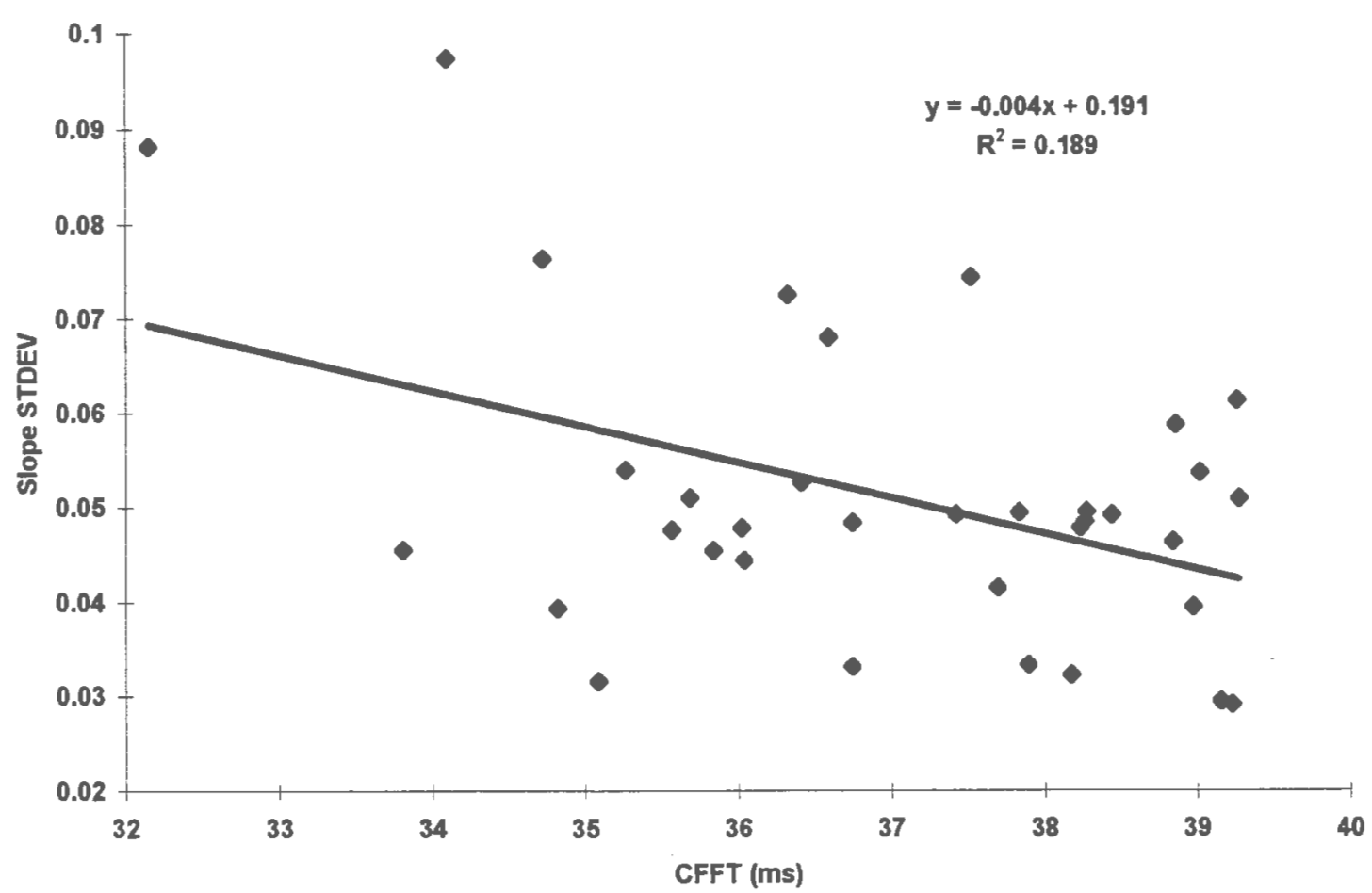

Figure 2. Scattergram: Slope of Standard Deviation vs ISI function and CFFT.

CFFT - Critical Flicker Fusion Threshold, Hz Slope STDEV-SIope of Standard Deviation vS ISI function.

As can be seen from Table 3 there is a positive correlation between Fast Relaxation Time and Simple Reaction Time $(r=.351, p<.05)$. With the increase of Simple Reaction Time, there is an increase in the Fast Relaxation Time. Both physiological processes employ a fast type of response. While some subjects, were fast on both tasks, some subjects were slow on both. 


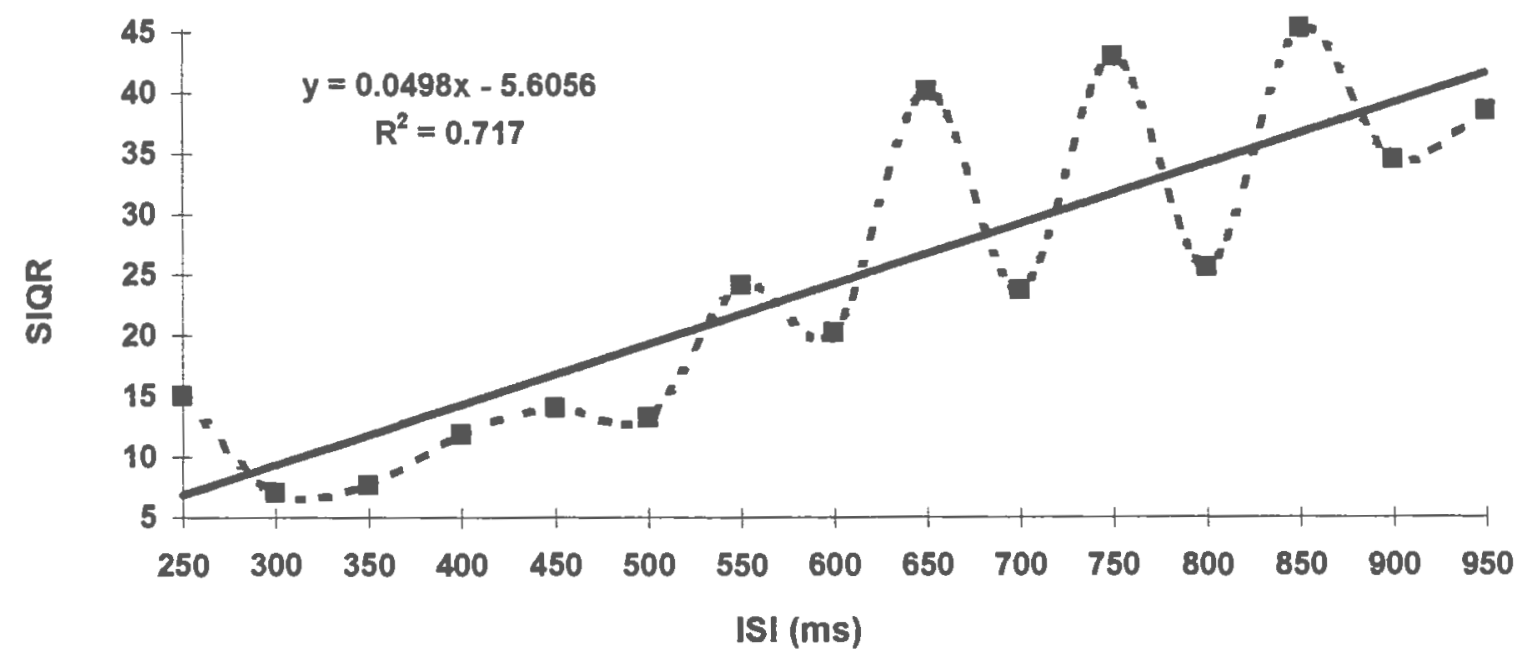

Figure 3a.An Example of Low Temporal Resolution. (CFFT=32.15 HZ) .

ISI -Interstimulus Interval, ms

SIQR - Semiinterquartile range

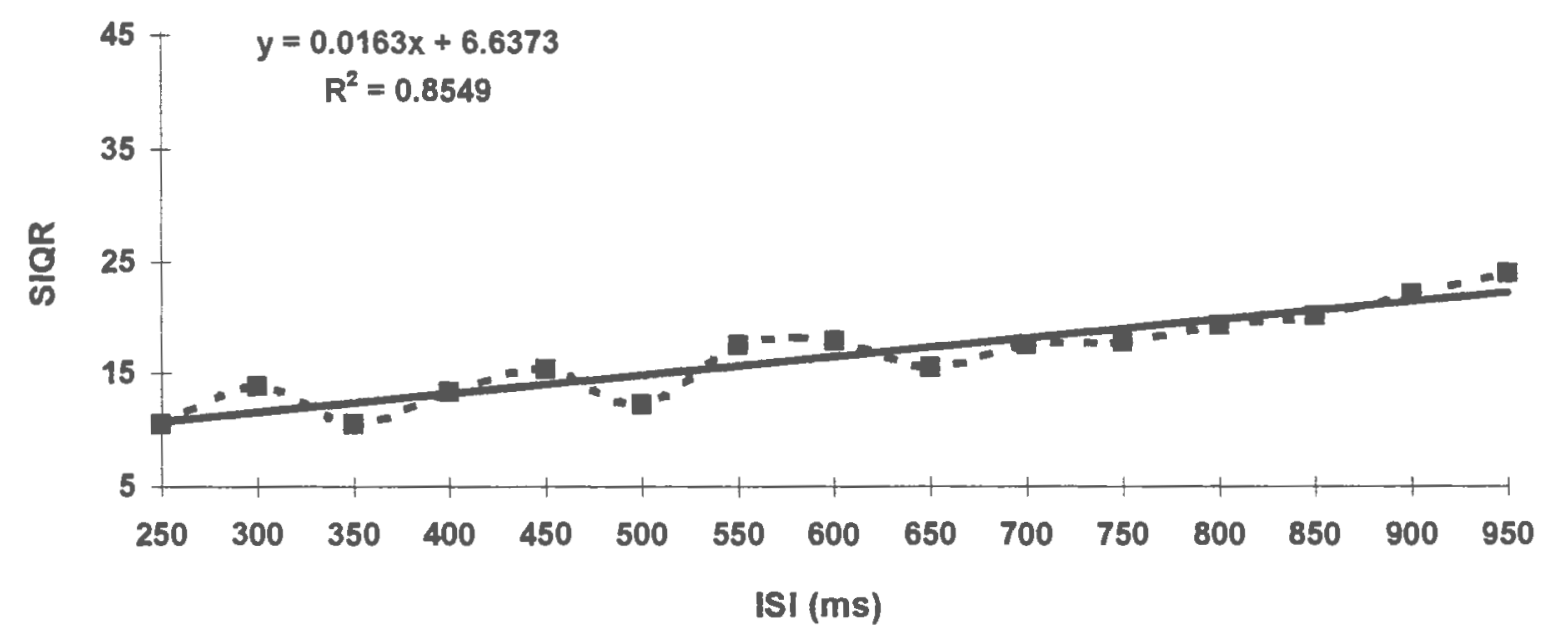

Figure 3b.An Example of High Temporal Resolution(CFFT=39.23)

ISI - Interstimulus Interval, ms

SIQR - Semiinterquartile Range 
Within-Task Correlations

simple and Choice reaction times were positively associated $(r=.620, p<0.01)$. With the increase of SRT values there is an increase in CRT values as well as in the reaction time button times. This type of association has been reported in the literature quite a few times and is replicated in our experiment.

There is a positive correlation between Fast Relaxation Time and Preferred Relaxation Time $(r=0.606, p<0.01)$. With the increase in Fast Relaxation Time, there is an increase in Preferred Relaxation Time, i.e. some subjects were slow on both tasks and some subjects were fast on both. Both tasks require a particular coordinated movement of the forearm associated with the specific brains' control of the skeletal muscle and therefore, a common neurophysiological mechanism may be accounted for by the relation between the two tasks.

The above results revealed significant linear relationships that were obtained in our research. Overall, our hypotheses were confirmed. However, we were unable to find a significant linear relationship between CFFT and Reaction Times as well as between variability in timing and Relaxation Time as we had originally predicted. Fast Relaxation Time appeared to be positively associated with 
the SRT, however, it failed to yield a significant correlation with CRT.

Non-linear relationships among the variables.

When additional analysis was attempted, it became apparent that non-linear relationships exist among the variables. The analysis revealed that subjects who resided in the middle of the Preferred Relaxation Time distribution of scores exhibited less variability (AMTP) in the timing task, and showed a slower increase in timing variance with the increasing of the interstimulus interval (see Figure 4). Figure 4 demonstrates the value of the variance in timing task for three groups of subjects. In the first group with short relaxation time (short PMRT group, $\mathrm{n}=12$ ) PMRT ranged from $300 \mathrm{msec}$ to $526 \mathrm{msec}$; in the group with intermediate relaxation time (intermediate PMRT group, $n=10$ ) PMRT ranged from 534 to $608 \mathrm{msec}$; and in the group with long relaxation time (long PMRT group, $n=14$ ) PMRT ranged from 613 to 794 msec. As seen in the Figure, the timing variances for both the first and the third group is higher, as compared with the intermediate group. The variances of the first and the third groups were compared to the variances in the intermediate group. The t-test was significant at $p<0.05$. Figure 5 demonstrates the difference in temporal resolution in groups with short, intermediate, and long PMRT. 


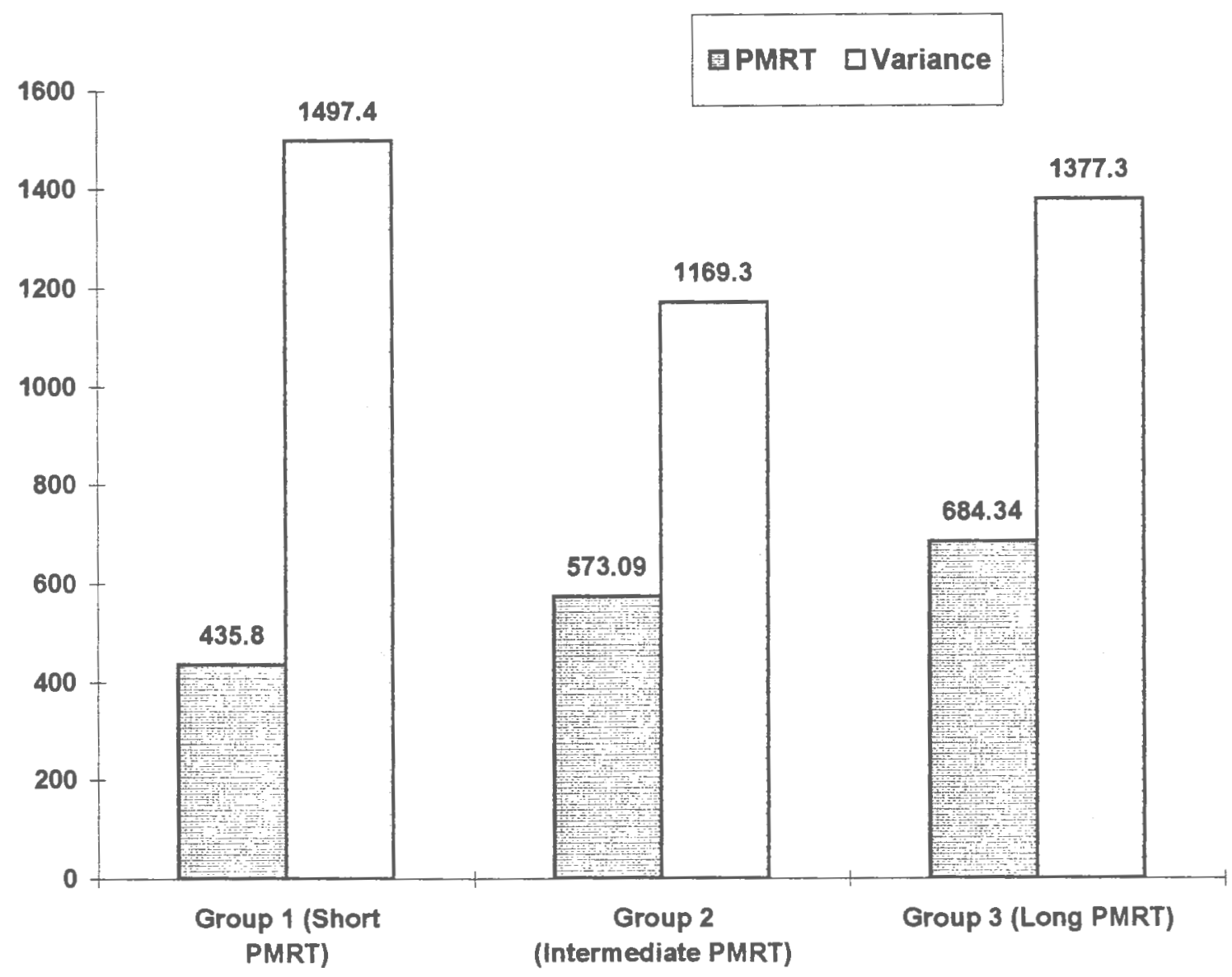

Figure 4. Comparative bar diagram for Preferred Muscular Relaxation Time (PMRT) and Accuracy in Manual Timing Performance (AMTP). 


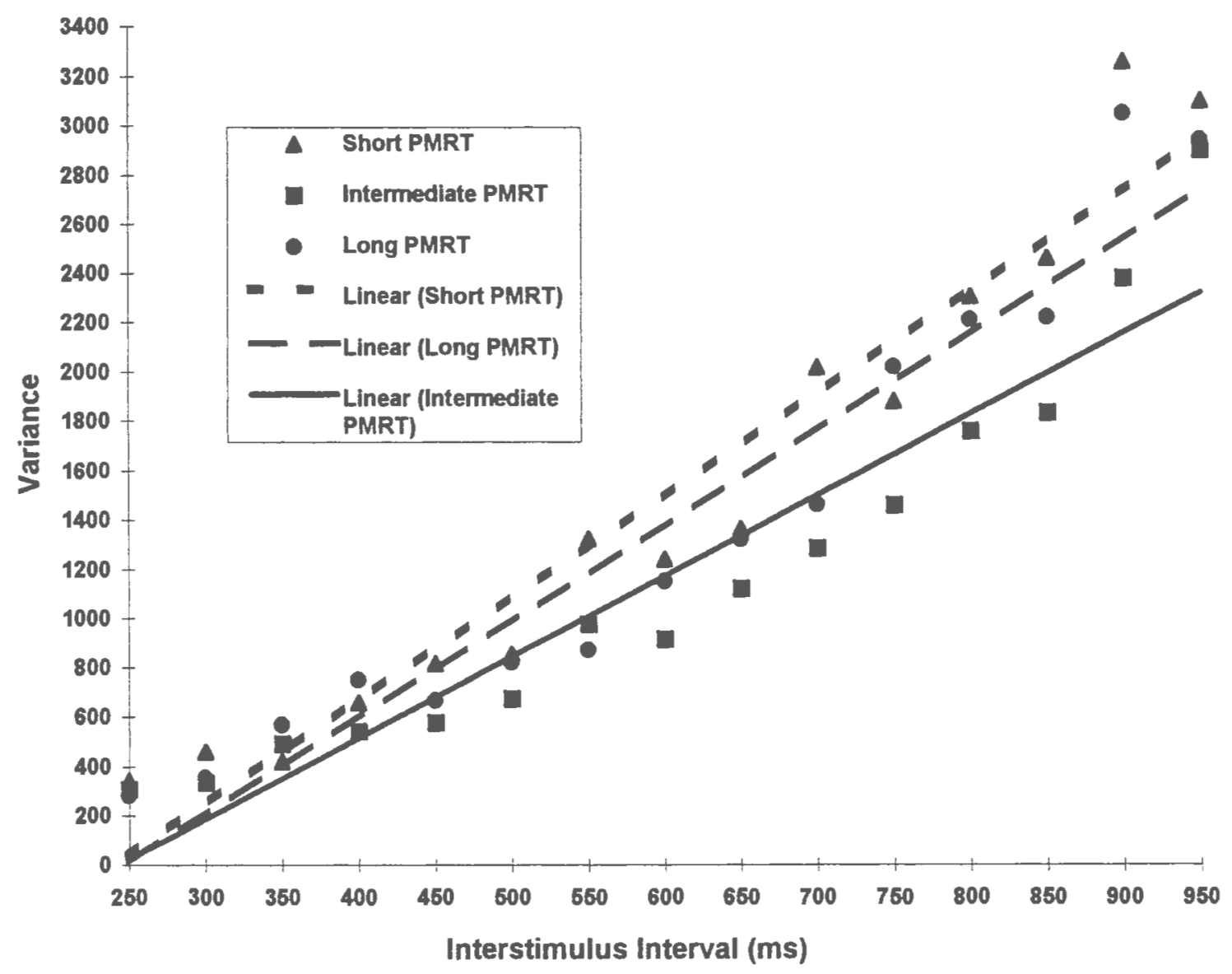

Figure 5. Temporal resolution in groups with short, intermediate, and long PMRT. 
Before discussing our findings further, we will provide a general description of the individual oscillator signature obtained in our research following collyer et al. (1992) developments.

The function relating IRI to ISI appears to have a strong linear relationship. However, as can be seen from Figure 6, there is a small departure from the identity function (regression line slope $=0.957$, intercept $=4.04)$

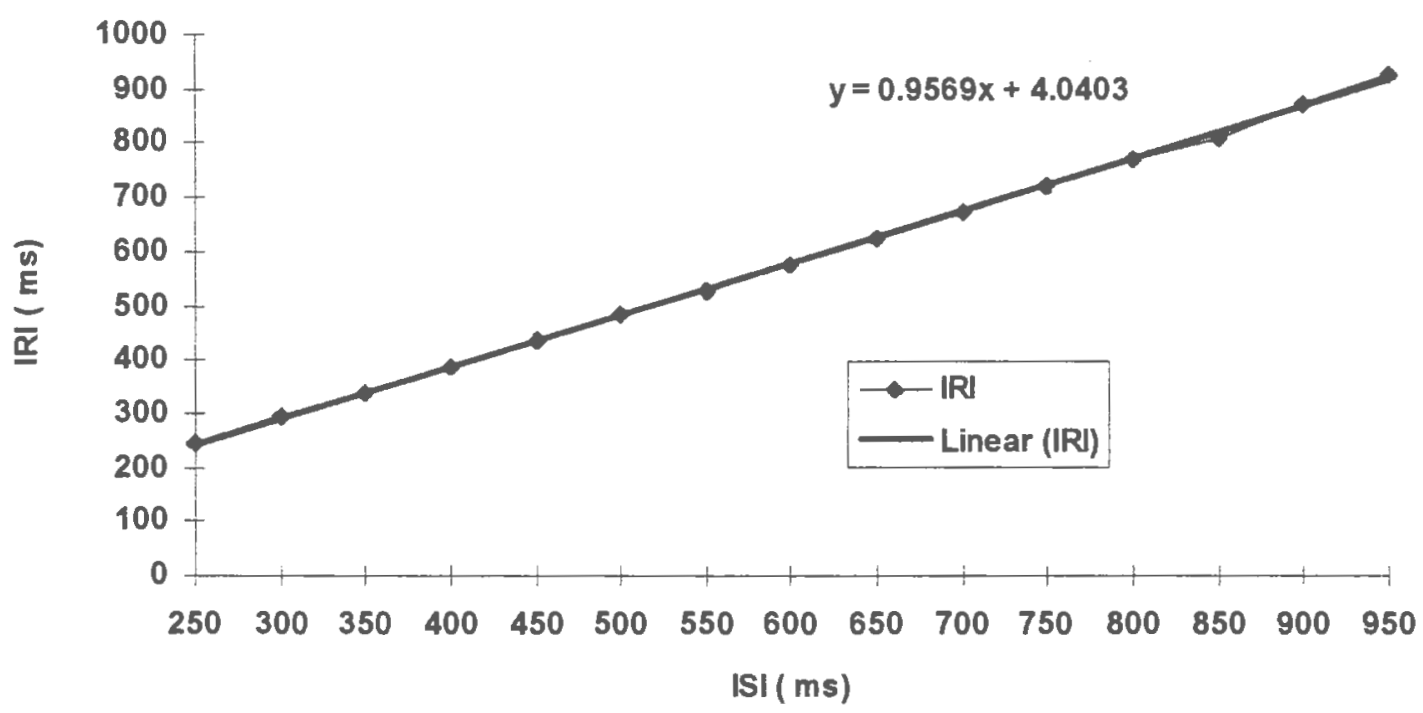

Figure 6. IRI as a function of ISI. Each data point of IRI represents a mean of 3 medians at each ISI averaged across 38 subjects.

ISI - Interstimulus Interval, ms

IRI - Interresponse Interval, ms 
Figure 7 shows the residual plot where residuals are nonrandomly dispersed around the predicted IRI over the range of ISI and resemble a wavelike function.

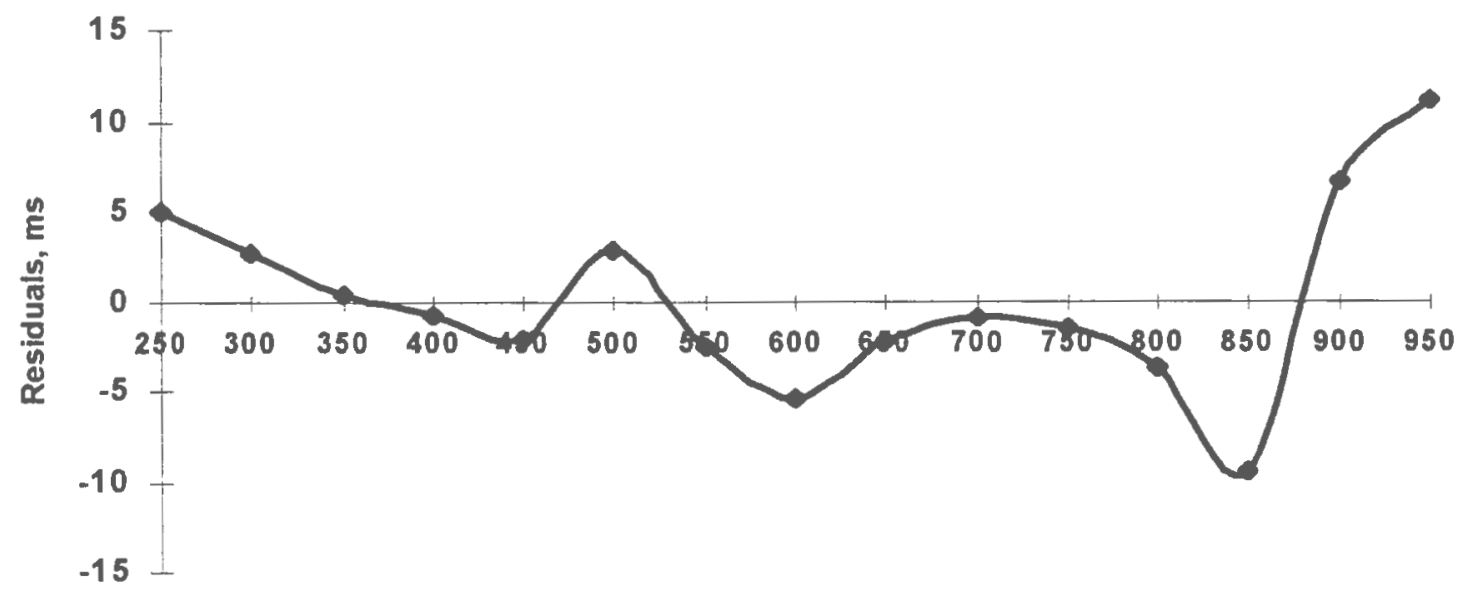

ISI ( $\mathrm{ms}$ )

Figure 7. Residual plot for linear regression IRI vs ISI $(n=38)$.

ISI - Interstimulus Interval, ms

In order to fit the standard deviation of IRI versus the ISI for each data set we regressed the standard deviations across the ISI conditions. Table 4 presents the slope, intercept and variance accounted for $\left(r^{2}\right)$ for each fitted line. All the slope values appeared to be highly significant, which indicates a strong linear relationship 
between the variability of the IRI and the ISI. In general, the standard deviation of IRI increases linearly with time

Table 4. Regression Coefficients for Standard Deviation of ISI

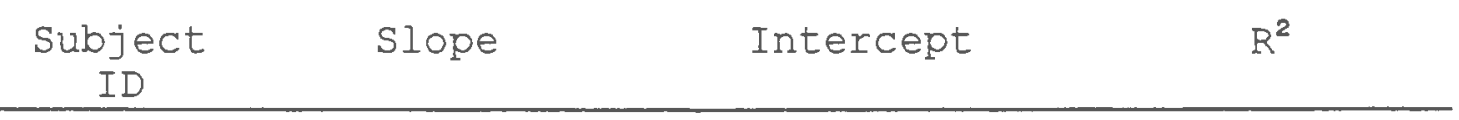

\begin{tabular}{|c|c|c|c|}
\hline 10 & 0.054 & -3.62 & 0.85 \\
\hline 11 & 0.046 & 2.94 & 0.87 \\
\hline 12 & 0.061 & -7.07 & 0.93 \\
\hline 13 & 0.049 & 12.34 & 0.72 \\
\hline 15 & 0.088 & -10.18 & 0.84 \\
\hline 16 & 0.033 & 9.27 & 0.73 \\
\hline 17 & 0.045 & 6.25 & 0.85 \\
\hline 18 & 0.033 & 17.79 & 0.51 \\
\hline 19 & 0.054 & -0.17 & 0.81 \\
\hline 20 & 0.053 & 1.53 & 0.93 \\
\hline 21 & 0.076 & -8.97 & 0.89 \\
\hline 22 & 0.051 & 2.69 & 0.88 \\
\hline 23 & 0.044 & 9.67 & 0.57 \\
\hline 24 & 0.097 & -15.93 & 0.94 \\
\hline 25 & 0.049 & 5.28 & 0.87 \\
\hline 26 & 0.051 & 4.96 & 0.88 \\
\hline 27 & 0.032 & 8.96 & 0.83 \\
\hline 28 & 0.050 & 4.22 & 0.81 \\
\hline 29 & 0.068 & 2.41 & 0.87 \\
\hline 30 & 0.069 & -5.05 & 0.94 \\
\hline 31 & 0.047 & -0.02 & 0.94 \\
\hline 32 & 0.049 & 2.65 & 0.84 \\
\hline 33 & 0.048 & 2.81 & 0.78 \\
\hline 34 & 0.073 & -4.94 & 0.78 \\
\hline 35 & 0.039 & 1.93 & 0.92 \\
\hline 36 & 0.029 & 9.38 & 0.80 \\
\hline 37 & 0.046 & 6.10 & 0.60 \\
\hline 38 & 0.059 & 3.00 & 0.92 \\
\hline 39 & 0.029 & 6.24 & 0.82 \\
\hline 40 & 0.038 & 11.27 & 0.81 \\
\hline 41 & 0.048 & 7.33 & 0.73 \\
\hline 42 & 0.049 & -1.42 & 0.94 \\
\hline 43 & 0.074 & -12.65 & 0.71 \\
\hline 44 & 0.048 & 4.04 & 0.81 \\
\hline 45 & 0.048 & 7.89 & 0.83 \\
\hline 47 & 0.032 & 10.85 & 0.73 \\
\hline 48 & 0.039 & 9.29 & 0.76 \\
\hline 49 & 0.041 & 9.29 & 0.77 \\
\hline
\end{tabular}




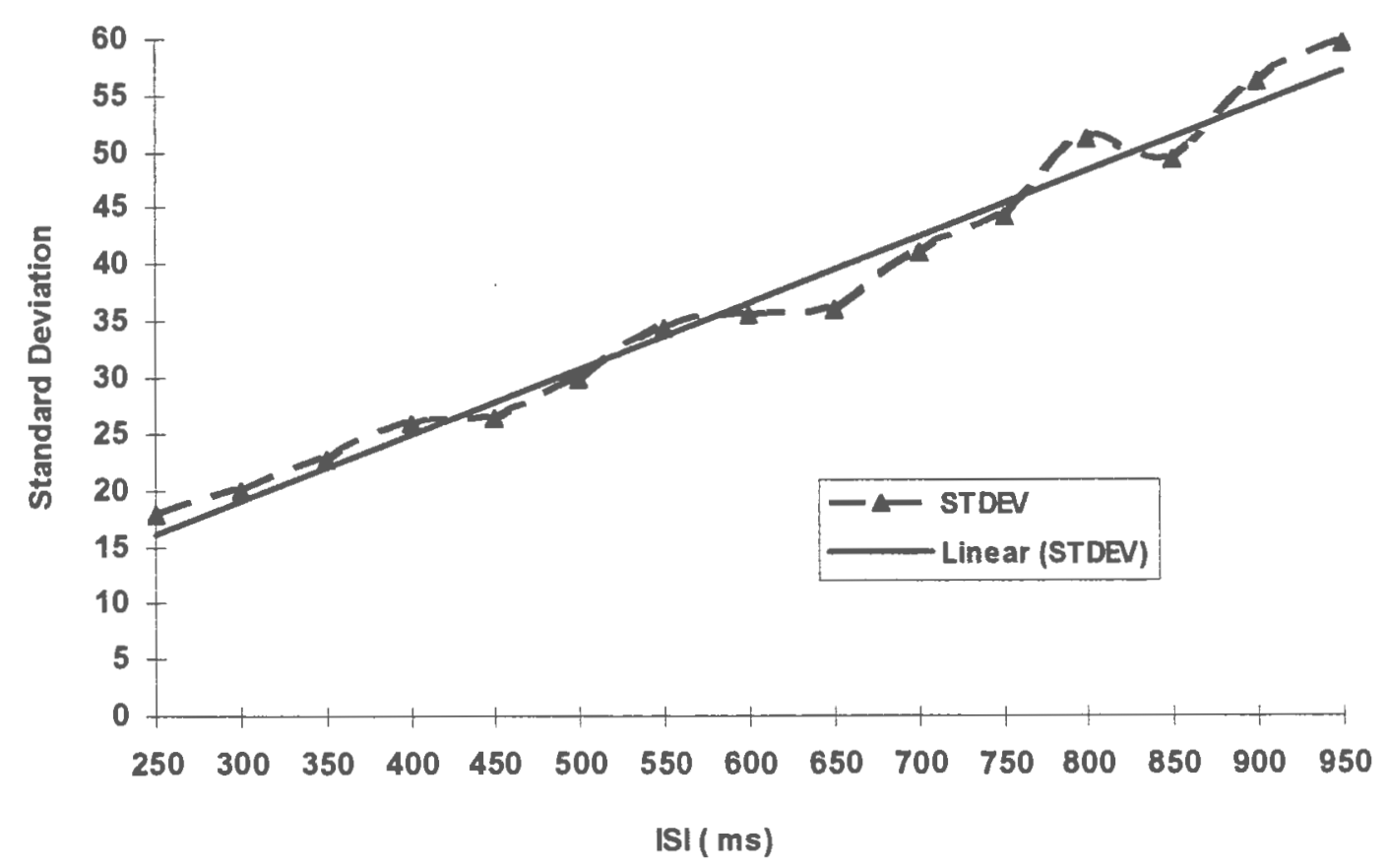

Figure 8. Average Standard Deviation ( $\mathrm{n}=38$ ) vS ISI

ISI - Interstimulus Interval, ms

(see Figure 8), which is consistent with the scalar property of timing (Gibbon, 1991).

Returning to Figure 7, the residuals resulting from the regression analysis represent systematic inaccuracies in tapping rate. Collyer (Collyer, et al, 1992) interpreted these inaccuracies as evidence for timing by an internal clock with multiple "natural periods". The following 
analysis focuses on inaccuracy relative to the identity function rather than to the regression line. The measure of interest is Percent Residual Bias (PRB). Following the data collection for Experiment 1, we observed that Choice Reaction and Fast Relaxation times seemed to be associated either with a peak or a trough of Percent Residual Bias. An example of this pattern is provided in Figure 9. As may be seen from Figure 9, the mean for Fast Relaxation Time tend to fall within the second trough of Percent Residual Bias while the mean for the Choice Reaction tend to fall within the third trough of PRB.

In Experiment 1, the interstimulus interval for the time production task ranged from $250 \mathrm{msec}$ to $750 \mathrm{msec}$ in steps of $50 \mathrm{msec}$. If we were to investigate further whether there is an association between a peak or a trough of Percent Residual Bias and Choice Reaction Time, we would have to increase the ISIs' duration at least up to $950 \mathrm{msec}$ because Choice reaction time tends to be longer than 750 msec in most of the subjects. In fact, this happened to be the case in 3 out of 7 subjects for this experiment. In Experiment 2 the range of the ISI was increased to $950 \mathrm{msec}$. Figure 10 is an example of an individual oscillator signature when the PRB function is located below the identity line. In this case the trough of the function between two peaks always represents the highest absolute 
error whereas the peak of the function between two troughs represents the lowest absolute error. The reverse is true

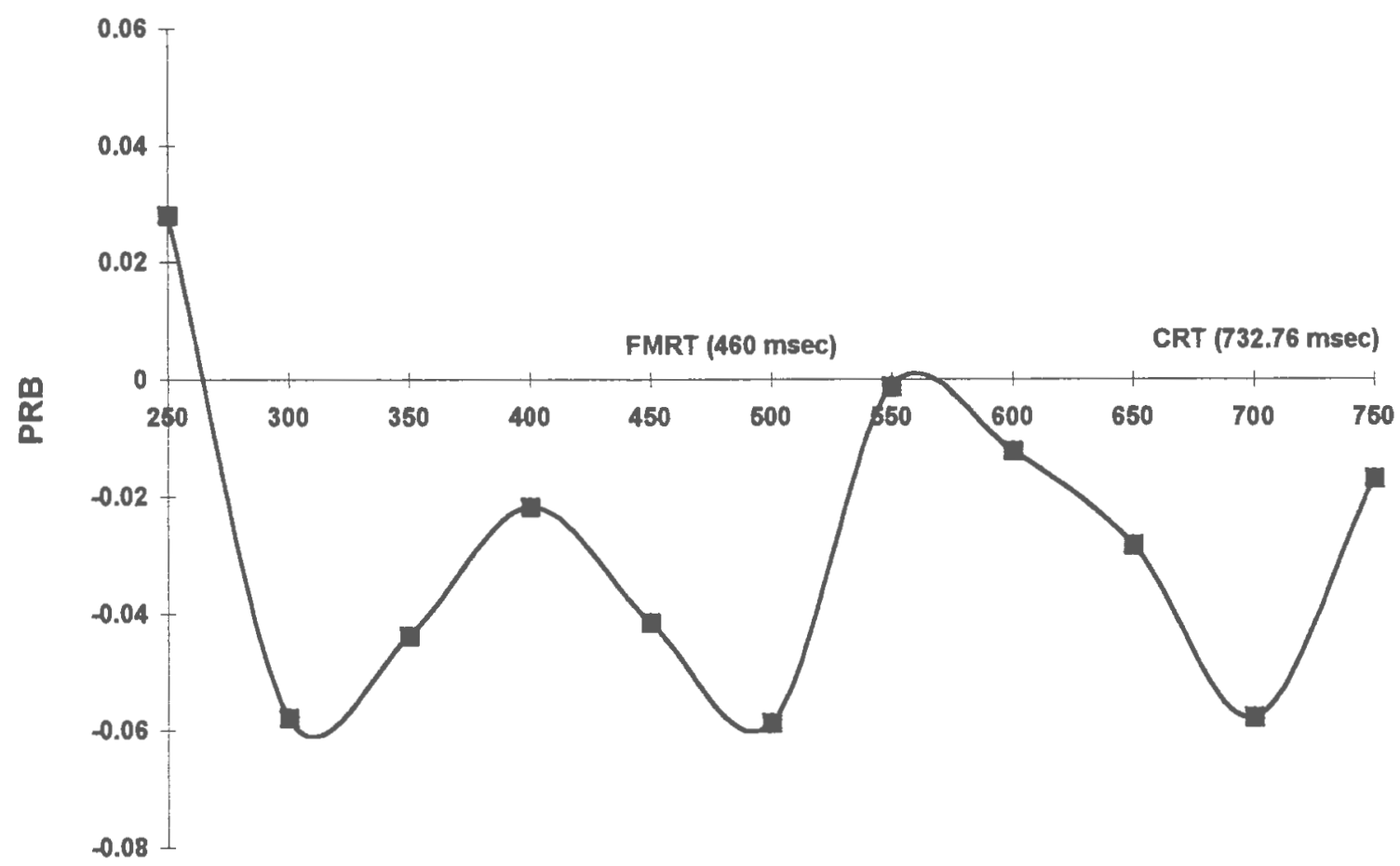

ISI (ms)

Figure 9. Oscillator Signature, Experiment 1.

ISI - Interstimulus Interval, ms

PRB - Percent Residual Bias

EMRT - Fast Muscular Relaxation Time, ms

CRT - Choice Reaction Time, ms

when the function is located above the identity line (see Figure 11). Figure 12 is an example of an intermediate case when the PRB function alternates across the identity line in 
which case both the peak and trough represent high absolute error. A trough occurs when tapping is relatively fast and a peak of the function occurs when tapping is relatively slow. Collyer, Broadbent and Church (1992, 1994) attributed the pattern of relatively slow and relatively fast rates to oscillatory processes and provided evidence that the influence of the oscillators could be found in different timing tasks. One aim of the present study was to examine the possibility that the influence of oscillatory processes can be found across a variety of different temporal tasks.

In this part of our research we entertained the hypothesis that Simple Reaction Time, Fast Relaxation Time, Preferred Relaxation Time and Choice Reaction Time occur either at a peak or at a trough of the individual oscillator signature.

The Individual Oscillator signature for each subject can be found in Appendix XIV. The error bands around each data point are based on the assumption of normality and represents the 95\% confidence interval at each ISI for the null hypothesis that IRI is equal to ISI$+(1.96 * \mathrm{SD} / \mathrm{SQRT}(86) /$ ISI). The thick line represents a cubic polynomial spline which was fit to the experimental points of the Oscillator Signature. The peaks and troughs were identified by the analysis of the first derivative. The peak can be defined as the point where the first derivative of 
the function changes from positive to negative while the trough's derivative changes in the opposite direction. Thus the value of the first derivative at a local maximum or

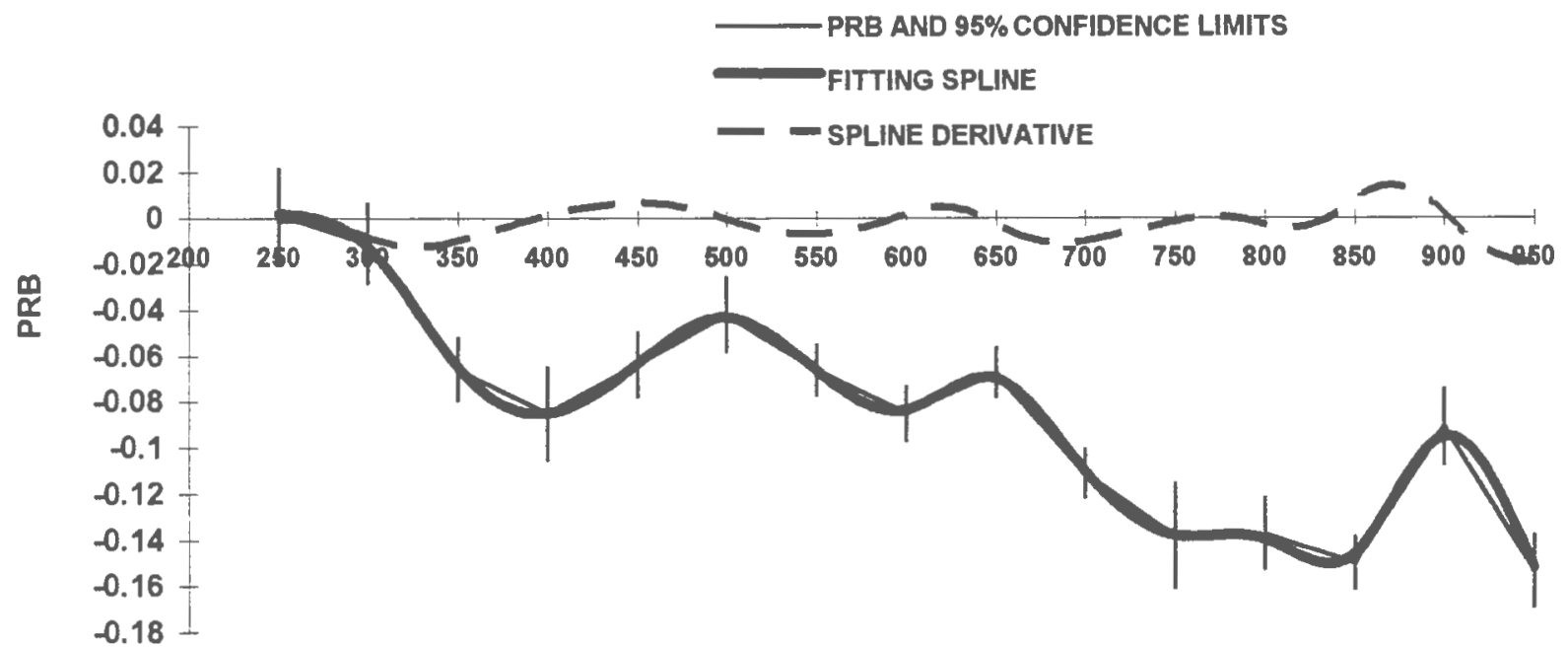

ISI (ms)

Figure 10. Oscillator Signature (Subject 41)

ISI - Interstimulus Interval, ms

PRB - Percent Residual Bias 


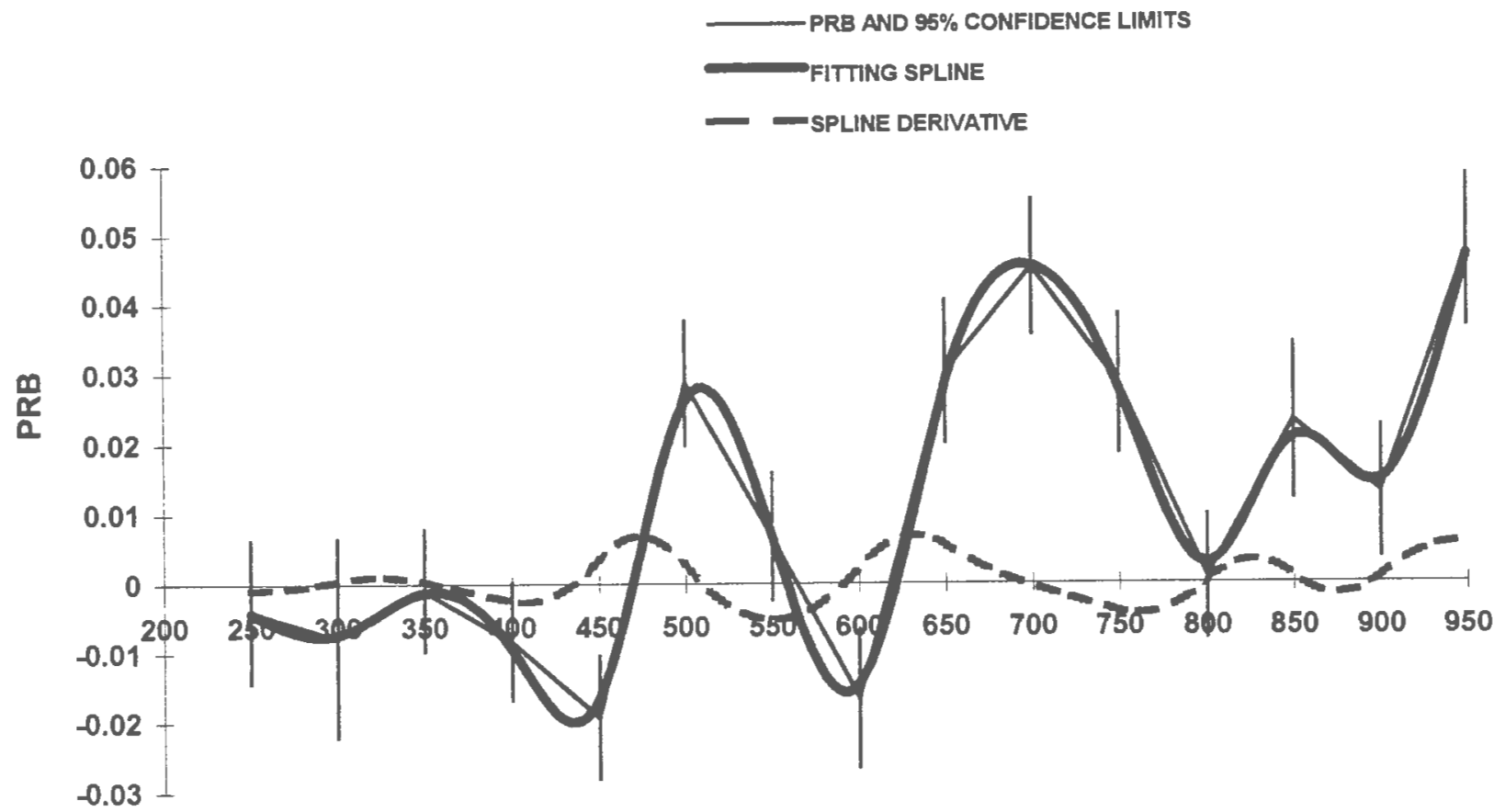

ISI (ms)

Figure 11. Osciliator Signature (Subject 35)

ISI - Interstimulus Interval, ms

PRB - Percent Residual Bias 
—PRB AND 95\% CONFIDENCE LIMITS

- SPLINE DERIVATIVE

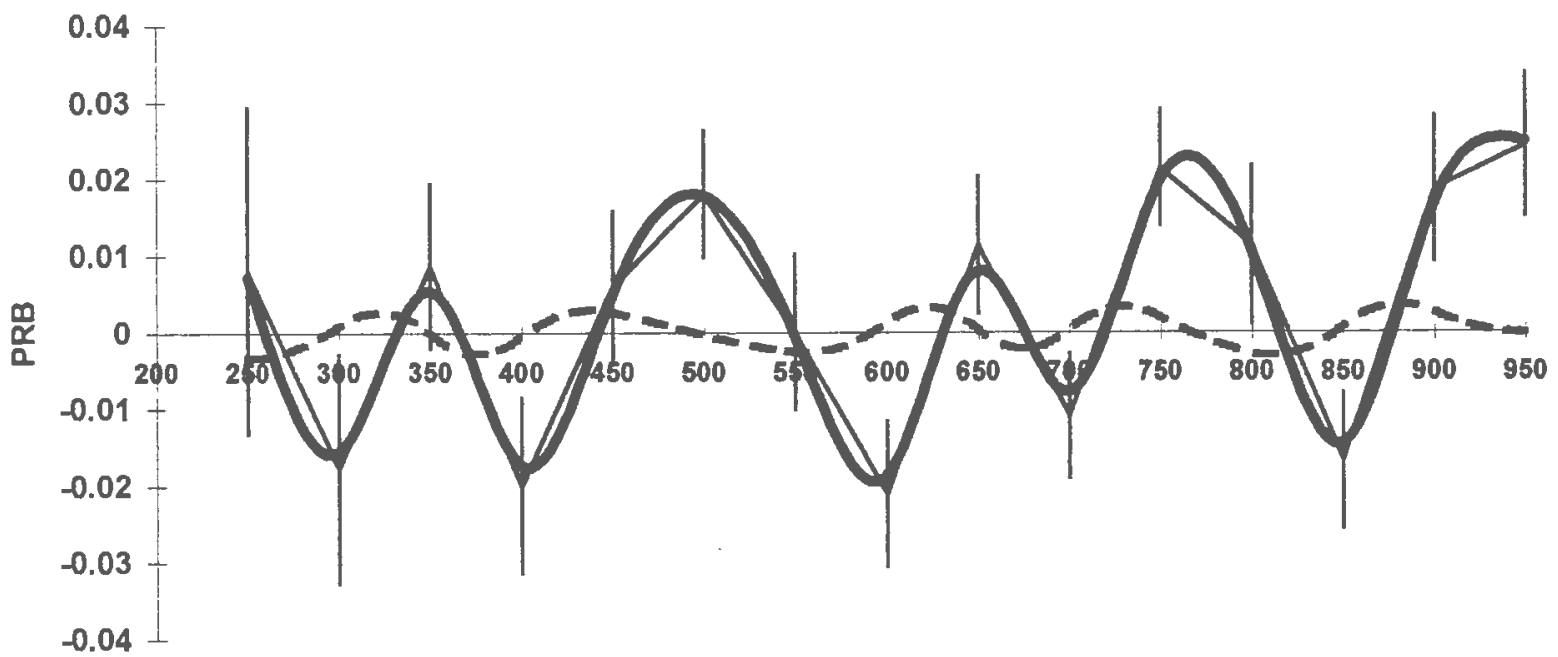

ISI (ms)

Figure 12. Oscillator Signature (Subject 36)

ISI - Interstimulus Interval, ms

PRB - Percent Residual Bias 
minimum is equal to zero. If our hypothesis is true, then the values of SRT, FMRT, PMRT, and CRT will be distributed around to the zero value of the first derivative, while values of any random points will not. Random values along the ISI axis were generated by means of the SAS software random points generator. Further, the corresponding PRB value along the ISI axis and respective first derivative values were estimated. Fifteen random points were generated for each subject separately. The Table of estimated first derivatives for SRT, FMRT, PMRT, and CRT is presented in Appendix V. The Table of estimated first derivatives for random points is presented in Appendix XV. The chi-square test was used in order to test the discrepancy between expected and obtained frequencies in the frequency distributions of the derivatives for the measures and for random points. The frequency distribution with one random point per subject was used as an expected frequency. It was compared with the observed frequency distributions for SRT, EMRT, PMRT, and CRT. The expected and obtained frequencies were significantly different for EMRT $(p<0.01)$, for PMRT $(p<0.0001)$, and for CRT $(p<0.005)$. The expected and observed frequencies did not differ significantly when compared for SRT $(p<0.06)$.

Additionally, the shape of the distributions for the measures and for the random points were examined (see 
Figures 13 and 14). As may be seen from the Figure 14, the distributions for FMRT, PMRT, and CRT and random points are quite different. While the distributions for the measures are more centered around zero (yielding from 51 to 69 percent of all values) and peaked more, the distribution of the random point only yields 35\% of all values around zero and is significantly shifted to the right. This appeared to be very characteristic for the distributions of random points generated from this particular data set as may

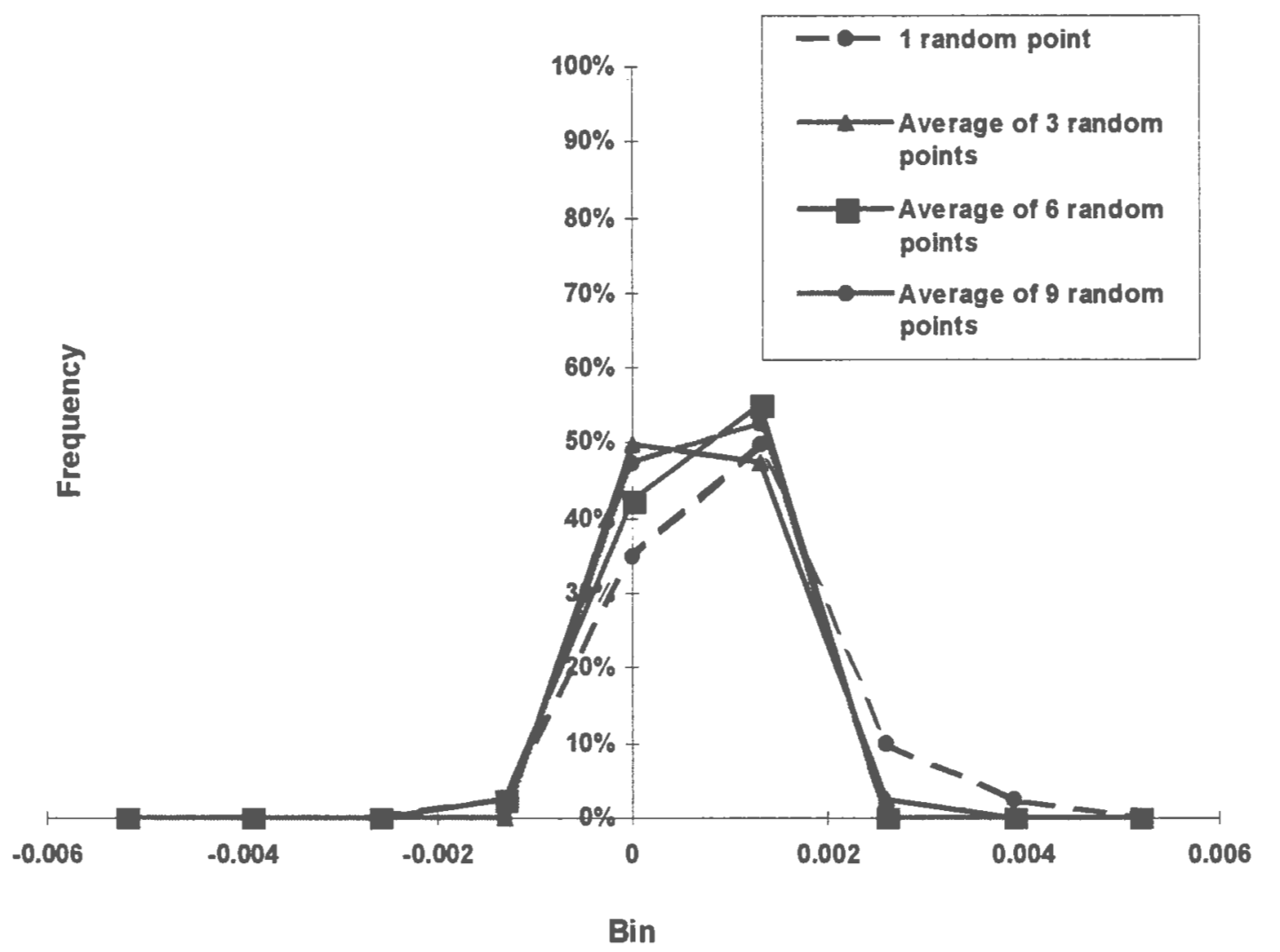

Figure 13.Distributions of the first derivatives of random points. 


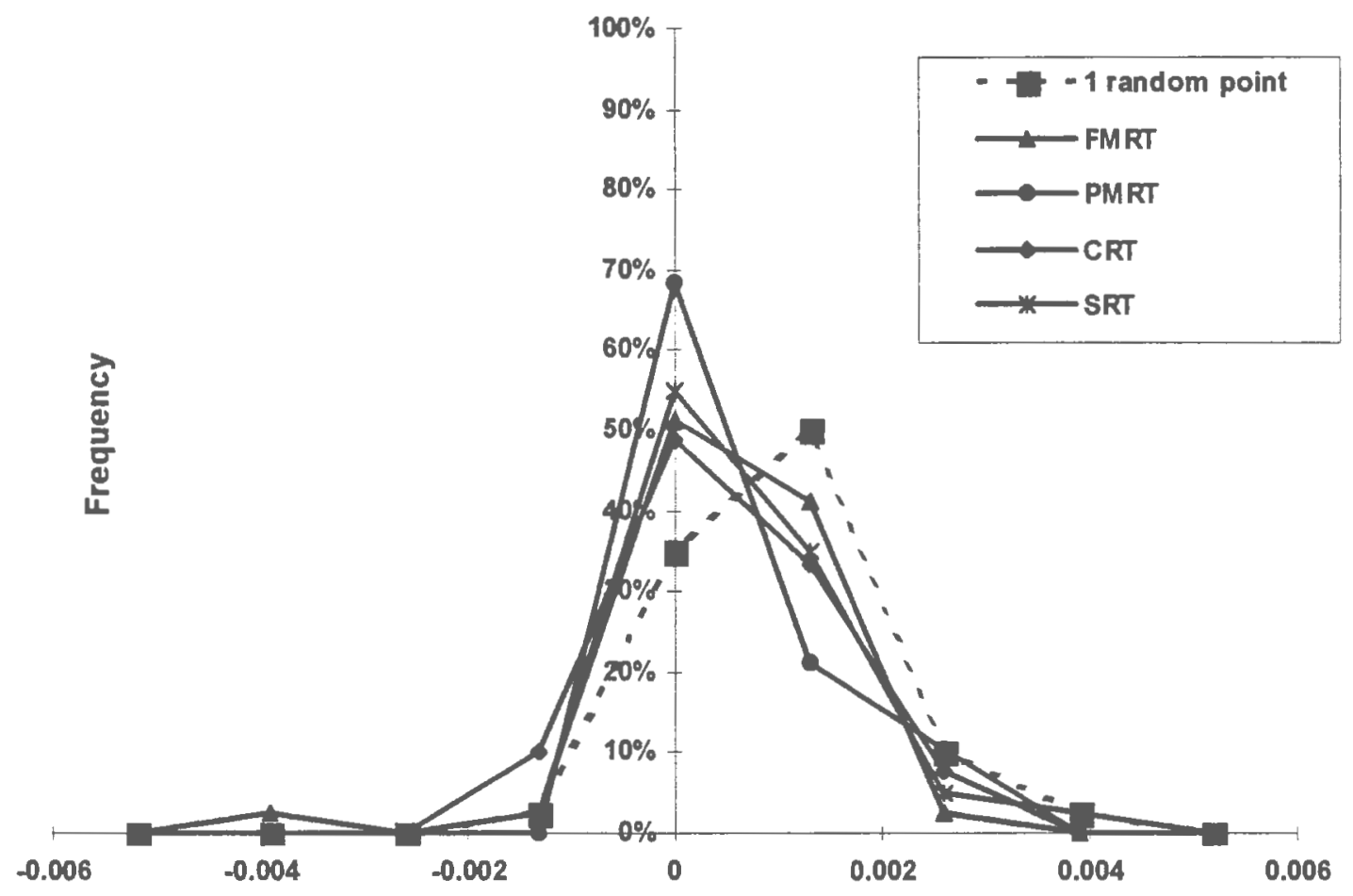

Bin

Figure 14. Distribution of the first derivatives for one random point and for the temporal measures. 


\section{Average Oscillator Signature}

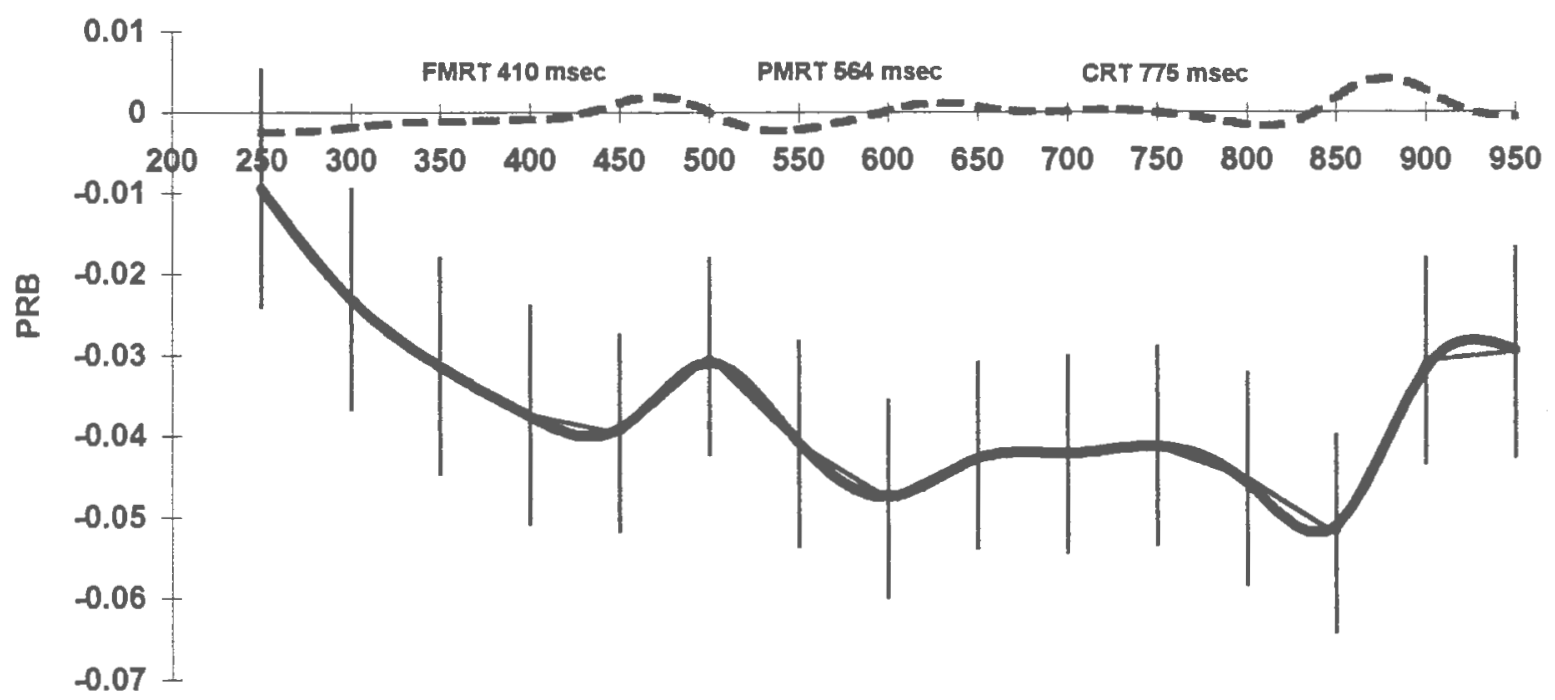

ISI (msec)

Figure 15. Average Oscillator Signature

ISI - Interstimulus Interval, ms

PRB - Percent Residual Bias 
be seen from Figure 14. Figure 14 gives an example of different distributions of the first derivatives for one random point per subject, as well as for averaged distributions of random points derivatives for 3,6 , and 9 random points per subject. All four distributions are significantly shifted to the right. The latter may be explained by the nature of the PRB function (which presumably, has a tendency to diminish at a faster rate compared to its growth). The random points correspond more often to the intervals of growing function by chance alone which suggests that the experimental data points are not randomly distributed, otherwise we would observe the same tendency for the experimental data points.

Averaged Percent Residual Bias function (across 38 subjects) is presented in Figure 15 where the group means for FMRT, PMRT, and CRT tend to fall within the three the respective troughs. 


\section{DISCUSSION}

Limitations of this study:

We attempted to perform a very large experiment. In order to avoid fatigue which could interfere with internal validity, the time of the experiment was limited to a reasonable duration of one hour and a half. However, in earlier studies the timing task alone usually lasted from about three to four hours. All of the measures in the experiment had to be collected during the same time. In order to do this, a much shorter version of the timing task was designed. This version consisted of three timing trials per ISI, where each trial contained 20 synchronization taps and 30 continuation taps as compared to 50 synchronization and 50 continuation taps per trial and five trials per ISI in Collyer's (Collyer et al, 1992, 1994) experiments, for example. The question that arises is to what extent the results from the latter timing experiment may be comparable to the results from our version of the timing experiment. Although the obtained data from the shortened version appears to be rather compelling, it would be very useful to compare the results of the two timing tasks.

Our sample represented the general adult population reasonably well. It embodied diverse age groups, 
occupations, and contained an equal number of men and women. However, $70 \%$ of our subjects were college graduate and undergraduate students. For psychophysiological research, this aspect may not be critical in terms of generalizing the results to the rest of the population, especially taking into account that very few of the subjects had any major health problems. The fact that almost $25 \%$ of our subjects have had musical training for a various durations of years (2 to 20) could be a somewhat larger problem and thus, we thought, that they might have had certain advantages in reproducing different time intervals in continuation tapping experiment in comparison with the rest of the group. Our results, nonetheless, did not confirm this hypothesis. Subjects with musical training were separated from the rest of the group and average variances in continuation tapping were studied in both of the two groups. In the group with musical training the average variance was equal to 1379.2 and in the group without musical training it was equal to 1419.3. The t-test did not reveal significant differences between the group with musical training and the group without musical training. We believe, however, that future research should study in more detail whether musical training affects performance on tasks such as the ones used here. 
Linear Relationships among the variables.

In this research we entertained several hypotheses regarding the interrelation of human temporal characteristics operating on different levels of functioning. The analysis of linear relationships among the variables yielded several significant correlations.

As was predicted, subjects with higher Critical Flicker Fusion threshold exhibited significantly less overall variability in timing as well as showed a slower increase in variability with the increasing of the interstimulus interval. The correlation suggests that motor timing and the perception of temporally varying stimuli may share common mechanisms.

In motor control, a simple pattern of rhythmical motor responses like tapping is considered to be associated with the lowest level of regulation; and, as unexpected as the association between Critical Flicker Fusion Threshold and accuracy in timing may appear, a large part of shared variability may be accounted for by a common biological functioning in the neural substrate that controls both processes. Such biologically based quality, as was discussed above, is the lability function "... which regulates the rhythmic action of successive stimuli, thus determining the speed of formation and termination of cycles 
of excitation aroused by the stimulus", (Nebylitsyn, 1972, p. 258). These results clearly point to the importance of the lability function as a measure in further study of human temporal characteristics.

Another finding of this research is the positive association between Simple Reaction time and Fast Relaxation time $(p<0.05)$. While timing involves a simple pattern of rhythmical motor responses, the response assessed by Simple Reaction time and Fast Relaxation time is the speed of reaction. Since both processes employ a fast type of response, the positive association between the two measures may be accounted for by a common involvement in cognitive processing such as the duration of encoding of the stimulus as well as the decision time for the execution of the response.

A search of the literature has revealed no investigations performed in regards to this problem. However, given the enormous amount of attention that has been directed at the research of reaction time since the middle of the century, and the various implications of reaction time research, further study of Simple Reaction time correlates may furnish more information, allowing it to continue its endeavors for meaningful applicability in a great number of different areas.

The positive correlation $(r=0.615)$ between Choice 
Reaction time and Simple Reaction time that has been obtained in the present study is a replication of the findings reported earlier; see Donders, for example (Donders, 1969).

The above results revealed significant linear relationships. Overall, our hypotheses were confirmed. However, we were unable to find a significant linear relationship between CFFT and Reaction Times as well as between variability in timing and Relaxation Time as we had originally predicted. Fast Relaxation Time appeared to be positively associated with the Simple Reaction Time, however, it failed to yield a significant correlation with Choice Reaction Time.

The non-linear relationships between temporal characteristics.

Another important finding of this research is that the subjects who were located in the middle of the Preferred Relaxation Time distribution of scores exhibited less variability in the timing task, and showed a slower increase in timing variance with the increasing of the interstimulus interval. That is, as was predicted by one of the hypotheses, those subjects who have very short or very long Preferred Muscular Relaxation time exhibited more 
variability in Manual Timing Performance. The variances of the groups with shorter and longer Preferred Relaxation time differed significantly $(p<0.05)$ when compared to the variances of the intermediate group. The mean preferred Relaxation time for all subjects was estimated to be 564 milliseconds.

These results seem to be in agreement with the data reported earlier in classical experiments in time perception. Since the middle of the $19^{\text {th }}$ century in different research the durations between two successive stimuli of approximately 500-600 $\mathrm{msec}$ have been reported as time intervals perceived with minimal error (Fraisse, 1963, pp 116-125). Woodrow, for example, has reported such intervals to be between .59 and .62 seconds and has named them a "temporal indifference interval" for which there was no systematic error (Woodrow, 1934). The unbiased reproduction of such durations was attributed to the mechanism of a biological clock associated with certain metabolic changes in the organism. Therefore, subjectively, the intervals of about $500-600 \mathrm{msec}$ were thought to be perceived as neither too long, nor too short (Woodrow, 1930, 1934; Fraisse, 1963). Much effort has also been directed toward the problem of psychophysiological basis of the perception process. In summarizing the results of research in the area, Fraisse came to a conclusion that the average 
duration for the underlying physiological process "...must be around half a second" (Fraisse, 1963, p 127). It is well known that the durations of many physiological events (for example, the average duration of a step, average duration of pronouncing a word in a speech, and durations of many brain evoked potentials) last for about $500 \mathrm{msec}$. Tsukanov (Tsukanov, 1985), claims to have calculated the average subjects' time unit $(550-600 \mathrm{msec}, \mathrm{n}=190)$ in time measurement and time estimation. In sports psychology the ability/inability to relax has been linked to individual variations in time perception as well as to the level of performance in athletes. This line of evidence suggests that people who are able to relax more deeply tend to exhibit less error in time perception and to demonstrate a higher level of performance (Moiseeva, 1985; Elkin, 1962).

Preferred Relaxation time in the intermediate group ranged from $534 \mathrm{msec}$ to $608 \mathrm{msec}$ with an average of 569 milliseconds and as has been shown above, this group of subjects exhibited significantly less variability in timing, while subjects who deviated from this value on PMRT exhibited more variability. An assumption can be made that the duration of Preferred Muscular Relaxation Time is associated with the mechanism of a biological clock. The time interval durations used in time perception are sometimes longer than those studied in timing research. Our 
data, nevertheless, seem to be in agreement with the results obtained in time perception. The relationship between Preferred Muscular Relaxation Time and timing accuracy appears to be a rather intriguing finding which, should certainly be a subject for further study in timing, time perception and related areas of research. For example, some other physiological observables that may be studied as a function of time should be related to Preferred Muscular Relaxation Time and to performance in timing tasks.

The relation of temporal characteristics to the oscillator signature.

There exists no simple or straightforward answer to how human temporal characteristics are organized. This becomes especially clear as one attempts to review numerous concepts, theories and models that have been proposed in the area of psychology of time and related disciplines, and yet no general theory has gained wide acceptance.

The general pattern of the relationship which exists among the variables suggests at least two possible explanations. The first one is that some pairs of variables are linearly related to each other, while those temporal measures that are not linearly related, are completely independent. The second one is that while some temporal measures are linearly related to each other, there is an 
overall non-linear relationship among the variables. The results seem to favor the second explanation.

Collyer (Collyer, et al, 1994) argues that the form of oscillator signature exhibits significant individual differences. In other words, the degree of deviation from the identity line as well as the location of peaks and troughs in the oscillator signature relative to the ISI durations vary across subjects. The authors attributed the pattern of relatively slow and relatively fast rates to an oscillatory process in the timing mechanism and showed that the influence of the oscillators can be found in different timing tasks. Our data provides evidence that the location of peaks and troughs in the oscillator signature are meaningfully related to the individual means of the three temporal measures (FMRT, PMRT and CRT). The shapes of the distributions of first derivatives for the measures and for the points randomly chosen along the ISI axis appeared to be rather different. While the distributions for the measures were more centered around zero and peaked more, the distribution for the random points was shifted to the right and peaked less. Values of the measures fall closer to peaks and troughs of oscillator signature than would be expected by chance, (chi-square was significant at $p<0.001$ ). The chi-square test did not reach significance for Simple Reaction time $(p<0.06)$. Visual inspection of the 
distributions of derivatives for Simple Reaction time and Fast Relaxation time, however, suggests that the two are very similar. In simple Reaction Time 55\% of all scores fall at zero interval while $51 \%$ of all scores in Fast Relaxation time fall at zero interval. Further, 41\% in FMRT fall into +0.001 interval, while in SRT 35\% fall into the same interval. The rest of the 3 to 5 percent of the scores in both distributions fall into 0.0026 and -0.0026 intervals. Taking into consideration the positive correlation between SRT and FMRT reported above, one may suggest that both measures may be related to the same interval of oscillator signature, however, further research is needed.

Setting aside the justification of the nature of nonlinear relationships among the variables, (for such a question is an overly large problem for a separate study), we conclude that both linear and non-linear relationships exist among human temporal characteristics operating on different levels of functioning. Overall, the results support the theory of multiple oscillators and the pattern of data suggests a rather strong possibility that such temporal characteristics as Fast Relaxation time, Preferred Relaxation time, and Choice Reaction time are regulated by a common underlying mechanism composed of multiple oscillators. 
APPENDIX I

\section{INFORMED CONSENT FORM FOR RESEARCH}

\section{Psychophysiological Correlates of Skeletal Muscular Relaxation Time.}

The subject has to be 18 years of age or older in order to be able to take part in a study Psycho- physiological Correlates of Skeletal Muscular Relaxation Time. It was explained to me that the purpose of present testing is to learn more about human timing and its association with relaxation time. The researcher Anna Klevak, a graduate student from Psychology Department, the person mainly responsible for this study (work phone 2744538 , home phone 861-8869), will explain the project to me in detail. I should feel free to ask questions. If I have questions or concerns about the study later, I may talk to Professor Charles Collyer, vice-president of the psychology department (work 792-4227).

\section{WHAT WILL BE DONE}

If I decide to take part in this study the following will happen. I will be asked to come to the Independence Square at a scheduled time. The experimenter will assess several psycho-physiological measures such as: Critical Flicker Frequency Threshold, Simple and Choice Reaction time, Manual Timing Interval Production and Muscular Relaxation Time. Each is described below:

Muscular Relaxation Time. If I consent to participate, physiological sensors will be applied to my arm. There will not be any pain or discomfort related to the procedure of recording my psycho-physiological responses. After the sensors are applied, I will be asked to relax in a comfortable chair for 2 minutes. Next, I will be asked to tense my arm as hard as possible and then to relax it. This procedure will take approximately 15 minutes. There should not be any pain or discomfort related to this procedure, however, if I have been physically inactive I might experience mild muscular fatigue in my arm the next day as a result of this testing.

Critical Flicker Threshold Method: If I consent to participate, I will be seated in a chair and my task will be to respond promptly to a flickering light in front of me by reporting when I see a flickering light become a steady light or when I see a steady light become a flickering light. The procedure will take approximately 10-15 minutes to complete. There should be no discomfort related to this procedure.

Manual Timing Interval Production: If I consent to participate, I will be asked to relax in a chair while I wear earphones through which I will hear a series of tones. I will be asked to tap in time with the changing tones and attempt to change my tapping with changes in the timing of tones. This method takes approximately 35 minutes to complete. There should be no pain or other discomfort related to the procedure.

Simple and Choice Reaction Times: If I consent to participate, I will be seated in a chair in front of a response box. The box has four buttons. I will be asked to follow the instructions on the screen in front of me and to press the corresponding button responding promptly to the instructions. 


\section{RISKS AND BENEFITS}

There should be no risks or discomforts while I participate in these psycho-physiological tests. However, if I have been physically inactive, I may experience a mild muscular fatigue the next day as a result of the Muscular Relaxation Speed test. A potential benefit to me is knowing that information I provide may be used for scientific purposes.

\section{CONFIDENTIALITY}

All data I consent to supply will be treated with confidentiality and will remain in a locked filing cabinet within the laboratory. Data being utilized in this project will be held on a computer disk and a code will be used so that I am not identified by name. The information may be used in a coded form for statistical, scientific and research purposes. My records will not be released to any person, other than to researchers in coded form, without my expressed written consent.

\section{DECISION TO PARTICIPATE AND RIGHT TO QUTT AT ANY TIME}

I understand that the decision to participate is up to me and I am not required to participate, and may quit at any time.

\section{COMPLAINTS AND RIGHTS}

If I have any concerns, questions or complaints about this research, I can call the individuals most directly responsible, Professor Charles Collyer at (401) 792-4227. I may also direct any questions about the way this research is being conducted or about my rights as a research subject to the office of the Vice-Provost for Research at the University of Rhode Island (401) 792-2635. I do not have to give my name.

CONSENT TO PARTICIPATE: Please check below to indicate whether you wish to participate in this research, and sign the form below. Please keep one copy of this form for yourself.

I do consent to participate in the research. I have read the consent form. My signature below indicates that I understand the information and that I agree to participate in this study.

I do not consent to participate in the research.

Printed Name of Participant

Participant's Signature

Date
Printed Name of Researcher

Signature of Researcher

Date 


\section{APPENDIX II}

Subject Protocol

Subject ID \#

Name:

Age:

Phone number:

The subject is:

Left-handed

right-handed

Has the subject had coffee one hour prior to the testing:

Yes

No

Major health problems:

Medications:

Has subject ever had seizures:

Yes

No

Comments:

Musical Training: 
APPENDIX III

PRB

Subject

ISI

ID

\begin{tabular}{cccccc}
\hline & 250 & 300 & 350 & 400 & 450 \\
\cline { 2 - 6 } 1 & 0.035 & 0.043 & -0.053 & 0.025 & -0.001 \\
2 & -0.067 & -0.052 & -0.144 & -0.113 & -0.141 \\
3 & -0.069 & -0.007 & -0.121 & -0.021 & -0.021 \\
4 & -0.055 & -0.108 & -0.110 & -0.106 & -0.087 \\
5 & -0.064 & 0.002 & -0.021 & -0.003 & -0.023 \\
6 & -0.077 & -0.079 & -0.048 & -0.053 & -0.070 \\
7 & 0.028 & -0.058 & -0.044 & -0.022 & -0.041
\end{tabular}




$\begin{array}{lll}500 & 550 & 600\end{array}$

ID

1

$-0.015-0.052$

$-0.029$

650

700

0.004

$-0.047$

$-0.076$

2

$\begin{array}{lll}-0.101 & -0.147 & -0.102\end{array}$

$-0.161$

$-0.218$

$-0.192$

3

$0.030 \quad-0.004$

0.000

$-0.038$

$-0.025$

$-0.072$

4

$-0.080-0.087$

$-0.086$

$-0.078$

$-0.087$

$-0.100$

5

$\begin{array}{ll}-0.041 & -0.017\end{array}$

$-0.058$

$-0.002$

$-0.039$

$-0.051$

6

$-0.05$

$-0.040$

$-0.093$

$-0.068$

$-0.041$

$-0.069$

7

$-0.059-0.001$

$-0.012$

$-0.028$

$-0.058$

$-0.017$ 
APPENDIX IV

Median

\begin{tabular}{cccccc}
$\begin{array}{c}\text { Subject } \\
\text { ID }\end{array}$ & \multicolumn{5}{c}{ ISI } \\
\hline & 250 & 300 & 350 & 400 & 450 \\
\cline { 2 - 6 } 1 & 259 & 313 & 331 & 410 & 450 \\
2 & 233 & 284 & 300 & 355 & 387 \\
3 & 233 & 298 & 308 & 392 & 440 \\
4 & 236 & 268 & 312 & 358 & 411 \\
5 & 234 & 301 & 343 & 399 & 440 \\
6 & 231 & 276 & 333 & 379 & 419 \\
7 & 257 & 283 & 335 & 391 & 431
\end{tabular}




\begin{tabular}{ccccccc}
$\begin{array}{c}\text { Subject } \\
\text { ID }\end{array}$ & \multicolumn{7}{c}{ ISI } \\
\hline 1 & 500 & 550 & 600 & 650 & 700 & 750 \\
\cline { 2 - 7 } 2 & 492 & 521 & 583 & 652 & 667 & 693 \\
3 & 450 & 469 & 539 & 546 & 548 & 606 \\
4 & 460 & 502 & 549 & 599 & 639 & 675 \\
5 & 480 & 541 & 565 & 649 & 673 & 712 \\
6 & 472 & 528 & 544 & 606 & 671 & 698 \\
7 & 471 & 549 & 593 & 632 & 660 & 737
\end{tabular}




\section{APENDIX V}

Values of first derivatives for PMRT, FMRT, CRT, and SRT measures

$\begin{array}{llll}\text { Subject } & \text { FMRT } & \text { PMRT } & \text { CRT }\end{array}$

ID

\begin{tabular}{|c|c|c|c|c|}
\hline 10 & -0.00013 & -0.00099 & 0.00087 & 0.00119 \\
\hline 11 & -0.00029 & -0.00011 & 0.00004 & -0.00010 \\
\hline 12 & 0.00066 & -0.00069 & 0.00000 & 0.00028 \\
\hline 13 & -0.00022 & -0.00070 & 0.00007 & 0.00000 \\
\hline 15 & -0.00138 & -0.00091 & -0.00008 & 0.00297 \\
\hline 16 & 0.00022 & -0.00081 & 0.00006 & 0.00015 \\
\hline 17 & 0.00138 & 0.00079 & -0.00073 & 0.00038 \\
\hline 18 & 0.00003 & -0.00017 & -0.00083 & 0.00101 \\
\hline 19 & -0.00008 & -0.00004 & -0.00015 & -0.00022 \\
\hline 20 & 0.00049 & -0.00001 & -0.00012 & 0.00008 \\
\hline 21 & -0.00088 & -0.00124 & -0.00161 & -0.00061 \\
\hline 22 & -0.00104 & -0.00058 & -0.00001 & 0.00051 \\
\hline 23 & -0.00507 & 0.00109 & -0.00073 & 0.00083 \\
\hline 24 & -0.00034 & -0.00015 & -0.00152 & -0.00207 \\
\hline 25 & -0.00093 & -0.00037 & -0.00224 & 0.00031 \\
\hline 26 & 0.00069 & 0.00185 & -0.00064 & -0.00033 \\
\hline 27 & -0.00061 & 0.00066 & -0.00028 & -0.00128 \\
\hline 28 & 0.00019 & -0.00039 & 0.00133 & 0.00141 \\
\hline 29 & 0.00039 & 0.00169 & 0.00055 & -0.00100 \\
\hline 30 & -0.00079 & 0.00145 & 0.00174 & 0.00118 \\
\hline 31 & 0.00078 & 0.00002 & -0.00084 & -0.00060 \\
\hline 32 & 0.00045 & 0.00103 & 0.00064 & 0.00029 \\
\hline 33 & -0.00018 & -0.00053 & -0.00042 & -0.00016 \\
\hline 34 & -0.00085 & 0.00173 & -0.00132 & 0.00070 \\
\hline 35 & -0.00004 & -0.00030 & 0.00035 & -0.00020 \\
\hline 36 & 0.00009 & -0.00061 & 0.00027 & -0.00028 \\
\hline 37 & -0.00029 & 0.00039 & 0.00039 & -0.00034 \\
\hline 38 & 0.00016 & -0.00124 & -0.00021 & -0.00010 \\
\hline 39 & -0.00002 & 0.00040 & -0.00002 & 0.00005 \\
\hline 40 & -0.00082 & - & 0.00000 & -0.00122 \\
\hline 41 & -0.00031 & -0.00099 & 0.00132 & -0.00098 \\
\hline 42 & 0.00006 & 0.00008 & -0.00001 & 0.00135 \\
\hline 43 & -0.00007 & -0.00042 & -0.00079 & -0.00086 \\
\hline 44 & 0.00025 & -0.00035 & 0.00124 & -0.00012 \\
\hline 45 & -0.00091 & -0.00016 & 0.00031 & -0.00022 \\
\hline 47 & 0.00002 & -0.00003 & 0.00042 & 0.00029 \\
\hline 48 & 0.00024 & -0.00052 & -0.00061 & -0.00051 \\
\hline 10 & 0.00028 & - & -0.00085 & -0.00084 \\
\hline
\end{tabular}


APPENDIX VI

Variance

Subject

IS I

ID

$250-300$

350

400

450

500

550

10

$89.33 \quad 108.25$

157.89

405.34

722.04

606.88

563.14

11

$299.24 \quad 160.25$

441.79

586.16

690.98

549.55

672.01

12

137.21

102.40

324.98

321.57

242.59

375.79

1176.53

13

914.02

694.70

481.90

894.88

787.33

1939.293644 .68

16

518.03

190.73

288.48

547.38

623.23

1441.6520

686.34

480.24

329.631157 .50

237.13

271.35

356.33

819.13

613.99

329.83

1157.50

18

271.35
484.20

865.11

1453.9327

379.55

500.36

2725.76

910.67

1516.33

19

324.98

404.96

402.88

714.53

657.66

$823.97 \quad 1109.07$

21

165.89

522.41

279.42

369.87

541.99

505.68

504.47

22

243.55

286.85

334.85

614.78

619.66

877.45

985.28

23

126.88

1410.04

621.75

1149.70

810.90

$712.15 \quad 1275.76$

383.41

25

$301.06 \quad 210.45$

501.73

421.75

847.72

758.56

875.81

$317.34 \quad 590.37$

663.21

594.39

542.08

697.43

1494.21

556.20

321.85

370.80

966.04

612.47

659.62

1143.751251 .76

279.45

435.59

848.83

544.58

613.12

810.11

468.01

385.85

689.91

676.38

658.34

473.05

436.56

598.12

730.95

1114.48

636.15

460.34

362.72

447.38

683.15

551.14

706.71

$30 \quad 306.00$

322.03

189.08

364.39

512.75

800.50

359.79

1018.11

32

233.65

250.35

413.68

391.78

681.56

781

889.66

756.19

631.23

618.03

496.46

1197.46

179.66

402.17

420.61

235.67

332.86

1409.211139 .00

$35 \quad 146.45$

403.84

213.45

473.57

429.00

429.06

533.01

36

591.67

471.73

332.29

1743.40

575.16

371.85

662.81

2119.10

590.95

995.57

476.72

654.92

$38 \quad 222.46$

393.33

591.43

296.13

565.55

1041.761355 .86

$39 \quad 208.67$

265.51

349.16

877.25

838.29

462.37

392.13

716.32

1363.27

763.28

950.23

662.25

$41 \quad 535.42$

537.97

480.32

406.43

329.15

1281.95

785.80

42

145.17

216.19

357.06

256.22

566.30

$438.06 \quad 682.18$

363.25

708.42

510.10

518.74

643.77

44

468.66

196.08

344.42

660.33

(1)

570.29

727.15

1220.241021 .501703 .89

47

304.93

515.43

1247.35

689.88

518.24

814.161010 .99

633.121188 .911038 .02

738.43

735.25

$587.17 \quad 1442.241132 .69$ 
$|S|$

$$
\text { ID }
$$

10

$\begin{array}{llll}600 & 650 & 700 & 750\end{array}$

11

$621 \quad 642$

1631

1366

800

850

850

2969

1817

1726

1250

1868

1952

2231

1380

2952

3737

$5686 \quad 3272$

989

1211

1254

2175

2428

$1023 \quad 2422$

1790

1441

2518

2053

2151

2053

1860

3030

3107

1867

$2025 \quad 1548$

2481

1569

1393

1000

1157

3124

5868

2457

2626

1808

2457

2356

2246

2731

1562

1407

1779

3367

2145

3124

2584

1297

1776

2092

3054

1370

2108

2218

2405

887

1285

1350

1234

$1735 \quad 1856$

1563

3787

3132

714

1334

531

2293

1989

1594

1776

1539

1713

979

1366

$2961 \quad 1922$

2450

1785

1475

1418

1141

2147

2186

\begin{tabular}{cc}
900 & 950 \\
\hline 1920 & 1547
\end{tabular}

$1343 \quad 2868$

$3066 \quad 2369$

$2587 \quad 3148$

$4752 \quad 4545$

$2267 \quad 1913$

$1859 \quad 1729$

$2010 \quad 3438$

$1565 \quad 4570$

$2205 \quad 2459$

$6141 \quad 3801$

$2572 \quad 2130$

$5655 \quad 1939$

50847971

$2432 \quad 2113$

$2818 \quad 2728$

$1635 \quad 1530$

$2506 \quad 2436$

$4853 \quad 3884$

$3440 \quad 4595$

$1953 \quad 1978$

$1873 \quad 1756$

$1253 \quad 4241$

$10076 \quad 3163$

$1339 \quad 1927$

$1477 \quad 1746$

$3451 \quad 3171$

$2622 \quad 2742$

$1341 \quad 1385$

$2183 \quad 2057$

$3939 \quad 3553$

$2078 \quad 2426$

$6126 \quad 6050$

$1588 \quad 2844$

$2492 \quad 3878$

$1520 \quad 1830$

$1646 \quad 2846$

20732350 
APPENDIX VII

Standard Deviation

Subject

ISI

ID

$250-300-350$

ID

10

$9.02 \quad 10.09$

350

400

450

500

550

11

16.45

12.65

12.36

19.74

26.52

24.22

23.54

12

11.55

9.93

19.50

24.08

26.24

23.35

25.82

13

27.51

25.74

17.50

17.84

15.57

19.18

33.53

15

12.27

13.25

21.73

29.89

27.84

42.14

56.88

16

21.27

21.66

18.79

23.34

24.94

36.86

42.95

17

15.09

16.47

19.46

26.09

21.81

18.13

33.95

18

22.32

21.31

29.36

28.26

24.62

29.78

38.74

19

17.89

20.08

19.38

37.64

49.95

28.57

33.10

$20 \quad 14.63$

13.42

19.51

21.54

24.57

22.46

22.34

21

22.38

16.70

26.66

23.04

28.99

30.68

22

15.42

16.89

18.05

19.11

24.24

25.94

35.43

23

11.09

34.06

24.69

24.44

28.37

27.51

29.30

$24 \quad 17.34$

14.32

19.56

33.11

28.24

26.12

37.76

23.20

33.46

34.32

$25 \quad 17.74$

24.27

22.09

20.40

24.62

24.32

27.48

$26 \quad 22.45$

17.61

25.43

29.84

25.59

26.00

25.66

$27 \quad 16.66$

20.59

19.08

28.66

23.20

25.08

21.39

28

19.75

20.64

21.10

19.59

26.16

23.24

26.38

23.55

26.55

33.30

36.94

33.78

17.87

18.40

20.91

25.95

29.01

30.30

31

13.71

16.03

13.64

18.56

22.57

22.02

29.65

32

14.98

18.14

26.91

18.50

27.86

34.22

13.26

19.62

27.10

19.65

26.07

22.21

24.40

34

13.08

19.41

20.11

24.98

24.48

37.32

33.14

14.55

14.69

18.18

20.51

22.69

21.38

17.81

21.73

20.56

19.04

25.21

41.66

37.89

23.97

21.74

25.57

19.83

24.03

24.16

31.15

32.15

36.42

39

14.42

16.18

18.35

17.20

23.69

21.44

19.24

26.65

28.28

28.78

30.72

25.39

22.82

21.36

35.24

27.29

35.23

27.89

18.76

20.10

18.01

20.87

26.00

43

10.53

13.14

18.80

15.93

23.75

22.12

25.27

17.77

26.08

22.34

28.67

35.10

$21.05 \quad 25.64$

33.83

31.94

40.90

23.72

26.66

22.70

28.46

31.67

19.11

32.13

26.26

24.99

33.43

31.66 25.83

27.04

24.14

37.79

33.61 
ID

\begin{tabular}{llllllll}
600 & 650 & 700 & 750 & 800 & 850 & 900 & 950 \\
\hline
\end{tabular}

10

11

12

13

15

16

17

18

19

20

21

22

23

24

25

26

27

28

29

30

31

32

33

34

35

36

37

38

39

40

41

42

43

44

45

47

48 49
$24.8025 .20 \quad 39.40$

$\begin{array}{llll}27.21 & 32.30 & 38.50\end{array}$

$28.8029 .16 \quad 32.41$

$37.7439 .36 \quad 53.54$

$53.1237 .15 \quad 68.25$

$25.1228 .15 \quad 32.18$

$33.1436 .62 \quad 34.83$

$41.9134 .67 \quad 42.17$

$33.2930 .58 \quad 34.44$

$29.22 \quad 35.60 \quad 44.61$

$27.42 \quad 36.50 \quad 44.57$

$29.76 \quad 41.75 \quad 35.21$

$37.1931 .32 \quad 49.18$

$42.8148 .65 \quad 44.07$

$32.46 \quad 46.91 \quad 42.14$

$36.1139 .60 \quad 33.01$

27.8023 .8928 .07

$35.56 \quad 45.29 \quad 36.94$

$52.1649 .23 \quad 52.64$

$\begin{array}{llll}29.91 & 42.79 & 42.27\end{array}$

$22.6328 .68 \quad 31.09$

$28.3632 .62 \quad 38.42$

$31.2736 .02 \quad 36.66$

$40.40 \quad 40.58 \quad 40.97$

$24.2231 .02 \quad 28.44$

$26.7525 .58 \quad 26.23$

$27.3626 .42 \quad 36.61$

$37.96 \quad 45.21 \quad 43.44$

$19.4523 .72 \quad 27.26$

$33.8534 .02 \quad 42.98$

$31.92 \quad 30.88 \quad 31.77$

$31.4024 .28 \quad 32.90$

$30.92 \quad 37.90 \quad 26.47$

$27.64 \quad 42.32 \quad 36.05$

$33.10 \quad 30.60 \quad 48.09$

$20.9022 .42 \quad 32.49$

$37.0929 .32 \quad 33.92$

$36.3929 .07 \quad 31.18$
36.93

41.25

36.80

46.75

44.48

35.24

46.58

41.74

43.46

45.81

48.34

38.67

33.51

50.37

41.68

47.18

33.49

54.37

62.99

39.26

39.92

37.59

36.90

46.73

32.98

26.40

39.11

45.65

22.84

35.45

49.25

31.16

34.78

35.00

43.44

41.66

39.42

34.46
51.58

35.07

43.94

53.27

75.33

34.52

45.84

31.58

37.78

45.09

50.28

54.34

44.84

55.29

49.57

51.86

37.49

39.27

57.87

55.49

35.51

44.58

36.60

44.69

29.69

35.94

41.63

59.50

26.67

47.86

39.46

38.93

30.95

52.46

46.71

38.35

33.66

45.41
42.31

42.17

46.69

60.68

56.71

31.03

49.16

47.48

49.46

42.51

52.77

42.72

39.23

75.88

49.12

48.37

39.49

41.65

46.21

50.68

41.92

54.89

45.57

48.72

35.63

34.44

43.06

55.50

34.78

44.50

41.78

41.14

36.77

43.14

41.66

37.48

46.31

54.81
$43.70 \quad 38.82$

$36.20 \quad 53.17$

$54.99 \quad 47.44$

$50.85 \quad 54.44$

$68.73 \quad 66.30$

$46.89 \quad 43.72$

$43.04 \quad 41.44$

$44.56 \quad 58.55$

$39.46 \quad 65.55$

$46.65 \quad 49.34$

$\begin{array}{ll}75.85 & 60.28\end{array}$

$50.30 \quad 45.43$

$69.97 \quad 44.03$

$71.23 \quad 86.42$

$49.04 \quad 45.74$

$52.69 \quad 52.20$

$40.29 \quad 38.90$

$50.04 \quad 48.96$

$\begin{array}{ll}69.25 & 61.91\end{array}$

$58.20 \quad 66.84$

$43.84 \quad 44.43$

$\begin{array}{ll}43.06 & 40.87\end{array}$

$\begin{array}{ll}35.23 & 62.27\end{array}$

88.0156 .00

$\begin{array}{ll}36.35 & 43.37\end{array}$

$38.11 \quad 41.46$

58.5155 .90

$50.67 \quad 52.35$

$36.39 \quad 36.86$

$46.49 \quad 44.12$

$61.88 \quad 58.74$

$44.65 \quad 49.15$

$\begin{array}{ll}74.88 & 77.08\end{array}$

$38.89 \quad 51.76$

$49.35 \quad 62.03$

$38.66 \quad 42.21$

40.25

53.24

48.41 
APPENDIX VIII

SIQR/ISI

Subject

ISI

ID

250

300

350

400

450

500

550

10

0.018

0.017

0.020

0.032

0.040

0.026

0.024

11

0.028

0.025

0.040

0.043

0.035

0.032

0.028

12

0.019

0.027

0.028

0.020

0.024

0.032

13

0.045

0.052

0.036

0.045

0.041

0.039

0.052

15

0.028

0.026

0.034

0.035

0.029

0.048

0.037

16
17

0.044

0.041

0.034

0.045

0.034

0.023

0.044

18

0.049

0.028

0.031

0.045

0.031

0.034

0.043

19

$0.030 \quad 0.051$

0.060

0.041

0.037

0.036

20

21

0.052

0.041

0.038

0.039

0.029

0.030

0.026

0.042

0.032

0.039

0.039

22

0.027

0.040

0.030

0.024

0.028

0.034

0.038

23

24

0.041

0.041

0.029

0.034

0.040

0.034

0.035

0.0490 .044

0.048

0.031

0.033

0.046

25

0.039

0.028

0.039

0.028

0.037

0.045

0.039

0.0490 .040

0.033

0.042

0.030

0.035

26

27

0.049

0.030

0.040

0.048

0.034

0.027

0.028

28

29

0.044

0.035

0.039

0.035

0.037

0.034

0.021

0.0430 .035

0.030

0.033

0.029

0.028

0.046

$0.045 \quad 0.043$

0.043

0.044

0.045

0.037

$30 \quad 0.049$

$0.038 \quad 0.036$

0.024

0.029

0.033

0.022

31

0.029

0.036

0.020

0.028

0.031

0.027

0.033

32

0.0330 .023

0.035

0.023

0.038

0.038

$33 \quad 0.034$

0.039

0.048

0.030

0.039

0.030

0.031

34

35

0.033

0.035

0.040

0.037

0.032

0.049

0.035

$\begin{array}{lll}0.051 & 0.026\end{array}$

0.022

0.026

0.030

0.021

36

37

0.042

0.046

0.030

0.033

0.034

0.024

0.032

38

0.033

0.027

0.040

0.041

0.038

0.020

0.028

0.042

0.041

0.043

0.037

$39 \quad 0.039$

0.042

0.041

0.024

0.037

0.029

0.019

$40 \quad 0.030$

0.057

0.050

0.038

0.038

0.035

0.029

41

0.038

0.042

0.041

0.046

0.042

0.031

$42 \quad 0.027$

0.027

0.032

0.030

0.024

0.027

0.027

43

0.0270 .030

0.019

0.027

0.026

0.025

$44 \quad 0.027$

0.026

0.033

0.030

0.029

0.031

0.028

45

0.043

0.034

0.035

0.036

0.035

0.034

47

0.041

0.053

0.044

0.047

0.028

0.029

0.033

48

$0.036 \quad 0.045$

0.046

0.036

0.042

0.035

49

$\begin{array}{lll}0.043 & 0.037\end{array}$

0.040

0.039

0.041

0.038 
ID

$600-650-700-750$

$700 \quad 750$

800

850

900

950

$\begin{array}{lllllllll}10 & 0.02 & 0.03 & 0.04 & 0.03 & 0.03 & 0.03 & 0.03 & 0.02\end{array}$

$\begin{array}{lll}11 & 0.03 & 0.03\end{array}$

$0.03 \quad 0.03$

0.03

0.03

0.03

0.04

$\begin{array}{lll}12 & 0.03 & 0.03\end{array}$

0.03

0.03

0.03

0.03

0.04

0.03

$\begin{array}{lll}13 & 0.04 & 0.04\end{array}$

0.04

0.04

0.04

0.04

0.04

$\begin{array}{lll}15 & 0.07 & 0.04\end{array}$

0.06

0.03

0.06

0.04

0.04

0.03

$\begin{array}{lll}16 & 0.02 & 0.03\end{array}$

0.03

0.03

0.02

0.02

0.03

0.03

$\begin{array}{lll}17 & 0.03 & 0.04\end{array}$

0.03

0.03

0.03

0.04

0.03

0.03

$\begin{array}{lll}18 & 0.05 & 0.04\end{array}$

0.03

0.03

0.02

0.04

0.04

0.03

$\begin{array}{lll}19 & 0.04 & 0.02\end{array}$

0.03

0.03

0.03

0.04

0.03

0.05

$\begin{array}{lll}20 & 0.03 & 0.04\end{array}$

0.04

0.04

0.04

0.04

0.03

0.03

$\begin{array}{lll}21 & 0.03 & 0.03\end{array}$

$0.04 \quad 0.04$

0.04

0.04

0.06

0.04

$\begin{array}{lll}22 & 0.03 & 0.04\end{array}$

0.03

0.03

0.04

0.03

0.05

0.03

$\begin{array}{lll}23 & 0.03 & 0.03\end{array}$

0.04

0.02

0.04

0.03

0.03

0.03

$\begin{array}{lll}24 & 0.04 & 0.05\end{array}$

0.04

0.04

0.05

0.06

0.05

0.07

$\begin{array}{lll}25 & 0.03 & 0.06\end{array}$

0.04

0.03

0.04

0.04

0.04

0.03

$\begin{array}{lll}26 & 0.04 & 0.03\end{array}$

0.03

0.03

0.04

0.03

0.03

0.03

$\begin{array}{lll}27 & 0.03 & 0.02\end{array}$

$0.02 \quad 0.03$

0.03

0.03

0.03

0.03

$\begin{array}{lll}28 & 0.04 & 0.04\end{array}$

0.04

0.04

0.04

0.03

0.03

0.03

$\begin{array}{lll}29 & 0.05 & 0.05\end{array}$

0.05

0.04

0.04

0.03

0.05

0.05

$\begin{array}{lll}30 & 0.03 & 0.04\end{array}$

0.04

0.03

0.03

0.04

0.04

0.04

$\begin{array}{lll}31 & 0.02 & 0.02\end{array}$

0.03

0.03

0.03

0.03

0.04

0.03

$\begin{array}{lll}32 & 0.03 & 0.03\end{array}$

0.04

0.03

0.03

0.04

0.03

0.03

$\begin{array}{lll}33 & 0.03 & 0.04\end{array}$

0.04

0.03

0.02

0.03

0.02

0.03

34

0.04

0.05

0.04

0.04

0.04

0.03

$\begin{array}{lll}35 & 0.03 & 0.03\end{array}$

0.02

0.03

$0.02 \quad 0.03$

0.02

0.03

$\begin{array}{lll}36 & 0.03 & 0.02\end{array}$

0.03

0.02

0.02

0.02

0.02

0.03

$\begin{array}{lll}37 & 0.04 & 0.03\end{array}$

0.03

0.04

0.04

0.03

0.04

0.04

$\begin{array}{lll}38 & 0.05 & 0.05\end{array}$

0.04

0.03

0.05

0.05

0.03

0.03

39

0.02

0.02

0.02

0.03

0.03

0.02

$\begin{array}{lll}40 & 0.03 & 0.03\end{array}$

0.04

0.03

0.04

0.03

0.03

0.03

$\begin{array}{lll}41 & 0.03 & 0.03\end{array}$

0.03

0.03

0.04

0.03

0.05

0.04

$\begin{array}{lll}42 & 0.03 & 0.02\end{array}$

0.03

0.02

0.03

0.03

0.03

0.04

$\begin{array}{lll}43 & 0.03 & 0.04 \\ 44 & 0.03 & 0.03\end{array}$

0.02

0.03

0.03

0.03

0.03

0.05

$\begin{array}{lll}45 & 0.03 & 0.03\end{array}$

0.03

0.03

0.04

0.04

0.03

0.03

$47 \quad 0.02$

0.03

0.04

0.04

0.03

0.03

0.02

0.04

48

$0.04 \quad 0.02$

0.02

0.04

0.03

0.03

0.03

0.03

49

$0.03 \quad 0.03$

0.03

0.04

0.03

0.03

$0.03 \quad 0.03$

0.03

0.05

0.03

0.04 
APPENDIX IX

SIQR

Subject

ISI

ID

250

$300 \quad 350$

400

450

500

550

10

4.50

$5.17 \quad 7.00$

12.67

18.17

13.17

13.00

11

7.00

7.50

13.83

17.17

15.83

16.17

15.67

13

8.17

5.83

9.50

11.00

9.17

12.00

17.83

15

11.17

15.50

12.50

18.17

18.67

19.33

28.67

16

7.00

7.67

11.83

14.00

13.17

24.17

20.17

17

9.33

12.17

11.83

18.00

15.33

11.33

18.00

14.17

17.17

24.33

18

12.17

9.00

17.83

24.17

18.50

18.67

23.50

19

13.00

12.33

13.17

15.50

13.17

15.17

19.67

20

8.83

12.00

10.17

16.67

14.50

19.67

14.33

21

6.83

12.33

9.50

12.67

17.17

21.67

10.17

10.33

13.67

18.00

17.00

20.83

23

6.17

14.83

15.33

19.33

13.83

16.67

19.50

9.67

8.50

13.50

11.00

16.50

22.67

25.33

25

10.83

$14.67 \quad 13.83$

13.33

18.83

15.17

21.67

26

12.33

$9.00 \quad 14.17$

19.33

15.50

13.50

19.50

11.00

$10.50 \quad 13.67$

14.00

16.67

16.83

15.33

28

7.17

$13.00 \quad 12.33$

12.17

14.67

14.33

11.50

11.50

$13.50 \quad 15.17$

17.00

19.83

22.33

15.33

30

12.33

$11.50 \quad 12.50$

9.50

13.17

16.67

20.50

31

7.17

10.83

7.17

11.00

13.83

13.33

12.17

32

10.67

10.00

8.00

14.17

10.50

18.83

18.00

33

8.50

11.83

16.83

11.83

17.33

14.83

20.67

8.17

10.50

13.83

14.67

14.50

24.50

17.00

35

9.50

15.33

9.17

8.83

11.67

14.83

19.17

10.50
8.33

13.83

10.50

13.33

15.33

12.17

11.67

37

7.67

10.17

13.83

16.33

17.0

10.00

17.50

38

39

9.67

12.67

14.50

16.67

18.50

21.67

15.67

7.50

17.17

11.00

9.67

16.83

14.50

20.50

41

14.50

11.50

17.67

15.00

17.00

17.50

10.33

42

6.83

8.17

14.83

16.50

20.67

21.17

15.83

43

5.67

8.17

11.33

12.17

11.00

13.33

17.00

44

6.83

7.83

10.33

7.50

12.33

13.00

15.00

16.00

12.83

11.50

12.17

12.83

15.67

13.50

47

10.33

16.00

11.83

14.00

16.00

17.50

15.33

18.67

12.67

14.50

18.50

48

6.50

10.83

15.67

18.50

16.33

21.17

18.00

16.17

17.50

20.67

19.00

$12.83 \quad 13.00$

16.17 


\section{$600-650-700$}

\begin{tabular}{|c|c|c|c|c|c|c|c|c|}
\hline & 600 & 650 & 700 & 750 & 800 & 850 & 900 & 950 \\
\hline 10 & 13.33 & 18.67 & 25.00 & 24.33 & 26.83 & 25.00 & 22.83 & 23.50 \\
\hline 11 & 17.33 & 20.17 & 23.50 & 25.33 & 24.33 & 25.00 & 27.17 & 34.17 \\
\hline 12 & 20.17 & 20.67 & 21.17 & 25.67 & 23.00 & 22.50 & 33.00 & 28.67 \\
\hline 13 & 23.50 & 23.33 & 28.00 & 30.33 & 34.00 & 36.00 & 33.83 & 39.83 \\
\hline 15 & 40.17 & 23.67 & 43.00 & 25.50 & 45.33 & 34.50 & 38.50 & 30.50 \\
\hline 16 & 14.00 & 19.67 & 23.33 & 23.33 & 18.00 & 16.67 & 23.83 & 31.17 \\
\hline 17 & 17.67 & 23.00 & 23.67 & 22.17 & 21.33 & 29.83 & 22.50 & 31.00 \\
\hline 18 & 28.33 & 23.17 & 21.50 & 24.33 & 17.17 & 34.67 & 32.00 & 29.00 \\
\hline 19 & 22.67 & 16.00 & 19.33 & 25.83 & 25.00 & 30.67 & 27.00 & 46.50 \\
\hline 20 & 17.50 & 25.00 & 29.33 & 28.83 & 32.50 & 34.00 & 29.83 & 26.17 \\
\hline 21 & 19.50 & 19.33 & 30.17 & 28.00 & 33.33 & 31.83 & 50.83 & 40.33 \\
\hline 22 & 20.17 & 28.67 & 21.67 & 26.00 & 33.83 & 24.83 & 40.50 & 29.17 \\
\hline 23 & 19.67 & 19.33 & 25.33 & 15.83 & 29.50 & 23.17 & 27.83 & 27.67 \\
\hline 24 & 26.00 & 32.50 & 27.67 & 28.67 & 39.50 & 49.00 & 49.00 & 63.00 \\
\hline 25 & 20.50 & 36.00 & 26.33 & 24.67 & 33.83 & 37.33 & 37.33 & 30.67 \\
\hline 26 & 22.67 & 22.00 & 21.00 & 23.67 & 29.17 & 28.00 & 28.50 & 32.17 \\
\hline 27 & 17.83 & 11.67 & 17.00 & 21.50 & 25.50 & 23.83 & 23.67 & 30.83 \\
\hline 28 & 24.17 & 27.00 & 27.33 & 33.00 & 29.83 & 25.00 & 26.83 & 29.67 \\
\hline 29 & 32.33 & 31.50 & 33.50 & 31.33 & 35.33 & 27.17 & 46.83 & 42.83 \\
\hline 30 & 19.17 & 23.67 & 25.83 & 23.33 & 27.83 & 35.67 & 35.00 & 37.83 \\
\hline 31 & 13.50 & 16.17 & 19.00 & 21.33 & 25.83 & 25.33 & 33.83 & 30.33 \\
\hline 32 & 18.33 & 20.50 & 25.50 & 23.17 & 21.83 & 35.33 & 23.83 & 32.00 \\
\hline 33 & 20.83 & 23.00 & 29.50 & 20.17 & 19.50 & 24.33 & 19.67 & 31.50 \\
\hline 34 & 17.67 & 24.50 & 31.33 & 35.00 & 32.50 & 34.17 & 39.00 & 32.33 \\
\hline 35 & 16.67 & 18.50 & 17.33 & 19.50 & 16.50 & 21.33 & 22.00 & 29.67 \\
\hline 36 & 17.83 & 15.50 & 17.50 & 17.67 & 19.17 & 20.00 & 22.00 & 23.83 \\
\hline 37 & 23.50 & 17.83 & 23.67 & 26.33 & 29.50 & 29.67 & 36.33 & 40.67 \\
\hline 38 & 28.67 & 30.83 & 25.83 & 25.50 & 37.67 & 41.00 & 30.17 & 30.00 \\
\hline 39 & 12.00 & 15.00 & 17.33 & 14.67 & 15.17 & 22.17 & 24.83 & 22.33 \\
\hline 40 & 18.00 & 21.83 & 26.67 & 23.17 & 30.83 & 25.00 & 26.50 & 27.83 \\
\hline 41 & 18.00 & 18.83 & 17.83 & 25.67 & 29.17 & 24.17 & 41.67 & 41.33 \\
\hline 42 & 18.00 & 16.00 & 20.33 & 15.33 & 22.50 & 23.50 & 26.83 & 35.00 \\
\hline 43 & 15.83 & 24.00 & 13.33 & 22.83 & 21.50 & 26.83 & 30.67 & 45.67 \\
\hline 44 & 17.17 & 21.83 & 23.67 & 26.00 & 34.67 & 31.33 & 24.00 & 31.33 \\
\hline 45 & 20.33 & 20.50 & 25.83 & 30.00 & 21.83 & 26.67 & 22.00 & 36.33 \\
\hline 47 & 9.83 & 16.33 & 17.33 & 26.83 & 26.33 & 21.83 & 24.83 & 24.83 \\
\hline 48 & 25.83 & 15.50 & 21.17 & 26.17 & 21.33 & 30.67 & 28.17 & 31.17 \\
\hline 49 & 21.33 & 20.00 & 17.67 & 22.67 & 25.17 & 40.83 & 30.33 & 34.00 \\
\hline
\end{tabular}


APPENDIX $X$

PRB

Subject

ISI

ID

\begin{tabular}{|c|c|c|c|c|c|c|c|}
\hline & 250 & 300 & 350 & 400 & 450 & 500 & 550 \\
\hline 10 & -0.025 & -0.036 & -0.046 & -0.037 & 0.013 & -0.049 & -0.015 \\
\hline 11 & 0.011 & -0.007 & -0.011 & -0.025 & -0.025 & -0.021 & -0.018 \\
\hline 12 & 0.001 & -0.050 & -0.061 & -0.031 & -0.044 & -0.052 & -0.021 \\
\hline 13 & -0.032 & 0.000 & -0.011 & -0.004 & -0.038 & -0.039 & -0.073 \\
\hline 15 & -0.040 & -0.048 & -0.122 & -0.115 & -0.181 & -0.139 & -0.047 \\
\hline 16 & -0.041 & 0.027 & -0.005 & -0.013 & -0.006 & -0.031 & 0.002 \\
\hline 17 & -0.020 & -0.010 & -0.047 & 0.021 & 0.002 & -0.029 & -0.048 \\
\hline 18 & -0.019 & -0.020 & -0.035 & -0.050 & -0.046 & -0.015 & -0.056 \\
\hline 19 & -0.101 & -0.081 & -0.049 & -0.077 & -0.071 & -0.094 & -0.106 \\
\hline 20 & 0.004 & -0.030 & -0.002 & -0.043 & -0.046 & -0.051 & -0.021 \\
\hline 21 & 0.012 & 0.022 & -0.076 & -0.047 & -0.113 & -0.111 & -0.126 \\
\hline 22 & -0.012 & -0.063 & -0.038 & -0.088 & -0.059 & -0.035 & -0.061 \\
\hline 23 & 0.040 & 0.058 & 0.083 & -0.157 & -0.146 & 0.004 & -0.066 \\
\hline 24 & 0.052 & -0.029 & -0.038 & 0.013 & -0.073 & -0.064 & -0.072 \\
\hline 25 & -0.059 & -0.022 & -0.076 & -0.088 & -0.081 & -0.077 & -0.095 \\
\hline 26 & 0.073 & -0.033 & 0.008 & 0.003 & -0.012 & -0.061 & -0.044 \\
\hline 27 & 0.040 & 0.044 & 0.017 & 0.039 & 0.039 & -0.001 & 0.010 \\
\hline 28 & -0.049 & 0.024 & -0.015 & -0.053 & -0.051 & -0.005 & -0.091 \\
\hline 29 & 0.067 & -0.050 & -0.033 & -0.019 & 0.002 & -0.009 & -0.012 \\
\hline 30 & 0.032 & -0.044 & -0.025 & -0.018 & 0.011 & -0.003 & -0.041 \\
\hline 31 & 0.013 & -0.037 & 0.006 & -0.020 & -0.055 & -0.057 & -0.096 \\
\hline 32 & 0.013 & 0.002 & -0.008 & -0.034 & -0.054 & -0.031 & -0.060 \\
\hline 33 & 0.040 & -0.004 & -0.007 & 0.022 & 0.038 & 0.030 & 0.017 \\
\hline 34 & -0.131 & -0.089 & -0.090 & -0.106 & -0.132 & -0.058 & -0.047 \\
\hline 35 & -0.004 & -0.008 & -0.001 & -0.008 & -0.019 & 0.029 & 0.007 \\
\hline 36 & 0.008 & -0.018 & 0.009 & -0.020 & 0.006 & 0.018 & 0.000 \\
\hline 37 & -0.021 & -0.062 & 0.038 & 0.016 & 0.001 & -0.030 & -0.044 \\
\hline 38 & -0.012 & -0.058 & -0.038 & -0.048 & -0.039 & -0.021 & -0.020 \\
\hline 39 & 0.028 & -0.047 & -0.024 & -0.019 & -0.015 & 0.005 & 0.016 \\
\hline 40 & -0.043 & -0.036 & -0.030 & 0.011 & 0.024 & 0.052 & -0.005 \\
\hline 41 & 0.001 & -0.011 & -0.066 & -0.085 & -0.064 & -0.042 & -0.066 \\
\hline 42 & -0.019 & -0.056 & -0.050 & -0.051 & -0.025 & -0.017 & -0.037 \\
\hline 43 & -0.101 & -0.064 & -0.066 & -0.024 & -0.008 & -0.026 & -0.039 \\
\hline 44 & -0.093 & -0.044 & -0.112 & -0.158 & -0.067 & -0.073 & -0.073 \\
\hline 45 & 0.003 & -0.043 & -0.077 & -0.045 & -0.126 & -0.052 & -0.081 \\
\hline 47 & -0.065 & -0.059 & -0.067 & -0.066 & -0.053 & -0.025 & -0.040 \\
\hline 48 & -0.075 & -0.060 & -0.050 & -0.038 & -0.019 & 0.000 & -0.027 \\
\hline 49 & 0.165 & 0.162 & 0.023 & 0.038 & 0.027 & 0.033 & 0.038 \\
\hline
\end{tabular}


ID

\begin{tabular}{|c|c|c|c|c|c|c|c|c|}
\hline & 600 & 650 & 700 & 750 & 800 & 850 & 900 & 950 \\
\hline 10 & -0.016 & -0.071 & -0.041 & -0.005 & -0.011 & -0.085 & -0.028 & -0.087 \\
\hline 11 & -0.022 & -0.027 & -0.025 & -0.018 & -0.048 & -0.037 & -0.039 & 0.006 \\
\hline 12 & -0.077 & -0.085 & -0.070 & -0.058 & -0.040 & -0.053 & -0.053 & -0.048 \\
\hline 13 & -0.050 & -0.042 & -0.093 & -0.074 & -0.102 & -0.062 & -0.082 & -0.055 \\
\hline 15 & -0.164 & -0.202 & -0.025 & -0.132 & -0.088 & -0.200 & -0.162 & -0.191 \\
\hline 16 & -0.022 & -0.073 & -0.023 & -0.046 & -0.023 & -0.028 & -0.080 & -0.098 \\
\hline 17 & -0.029 & -0.025 & 0.009 & -0.058 & -0.063 & -0.102 & -0.041 & -0.072 \\
\hline 18 & -0.018 & 0.008 & -0.024 & 0.056 & 0.006 & 0.051 & 0.000 & -0.055 \\
\hline 19 & -0.137 & -0.117 & -0.123 & -0.111 & -0.083 & -0.073 & -0.013 & -0.036 \\
\hline 20 & -0.025 & -0.031 & -0.046 & -0.004 & 0.002 & 0.027 & 0.030 & 0.084 \\
\hline 21 & -0.169 & -0.156 & -0.127 & -0.252 & -0.229 & -0.328 & -0.227 & -0.165 \\
\hline 22 & -0.033 & -0.073 & -0.033 & -0.002 & -0.064 & -0.013 & -0.043 & -0.021 \\
\hline 23 & -0.052 & -0.026 & -0.066 & -0.055 & 0.002 & -0.049 & 0.017 & -0.011 \\
\hline 24 & -0.117 & -0.149 & -0.075 & -0.064 & -0.159 & -0.116 & -0.134 & -0.158 \\
\hline 25 & -0.095 & -0.064 & -0.098 & -0.140 & -0.128 & -0.173 & -0.080 & -0.154 \\
\hline 26 & -0.057 & 0.028 & -0.029 & 0.020 & -0.030 & -0.065 & -0.010 & -0.016 \\
\hline 27 & 0.034 & -0.029 & -0.004 & -0.007 & -0.023 & 0.010 & -0.003 & -0.006 \\
\hline 28 & 0.017 & -0.047 & 0.000 & 0.036 & -0.040 & -0.074 & 0.001 & 0.071 \\
\hline 29 & -0.078 & 0.014 & -0.029 & 0.068 & 0.034 & 0.029 & 0.048 & -0.019 \\
\hline 30 & -0.021 & -0.003 & -0.088 & -0.015 & 0.029 & 0.134 & 0.056 & 0.062 \\
\hline 31 & -0.034 & -0.064 & -0.095 & -0.148 & -0.110 & -0.111 & -0.116 & -0.073 \\
\hline 32 & -0.036 & 0.006 & -0.026 & -0.012 & -0.021 & 0.007 & 0.023 & -0.004 \\
\hline 33 & -0.028 & -0.028 & -0.027 & -0.032 & -0.073 & -0.076 & -0.130 & -0.083 \\
\hline 34 & -0.076 & 0.018 & 0.034 & -0.025 & 0.005 & -0.022 & 0.024 & -0.024 \\
\hline 35 & -0.017 & 0.030 & 0.045 & 0.028 & 0.001 & 0.023 & 0.013 & 0.047 \\
\hline 36 & -0.021 & 0.011 & -0.011 & 0.021 & 0.011 & -0.017 & 0.019 & 0.024 \\
\hline 37 & -0.044 & -0.059 & -0.045 & -0.028 & -0.029 & -0.025 & 0.079 & 0.038 \\
\hline 38 & 0.007 & 0.007 & -0.052 & -0.028 & -0.033 & -0.047 & 0.048 & 0.041 \\
\hline 39 & 0.005 & -0.012 & 0.047 & 0.022 & 0.039 & 0.034 & 0.023 & 0.033 \\
\hline 40 & -0.021 & 0.022 & -0.050 & -0.041 & -0.068 & -0.065 & -0.046 & -0.058 \\
\hline 41 & -0.085 & -0.067 & -0.111 & -0.138 & -0.137 & -0.150 & -0.091 & -0.153 \\
\hline 42 & -0.033 & -0.040 & -0.015 & -0.032 & 0.035 & 0.025 & -0.038 & 0.020 \\
\hline 43 & -0.049 & 0.001 & -0.064 & -0.044 & -0.078 & -0.091 & 0.057 & 0.133 \\
\hline 44 & -0.081 & -0.007 & -0.053 & -0.100 & -0.048 & -0.030 & -0.099 & -0.035 \\
\hline 45 & -0.080 & -0.121 & -0.084 & -0.088 & -0.069 & -0.103 & -0.066 & -0.063 \\
\hline 47 & -0.042 & -0.060 & -0.037 & 0.012 & 0.004 & -0.022 & -0.023 & 0.029 \\
\hline 48 & -0.009 & -0.033 & -0.042 & -0.037 & -0.076 & -0.032 & -0.011 & -0.048 \\
\hline 49 & -0.040 & -0.048 & -0.011 & -0.037 & -0.019 & -0.073 & 0.008 & 0.015 \\
\hline
\end{tabular}


APPENDIX XI

Average IRI

Subject

ISI ID

\begin{tabular}{|c|c|c|c|c|c|c|c|}
\hline & 250 & 300 & 350 & 400 & 450 & 500 & 550 \\
\hline 10 & 243.77 & 291.49 & 335.69 & 386.62 & 455.93 & 478.06 & 541.36 \\
\hline 11 & 255.78 & 299.24 & 346.45 & 393.18 & 438.80 & 487.53 & 540.17 \\
\hline 12 & 252.36 & 285.24 & 326.70 & 388.83 & 429.36 & 478.85 & 541.33 \\
\hline 13 & 244.57 & 303.94 & 346.72 & 395.80 & 431.13 & 485.74 & 510.28 \\
\hline 15 & 239.59 & 286.87 & 304.69 & 353.01 & 373.48 & 433.71 & 523.76 \\
\hline 16 & 244.69 & 306.51 & 349.61 & 399.66 & 448.95 & 483.43 & 547.67 \\
\hline 17 & 246.64 & 298.32 & 337.82 & 410.85 & 450.91 & 484.11 & 524.49 \\
\hline 18 & 248.20 & 295.21 & 338.10 & 383.69 & 430.98 & 491.47 & 522.38 \\
\hline 19 & 221.70 & 275.57 & 333.47 & 370.70 & 419.67 & 453.51 & 493.87 \\
\hline 20 & 250.07 & 292.23 & 347.18 & 378.44 & 427.30 & 473.38 & 540.71 \\
\hline 21 & 254.63 & 305.01 & 322.06 & 383.29 & 403.33 & 443.67 & 483.80 \\
\hline 22 & 245.37 & 281.66 & 337.10 & 367.20 & 423.49 & 482.68 & 519.72 \\
\hline 23 & 259.49 & 323.02 & 378.16 & 341.49 & 388.75 & 504.84 & 510.05 \\
\hline 24 & 261.66 & 291.22 & 336.26 & 404.52 & 417.20 & 471.98 & 510.95 \\
\hline 25 & 236.75 & 294.98 & 321.83 & 363.22 & 413.31 & 459.48 & 495.98 \\
\hline 26 & 273.53 & 286.97 & 354.72 & 402.75 & 447.37 & 472.37 & 528.61 \\
\hline 27 & 261.84 & 311.52 & 357.61 & 417.97 & 465.48 & 496.08 & 554.94 \\
\hline 28 & 239.84 & 310.20 & 346.57 & 382.20 & 431.56 & 497.52 & 503.17 \\
\hline 29 & 266.51 & 288.49 & 341.24 & 392.98 & 452.84 & 494.43 & 547.49 \\
\hline 30 & 255.59 & 289.17 & 341.06 & 392.99 & 452.24 & 497.89 & 527.40 \\
\hline 31 & 255.37 & 290.03 & 352.31 & 392.51 & 426.78 & 468.71 & 501.78 \\
\hline 32 & 252.90 & 302.64 & 346.91 & 384.66 & 426.17 & 483.94 & 520.97 \\
\hline 33 & 261.63 & 296.80 & 348.24 & 406.97 & 467.26 & 515.14 & 558.94 \\
\hline 34 & 216.92 & 270.83 & 319.68 & 359.24 & 392.05 & 470.75 & 526.13 \\
\hline 35 & 249.48 & 300.94 & 348.24 & 397.52 & 440.76 & 514.01 & 551.52 \\
\hline 36 & 253.95 & 296.68 & 352.85 & 393.36 & 451.75 & 506.70 & 548.17 \\
\hline 37 & 244.49 & 281.79 & 367.63 & 413.36 & 452.68 & 483.89 & 526.59 \\
\hline 38 & 247.07 & 281.08 & 336.66 & 380.26 & 433.23 & 493.13 & 540.00 \\
\hline 39 & 256.33 & 289.26 & 341.46 & 392.10 & 445.01 & 501.41 & 557.97 \\
\hline 40 & 239.85 & 292.94 & 338.36 & 400.61 & 456.11 & 524.06 & 543.23 \\
\hline 41 & 250.22 & 297.54 & 323.69 & 373.67 & 423.15 & 482.14 & 514.69 \\
\hline 42 & 247.32 & 284.59 & 331.89 & 379.69 & 437.61 & 492.24 & 530.43 \\
\hline 43 & 222.99 & 279.74 & 326.63 & 390.49 & 445.34 & 489.87 & 526.64 \\
\hline 44 & 227.06 & 285.90 & 311.70 & 340.89 & 415.13 & 466.20 & 503.84 \\
\hline 45 & 251.99 & 287.69 & 321.87 & 380.80 & 396.11 & 473.55 & 508.47 \\
\hline 47 & 233.33 & 279.75 & 329.98 & 369.78 & 423.53 & 485.02 & 527.03 \\
\hline 48 & 230.01 & 281.06 & 333.71 & 384.57 & 440.78 & 501.26 & 534.69 \\
\hline 49 & 291.15 & 348.98 & 358.86 & 416.11 & 460.99 & 518.71 & 568.21 \\
\hline
\end{tabular}


ISI

ID

600

10586.99

11586.64

12557.02

13575.79

15505.68

16591.39

17580.18

18593.60

19516.90

20587.55

21498.76

22585.01

23567.82

24525.37

25546.94

26564.20

$27 \quad 622.47$

28607.98

29557.82

$30 \quad 585.91$

31581.13

32580.17

33584.17

34558.53

35588.92

36587.53

37574.86

38607.78

39603.78

40584.46

41554.64

42581.55

43569.54

44554.26

45553.22

47576.56

48597.34

49581.11
604.59

636.62

596.67

622.64

520.52

603.84

640.36

657.43

576.15

629.09

554.92

604.43

631.57

560.00

607.26

662.28

630.46

628.24

665.29

649.98

606.66

653.05

634.92

669.24

667.77

655.36

611.15

651.45

644.13

659.89

606.16

625.00

656.97

642.46

574.49

612.20

631.28

620.00
677.11

685.90

655.05

639.61

698.54

686.67

698.71

687.85

615.10

667.85

620.32

676.44

650.18

651.07

633.47

683.90

697.71

695.63

682.76

651.06

635.44

685.70

681.98

725.06

731.76

696.38

670.24

665.21

733.32

666.55

621.74

691.41

654.47

662.51

648.20

677.09

670.56

697.13

750

800

850

900

950

$749.22 \quad 793.38$

730.41758 .09

$707.75 \quad 771.48$

$698.07 \quad 718.16$

647.31

717.11

710.10

794.21

672.72

754.21

568.00

748.03

712.68

707.31

644.37

762.89

746.32

778.18

793.78

736.38

639.71

734.39

725.44

739.56

769.71

766.31

733.93

729.55

769.53

719.71

643.32

725.20

718.56

678.13

692.55

755.55

722.44

722.00

736.46

736.46

786.29

753.13

806.11

735.68

807.40

628.49

750.94

796.55

682.86

701.13

773.53

786.51

772.02

828.63

713.10

778.17

740.95

805.44

804.41

810.61

783.14

774.74

831.64

750.91

702.68

826.56

737.49

766.29

745.76

797.20

744.06

784.23
$782.16 \quad 876.86$

$819.89 \quad 866.17$

863.22

.80854 .74

906.21

$796.83 \quad 824.54$

897.31

$688.55 \quad 764.74$

772.83

$831.16 \quad 834.20$

850.95

$763.13 \quad 865.18$

880.90

886.26

891.31

911.34

784.69891 .03

903.47

873.75

921.451035 .24

799.86

832.31860 .56

933.13

811.05902 .34

938.93

$744.70 \quad 788.00$

806.43

$710.15 \quad 829.03$

808.62

935.76

856.69

897.98

946.24

$797.01 \quad 901.94 \quad 1010.55$

$873.95 \quad 939.38 \quad 937.53$

$\begin{array}{llll}817.80 & 960.29 & 944.02 & 1007.31\end{array}$

$\begin{array}{lll}760.26 & 792.31 & 877.70\end{array}$

$859.10 \quad 917.68$

951.68

788.74784 .63

876.57

$836.74 \quad 902.39$

932.31

$869.76 \quad 905.20$

998.24

835.31914 .40

975.56

825.31973 .91

987.72

818.32946 .79

991.07

$880.70 \quad 919.15$

981.79

$799.26 \quad 861.53$

900.25

$731.74 \quad 811.16$

816.44

$867.52 \quad 864.52$

974.25

$\begin{array}{llll}775.98 & 947.70 & 1078.22\end{array}$

29.98

810.83

920.10

$765.83 \quad 843.18$

896.79

$833.62 \quad 875.91$

981.22

$826.53 \quad 892.20$

908.55

$795.99 \quad 904.99 \quad 966.56$ 
APPENDIX XII

Median

\begin{tabular}{|c|c|c|c|c|c|c|c|}
\hline $\begin{array}{l}\text { ubject } \\
\text { ID }\end{array}$ & & & ISI & & & & \\
\hline & 250 & 300 & 350 & 400 & 450 & 500 & 550 \\
\hline 10 & 243.67 & 289.33 & 334.00 & 385.33 & 456.00 & 475.33 & 541.67 \\
\hline 11 & 252.67 & 298.00 & 346.00 & 390.00 & 438.67 & 489.33 & 540.00 \\
\hline 12 & 250.33 & 285.00 & 328.67 & 387.67 & 430.00 & 474.00 & 538.67 \\
\hline 13 & 242.00 & 300.00 & 346.00 & 398.33 & 433.00 & 480.67 & 510.00 \\
\hline 15 & 240.00 & 285.67 & 307.33 & 354.00 & 368.33 & 430.67 & 524.33 \\
\hline 16 & 239.67 & 308.00 & 348.33 & 395.00 & 447.33 & 484.33 & 551.00 \\
\hline 17 & 245.00 & 297.00 & 333.67 & 408.33 & 451.00 & 485.67 & 523.33 \\
\hline 18 & 245.33 & 294.00 & 337.67 & 380.00 & 429.33 & 492.33 & 519.33 \\
\hline 19 & 224.67 & 275.67 & 333.00 & 369.33 & 418.00 & 453.00 & 491.67 \\
\hline 20 & 251.00 & 291.00 & 349.33 & 383.00 & 429.33 & 474.33 & 538.67 \\
\hline 21 & 253.00 & 306.67 & 323.33 & 381.33 & 399.00 & 444.67 & 480.67 \\
\hline 22 & 247.00 & 281.00 & 336.67 & 365.00 & 423.67 & 482.67 & 516.33 \\
\hline 23 & 260.00 & 317.33 & 379.00 & 337.33 & 384.33 & 502.00 & 513.67 \\
\hline 24 & 263.00 & 291.33 & 336.67 & 405.00 & 417.00 & 468.00 & 510.33 \\
\hline 25 & 235.33 & 293.33 & 323.33 & 364.67 & 413.33 & 461.67 & 498.00 \\
\hline 26 & 268.33 & 290.00 & 352.67 & 401.33 & 444.67 & 469.33 & 525.67 \\
\hline 27 & 260.00 & 313.33 & 356.00 & 415.67 & 467.67 & 499.67 & 555.33 \\
\hline 28 & 237.67 & 307.33 & 344.67 & 379.00 & 427.00 & 497.33 & 500.00 \\
\hline 29 & 266.67 & 285.00 & $338: 33$ & 392.33 & 451.00 & 495.67 & 543.33 \\
\hline 30 & 258.00 & 286.67 & 341.33 & 393.00 & 455.00 & 498.33 & 527.67 \\
\hline 31 & 253.33 & 289.00 & 352.00 & 392.00 & 425.33 & 471.67 & 497.00 \\
\hline 32 & 253.33 & 300.67 & 347.33 & 386.33 & 425.67 & 484.67 & 517.00 \\
\hline 33 & 260.00 & 298.67 & 347.67 & 408.67 & 467.00 & 515.00 & 559.33 \\
\hline 34 & 217.33 & 273.33 & 318.67 & 357.67 & 390.67 & 471.00 & 524.33 \\
\hline 35 & 249.00 & 297.67 & 349.67 & 396.67 & 441.33 & 514.33 & 553.67 \\
\hline 36 & 252.00 & 294.67 & 353.00 & 392.00 & 452.67 & 509.00 & 550.00 \\
\hline 37 & 244.67 & 281.33 & 363.33 & 406.33 & 450.33 & 485.00 & 525.67 \\
\hline 38 & 247.00 & 282.67 & 336.67 & 381.00 & 432.33 & 489.67 & 539.00 \\
\hline 39 & 257.00 & 286.00 & 341.67 & 392.33 & 443.33 & 502.33 & 559.00 \\
\hline 40 & 239.33 & 289.33 & 339.67 & 404.33 & 460.67 & 526.00 & 547.33 \\
\hline 41 & 250.33 & 296.67 & 327.00 & 366.00 & 421.33 & 479.00 & 513.67 \\
\hline 42 & 245.33 & 283.33 & 332.67 & 379.67 & 438.67 & 491.33 & 529.67 \\
\hline 43 & 224.67 & 280.67 & 327.00 & 390.33 & 446.33 & 487.00 & 528.67 \\
\hline 44 & 226.67 & 286.67 & 310.67 & 337.00 & 419.67 & 463.67 & 509.67 \\
\hline 45 & 250.67 & 287.00 & 323.00 & 382.00 & 393.33 & 474.00 & 505.67 \\
\hline 47 & 233.67 & 282.33 & 326.67 & 373.67 & 426.00 & 487.33 & 528.00 \\
\hline 48 & 231.33 & 282.00 & 332.33 & 384.67 & 441.33 & 500.00 & 535.00 \\
\hline 49 & 291.33 & 348.67 & 358.00 & 415.33 & 462.33 & 516.33 & 570.67 \\
\hline
\end{tabular}


ID

\begin{tabular}{|c|c|c|c|c|c|c|c|c|}
\hline & 600 & 650 & 700 & 750 & 800 & 850 & 900 & 950 \\
\hline 10 & 590.67 & 603.67 & 671.00 & 746.00 & 791.00 & 778.00 & 875.00 & 867.67 \\
\hline 11 & 587.00 & 632.67 & 682.33 & 736.33 & 762.00 & 818.33 & 865.33 & 956.00 \\
\hline 12 & 553.67 & 594.67 & 650.67 & 706.67 & 768.00 & 804.67 & 852.33 & 904.67 \\
\hline 13 & 570.00 & 622.67 & 634.67 & 694.67 & 718.67 & 797.67 & 826.33 & 897.33 \\
\hline 15 & 501.67 & 519.00 & 682.67 & 650.67 & 729.33 & 680.33 & 754.00 & 768.67 \\
\hline 16 & 587.00 & 602.67 & 683.67 & 715.67 & 781.33 & 826.00 & 827.67 & 857.33 \\
\hline 17 & 582.67 & 634.00 & 706.33 & 706.67 & 750.00 & 763.67 & 863.33 & 881.67 \\
\hline 18 & 589.33 & 655.33 & 683.00 & 792.00 & 804.67 & 893.67 & 899.67 & 897.67 \\
\hline 19 & 517.67 & 573.67 & 613.67 & 666.67 & 734.00 & 788.33 & 888.67 & 915.67 \\
\hline 20 & 585.00 & 629.67 & 668.00 & 747.00 & 801.33 & 873.00 & 927.33 & 1029.33 \\
\hline 21 & 498.67 & 548.33 & 611.00 & 560.67 & 617.00 & 571.00 & 695.33 & 793.67 \\
\hline 22 & 580.00 & 602.67 & 677.00 & 748.67 & 749.00 & 839.00 & 861.67 & 930.33 \\
\hline 23 & 568.67 & 633.33 & 654.00 & 709.00 & 801.33 & 808.00 & 915.67 & 940.00 \\
\hline 24 & 529.67 & 553.00 & 647.33 & 701.67 & 673.00 & 751.33 & 779.33 & 800.00 \\
\hline 25 & 543.00 & 608.67 & 631.33 & 644.67 & 697.67 & 703.33 & 827.67 & 804.00 \\
\hline 26 & 566.00 & 668.33 & 679.67 & 764.67 & 776.33 & 794.67 & 891.33 & 934.33 \\
\hline 27 & 620.33 & 631.00 & 697.33 & 745.00 & 782.00 & 858.67 & 897.00 & 944.33 \\
\hline 28 & 610.00 & 619.33 & 700.33 & 777.33 & 768.33 & 787.33 & 900.67 & 1017.33 \\
\hline 29 & 553.33 & 659.00 & 679.67 & 800.67 & 827.33 & 874.33 & 943.00 & 932.00 \\
\hline 30 & 587.33 & 648.33 & 638.33 & 738.67 & 823.33 & 963.67 & 950.00 & 1009.00 \\
\hline 31 & 579.33 & 608.33 & 633.67 & 638.67 & 711.67 & 755.67 & 796.00 & 880.33 \\
\hline 32 & 578.33 & 653.67 & 681.67 & 740.67 & 783.00 & 855.67 & 920.33 & 946.67 \\
\hline 33 & 583.33 & 631.67 & 681.00 & 726.00 & 741.33 & 785.67 & 783.00 & 871.33 \\
\hline 34 & 554.33 & 662.00 & 723.67 & 731.00 & 804.33 & 831.00 & 921.67 & 927.00 \\
\hline 35 & 590.00 & 669.67 & 731.67 & 771.33 & 800.67 & 869.67 & 911.67 & 995.00 \\
\hline 36 & 587.33 & 657.33 & 692.33 & 766.00 & 809.00 & 835.67 & 916.67 & 973.00 \\
\hline 37 & 573.67 & 611.67 & 668.33 & 728.67 & 776.67 & 829.00 & 970.67 & 986.00 \\
\hline 38 & 604.33 & 654.33 & 663.33 & 728.67 & 773.33 & 810.33 & 943.00 & 989.33 \\
\hline 39 & 603.00 & 642.00 & 732.67 & 766.33 & 831.33 & 879.00 & 921.00 & 981.00 \\
\hline 40 & 587.33 & 664.33 & 665.00 & 719.00 & 745.67 & 794.33 & 858.33 & 894.67 \\
\hline 41 & 549.00 & 606.33 & 622.33 & 646.33 & 690.33 & 722.67 & 818.33 & 804.33 \\
\hline 42 & 580.00 & 624.00 & 689.67 & 726.33 & 827.67 & 871.67 & 865.67 & 968.67 \\
\hline 43 & 570.33 & 650.33 & 655.00 & 717.00 & 738.00 & 772.33 & 951.00 & 1076.67 \\
\hline 44 & 551.67 & 645.67 & 663.00 & 675.33 & 761.67 & 824.33 & 810.67 & 917.00 \\
\hline 45 & 552.00 & 571.67 & 641.00 & 684.33 & 745.00 & 762.67 & 840.33 & 890.00 \\
\hline 47 & 575.00 & 611.00 & 674.33 & 759.33 & 803.33 & 831.33 & 879.67 & 977.67 \\
\hline 48 & 594.67 & 628.33 & 670.33 & 722.33 & 739.33 & 823.00 & 890.33 & 904.00 \\
\hline 49 & 576.00 & 619.00 & 692.33 & 722.33 & 784.67 & 788.00 & 907.00 & 964.67 \\
\hline
\end{tabular}




\section{APPENDIX XIII}

Timing Test Reliability

\begin{tabular}{|c|c|c|c|c|c|c|c|c|}
\hline & & & & Target & ISI & & & \\
\hline & 250 & 300 & 350 & 400 & 450 & 500 & 550 & 600 \\
\hline & 250 & 300 & 350 & 400 & 450 & 500 & 550 & 600 \\
\hline & 251 & 301 & 351 & 400 & 450 & 500 & 550 & 600 \\
\hline & 250 & 300 & 350 & 400 & 450 & 500 & 550 & 600 \\
\hline & 250 & 300 & 350 & 400 & 450 & 500 & 550 & 600 \\
\hline & 250 & 300 & 350 & 400 & 450 & 500 & 550 & 600 \\
\hline & 250 & 300 & 350 & 400 & 450 & 500 & 550 & 600 \\
\hline Response ISI & 250 & 300 & 350 & 400 & 450 & 500 & 550 & 600 \\
\hline & 250 & 300 & 350 & 400 & 450 & 500 & 550 & 600 \\
\hline & 250 & 300 & 350 & 400 & 450 & 500 & 550 & 600 \\
\hline & 250 & 300 & 350 & 400 & 450 & 500 & 551 & 600 \\
\hline & 250 & 300 & 350 & 400 & 450 & 500 & 549 & 600 \\
\hline & 250 & 300 & 350 & 400 & 450 & 500 & 550 & 600 \\
\hline & 250 & 300 & 350 & 400 & 450 & 500 & 551 & 600 \\
\hline & 250 & 300 & 350 & 400 & 450 & 500 & 550 & 600 \\
\hline & 250 & 300 & 350 & 400 & 450 & 500 & 550 & 600 \\
\hline & 250 & 300 & 350 & 400 & 450 & 500 & 550 & 600 \\
\hline & 250 & 300 & 350 & 400 & 450 & 500 & 550 & 600 \\
\hline & 250 & 300 & 350 & 400 & 450 & 500 & 550 & 600 \\
\hline & 250 & 300 & 350 & 400 & 450 & 500 & 550 & 600 \\
\hline & 250 & 300 & 350 & 400 & 450 & 500 & 550 & 600 \\
\hline $\begin{array}{l}\text { Average } \\
\text { response }\end{array}$ & 250.05 & 300.05 & 350.05 & 400.00 & 450.00 & 500.00 & 550.05 & $\begin{array}{c}600.0 \\
0\end{array}$ \\
\hline Median & 250 & 300 & 350 & 400 & 450 & 500 & 550 & 600 \\
\hline $\begin{array}{l}\text { Standard } \\
\text { deviation }\end{array}$ & 0.2236 & 0.2236 & 0.2236 & 0 & 0 & 0 & 0.394 & 0 \\
\hline Variance & 0.05 & 0.05 & 0.05 & 0 & 0 & 0 & 0.1553 & 0 \\
\hline
\end{tabular}


Target ISI

\begin{tabular}{llllllll}
\hline & 650 & 700 & 750 & 800 & 850 & 900 & 950 \\
\hline & 650 & 700 & 750 & 800 & 850 & 900 & 950 \\
& 650 & 700 & 750 & 800 & 850 & 900 & 950 \\
650 & 700 & 750 & 800 & 850 & 900 & 950 \\
Response ISI & 650 & 700 & 750 & 800 & 850 & 900 & 950 \\
& 650 & 700 & 750 & 800 & 850 & 900 & 950 \\
& 650 & 700 & 750 & 800 & 850 & 900 & 950 \\
& 650 & 700 & 750 & 800 & 850 & 900 & 950 \\
& 650 & 700 & 750 & 800 & 850 & 900 & 950 \\
& 650 & 700 & 750 & 800 & 850 & 900 & 950 \\
& 650 & 700 & 750 & 800 & 850 & 900 & 950 \\
& 650 & 700 & 750 & 800 & 850 & 900 & 951 \\
& 650 & 700 & 750 & 800 & 850 & 900 & 950 \\
& 650 & 700 & 750 & 800 & 850 & 900 & 950 \\
& 650 & 700 & 750 & 800 & 850 & 900 & 950 \\
& 650 & 700 & 750 & 800 & 850 & 900 & 950 \\
& 650 & 700 & 750 & 800 & 850 & 900 & 950 \\
& 650 & 700 & 750 & 800 & 850 & 900 & 950 \\
& 650 & 700 & 750 & 800 & 850 & 900 & 950 \\
650 & 700 & 750 & 800 & 850 & 900 & 950 \\
& 650 & 700 & 750 & 800 & 850 & 900 & 950 \\
\hline
\end{tabular}

$\begin{array}{lcccccccc}\begin{array}{l}\text { Average } \\ \text { response }\end{array} & 650.00 & 700.00 & 750.00 & 800.00 & 850.00 & 900.00 & 950.05 \\ \text { Median } & 650 & 700 & 750 & 800 & 850 & 900 & 950 \\ \begin{array}{l}\text { Standard } \\ \text { deviation }\end{array} & 0 & 0 & 0 & 0 & 0 & 0 & 0.2236 \\ \text { variance } & 0 & 0 & 0 & 0 & 0 & 0 & 0.05\end{array}$




\section{APPENDIX XIV}

Individual Oscillator Signatures

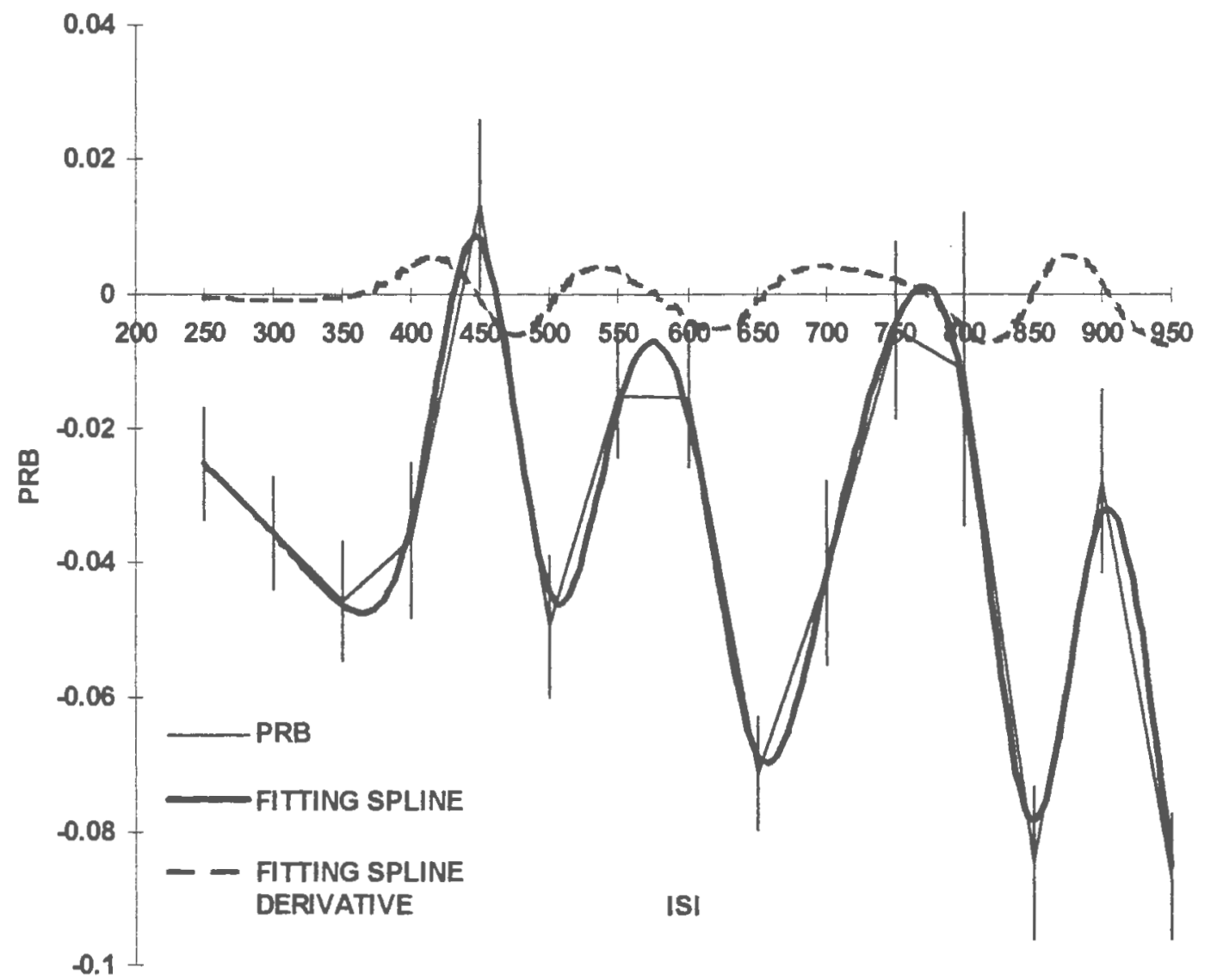

Figure XIV.1 Oscillator Signature (Sub.10)

PRB - Percent Residual Bias

ISI - Interstimulus Interval 


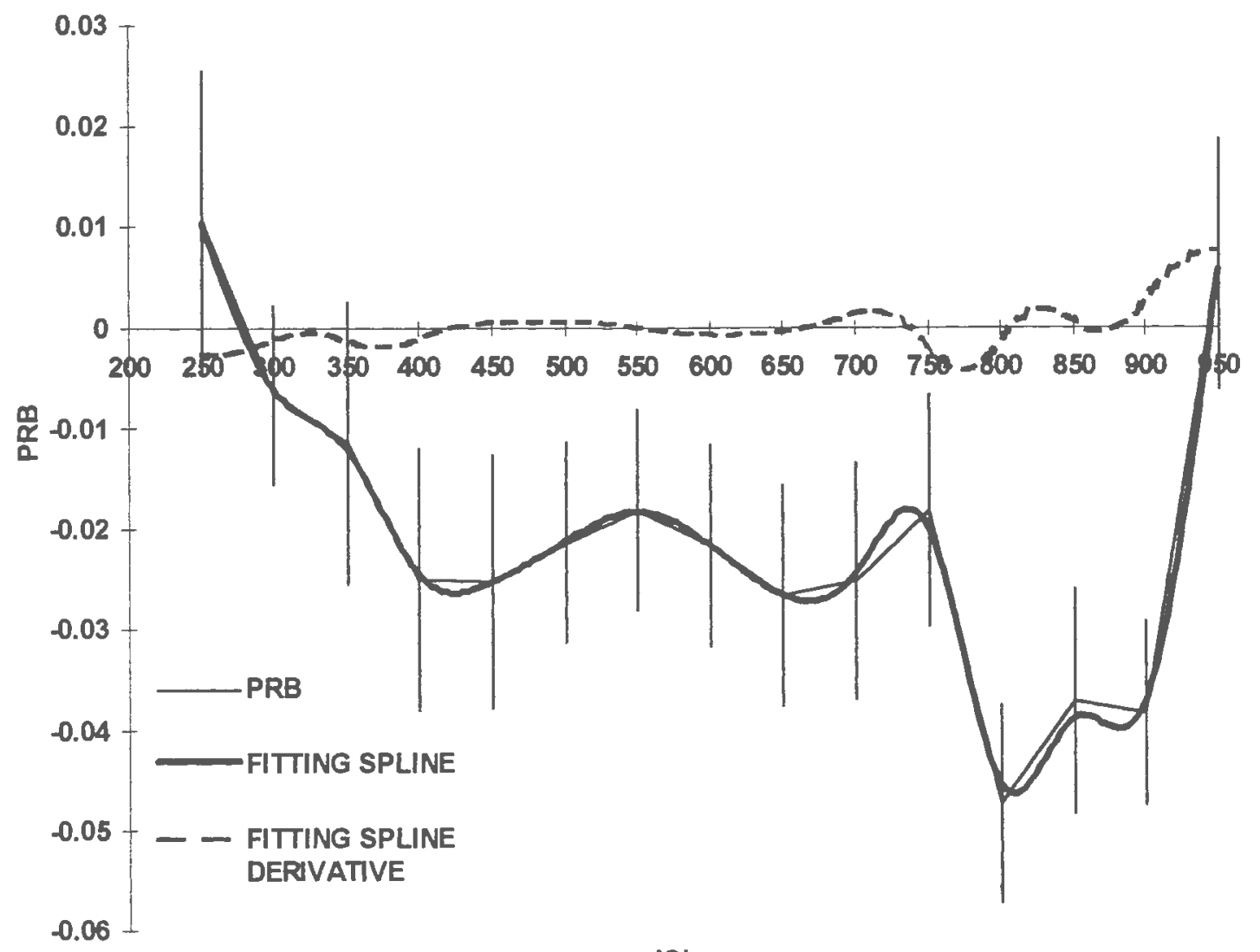

ISI

Figure XIV.2 Oscillator Signature (Sub.11)

PRB - Percent Residual Bias

ISI - Interstimulus Interval 


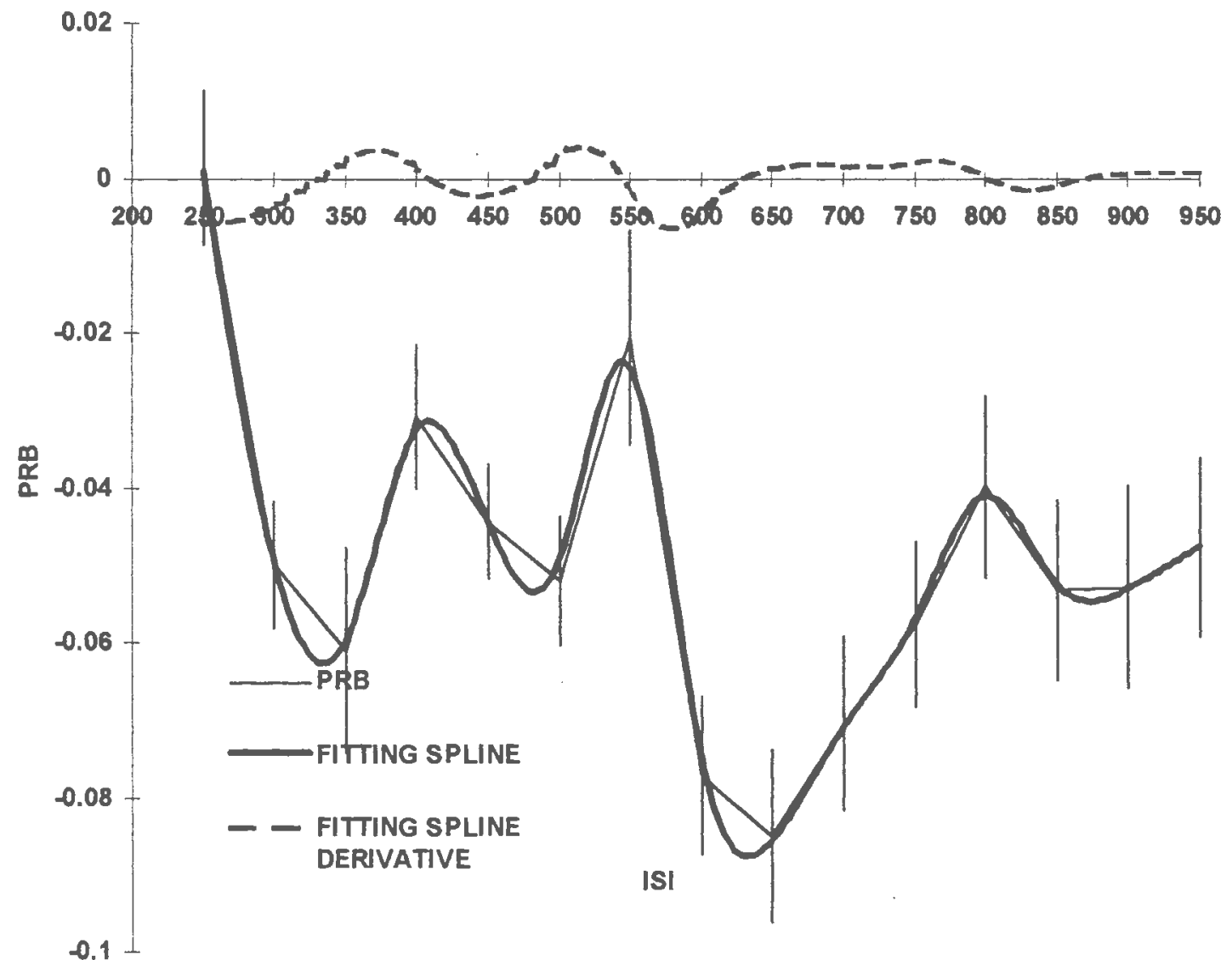

Figure XIV.3 Oscillator Signature (Sub.12)

PRB - Percent Residual Bias

ISI - Interstimulus Interval 


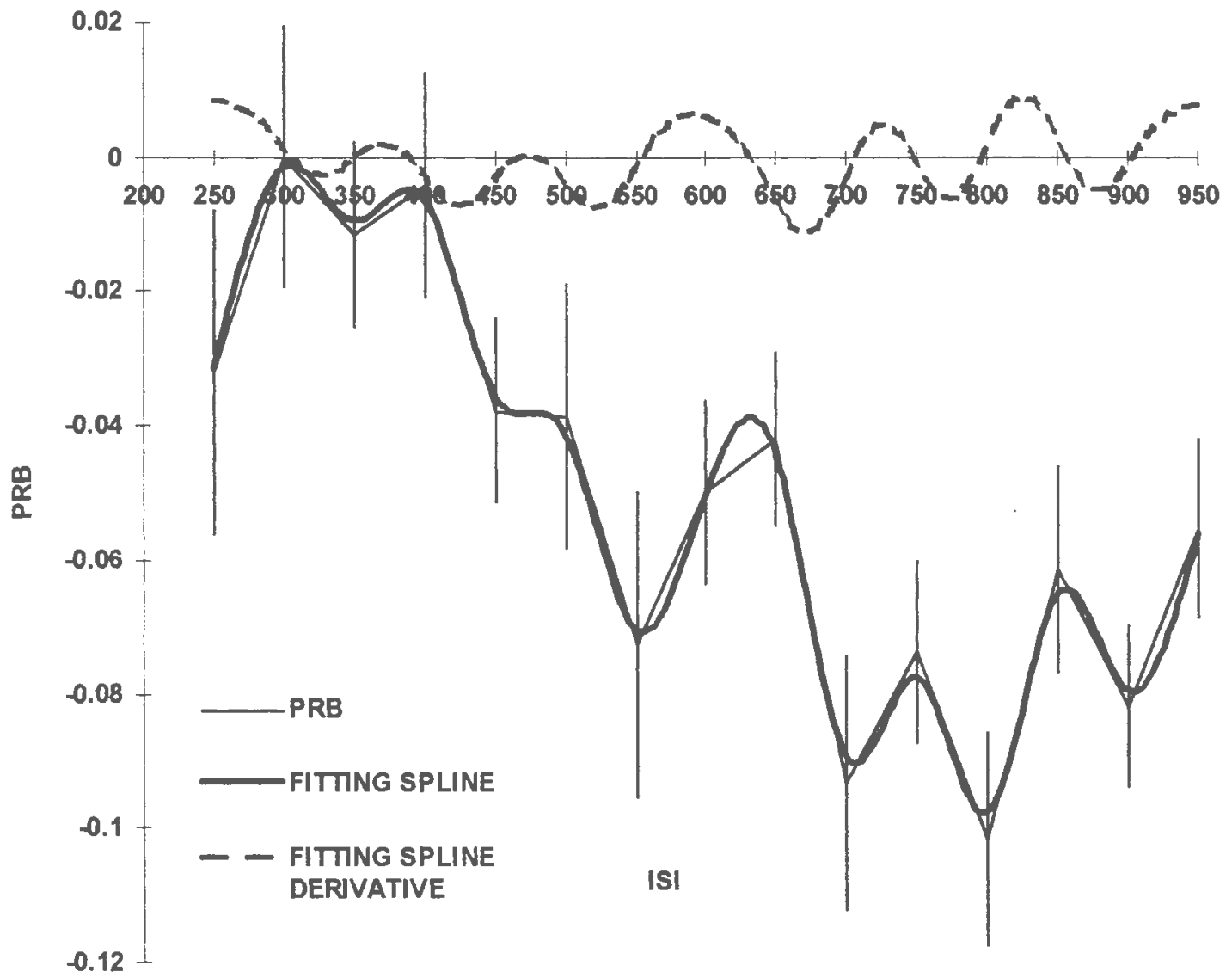

Figure XIV.4 Oscillator Signature (Sub.13)

PRB - Percent Residual Bias

ISI - Interstimulus Interval 


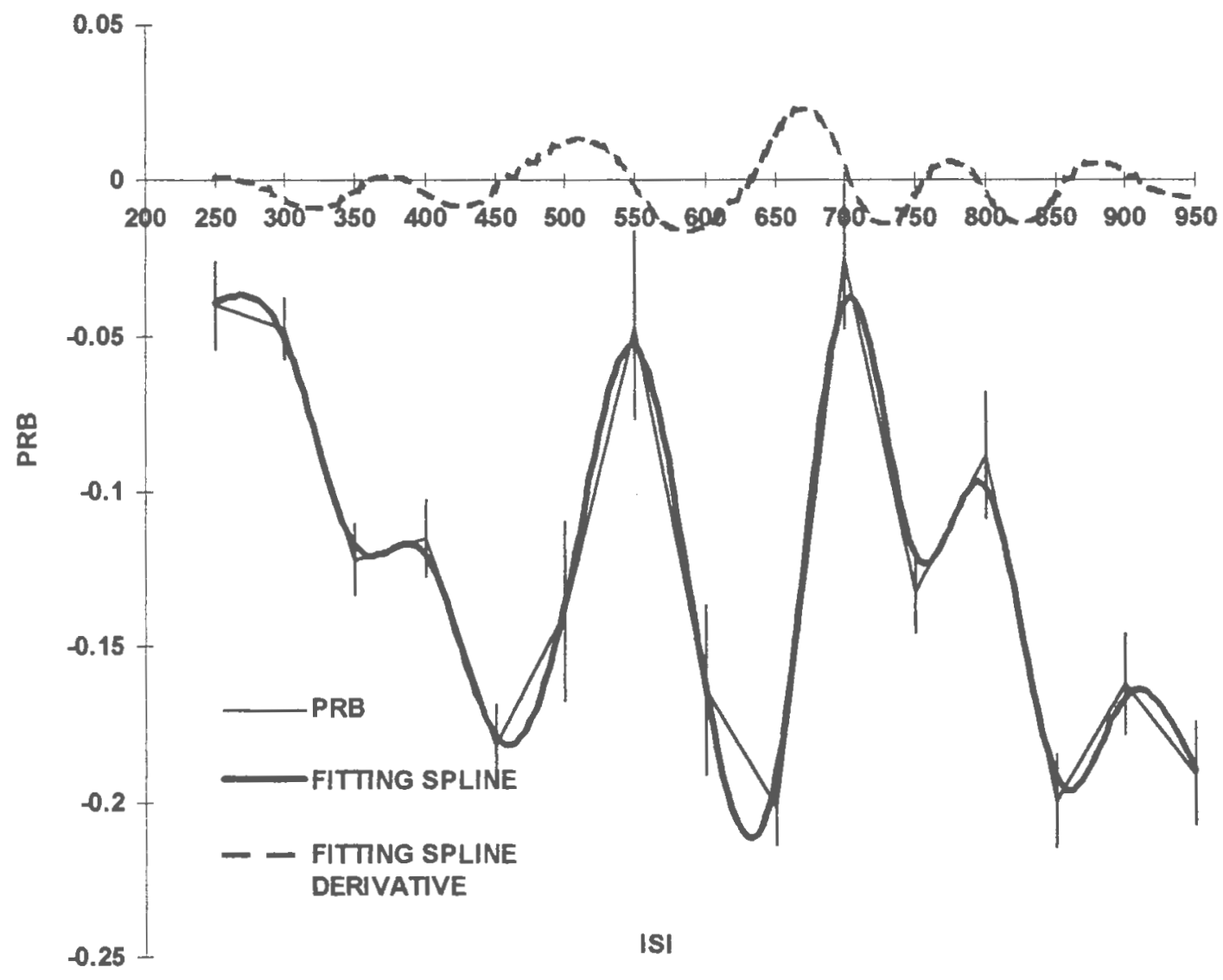

Figure XIV.5 Oscillator Signature (Sub.15)

PRB - Percent Residual Bias

ISI - Interstimulus Interval 


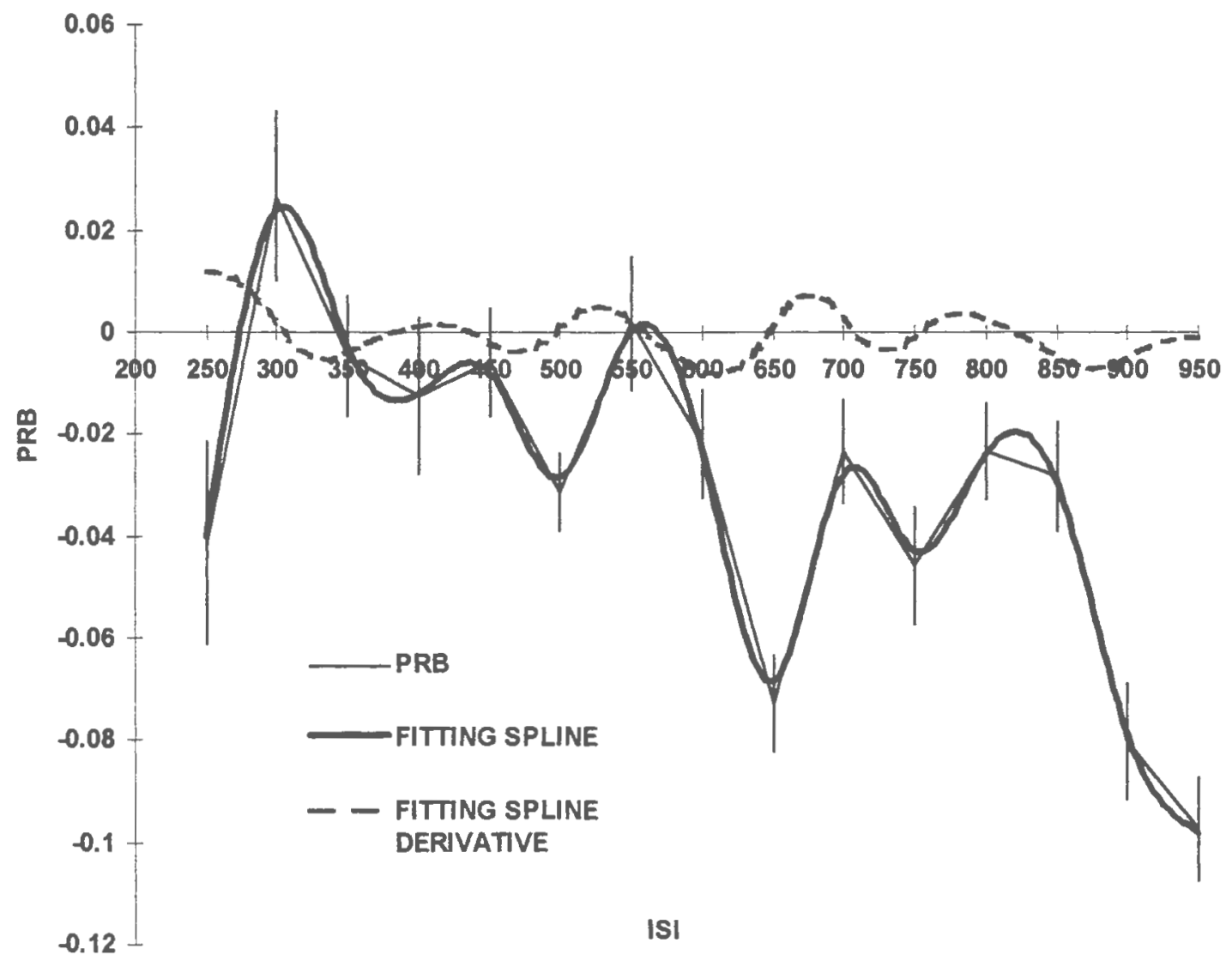

Figure XIV.6 Oscillator Signature (Sub.16)

PRB - Percent Residual Bias

ISI - Interstimulus Interval 


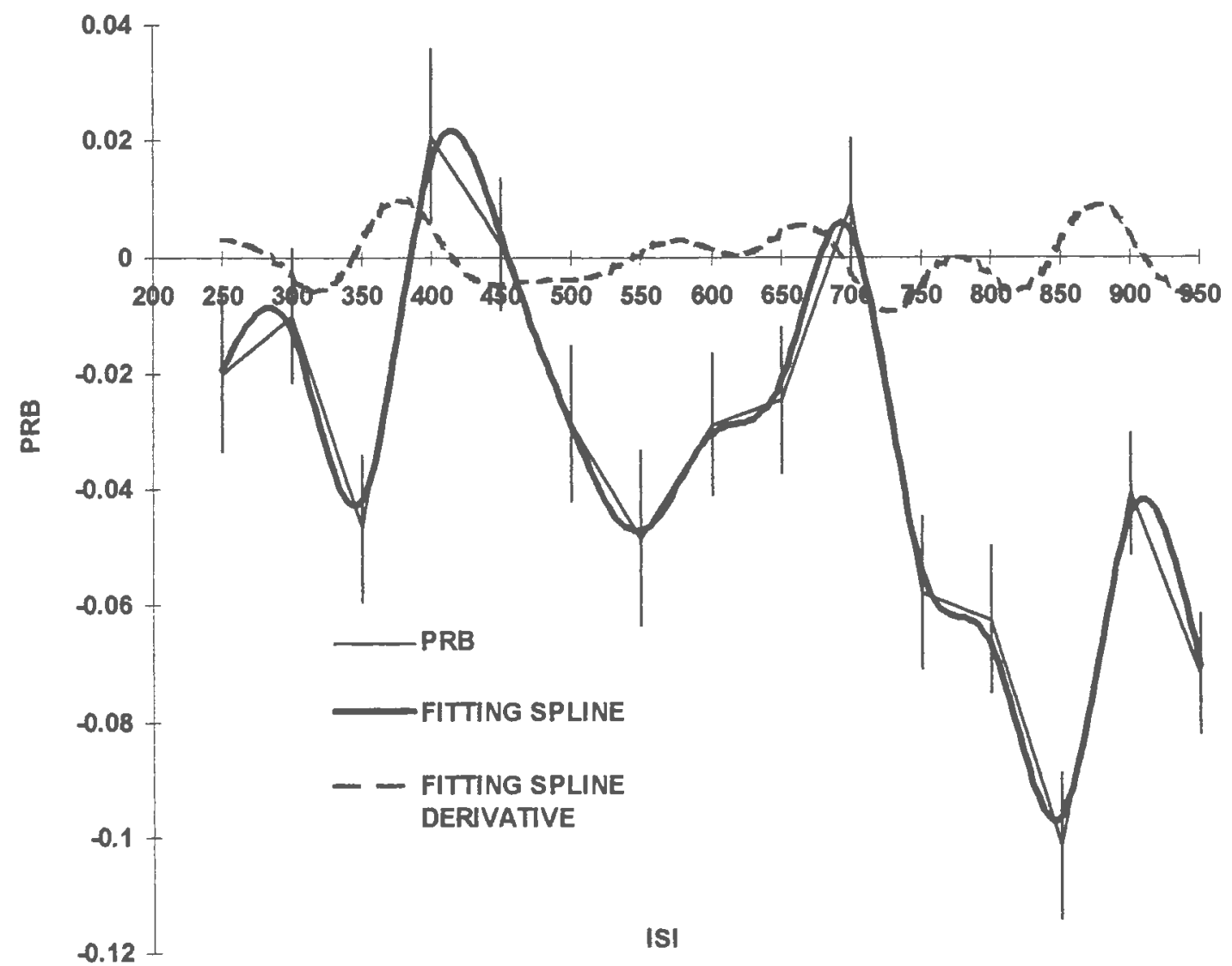

Figure XIV.7 Oscillator Signature (Sub.17)

PRB - Percent Residual Bias

ISI - Interstimulus Interval 


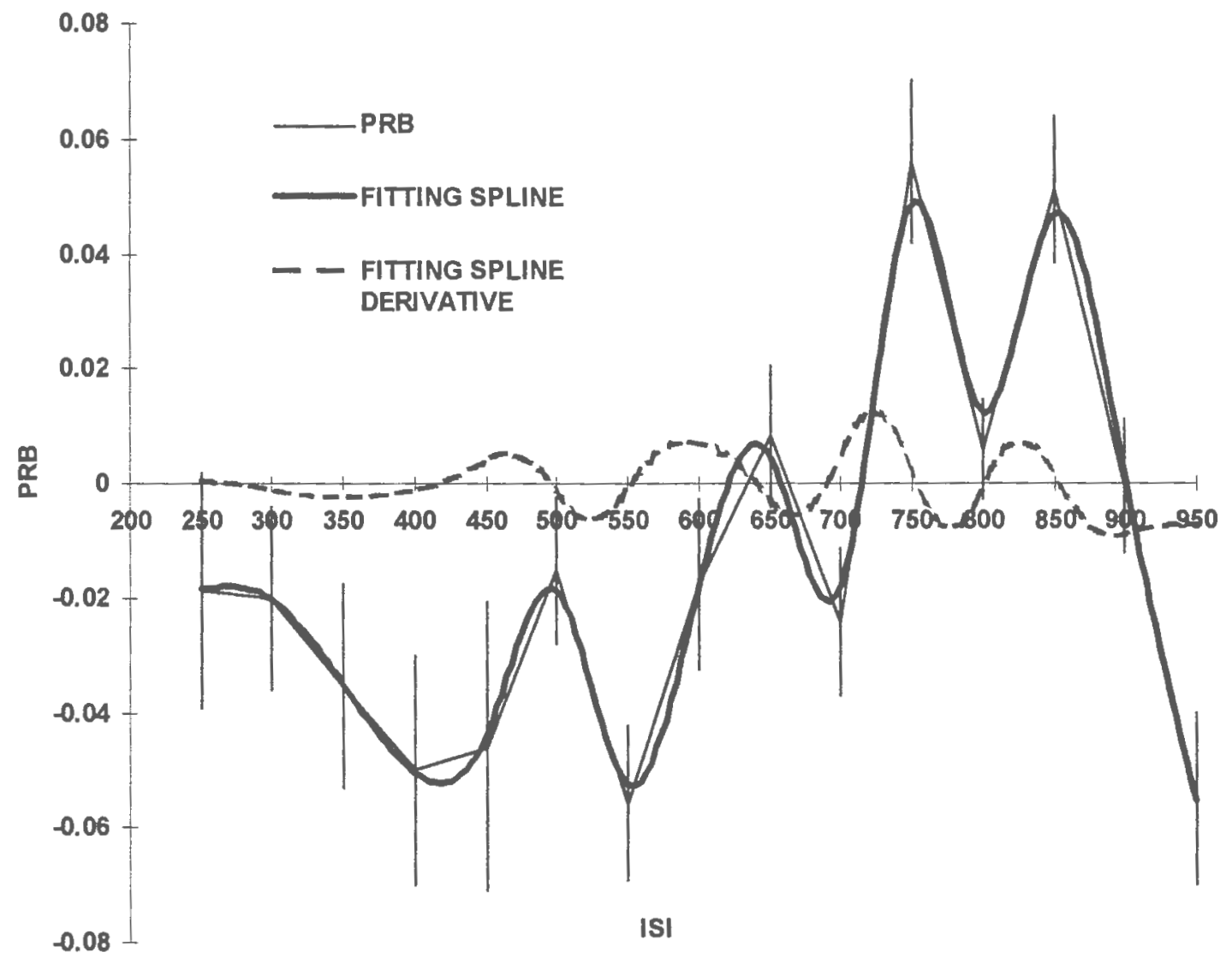

Figure XIV.8 Oscillator Signature (Sub.18)

PRB - Percent Residual Bias

ISI - Interstimulus Interval 


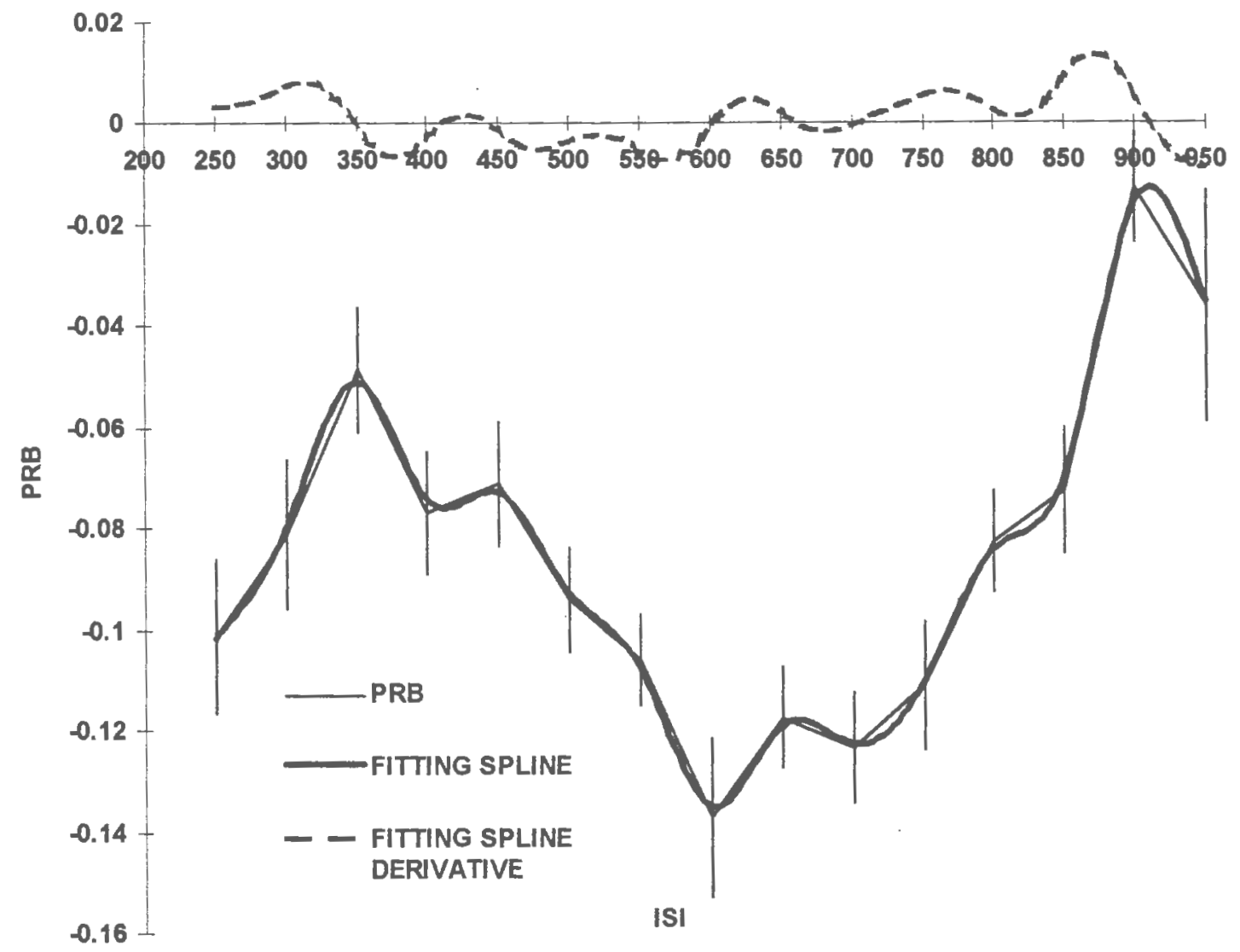

Figure XIV.9 Oscillator Signature (Sub.19)

PRB - Percent Residual Bias

ISI - Interstimulus Interval 


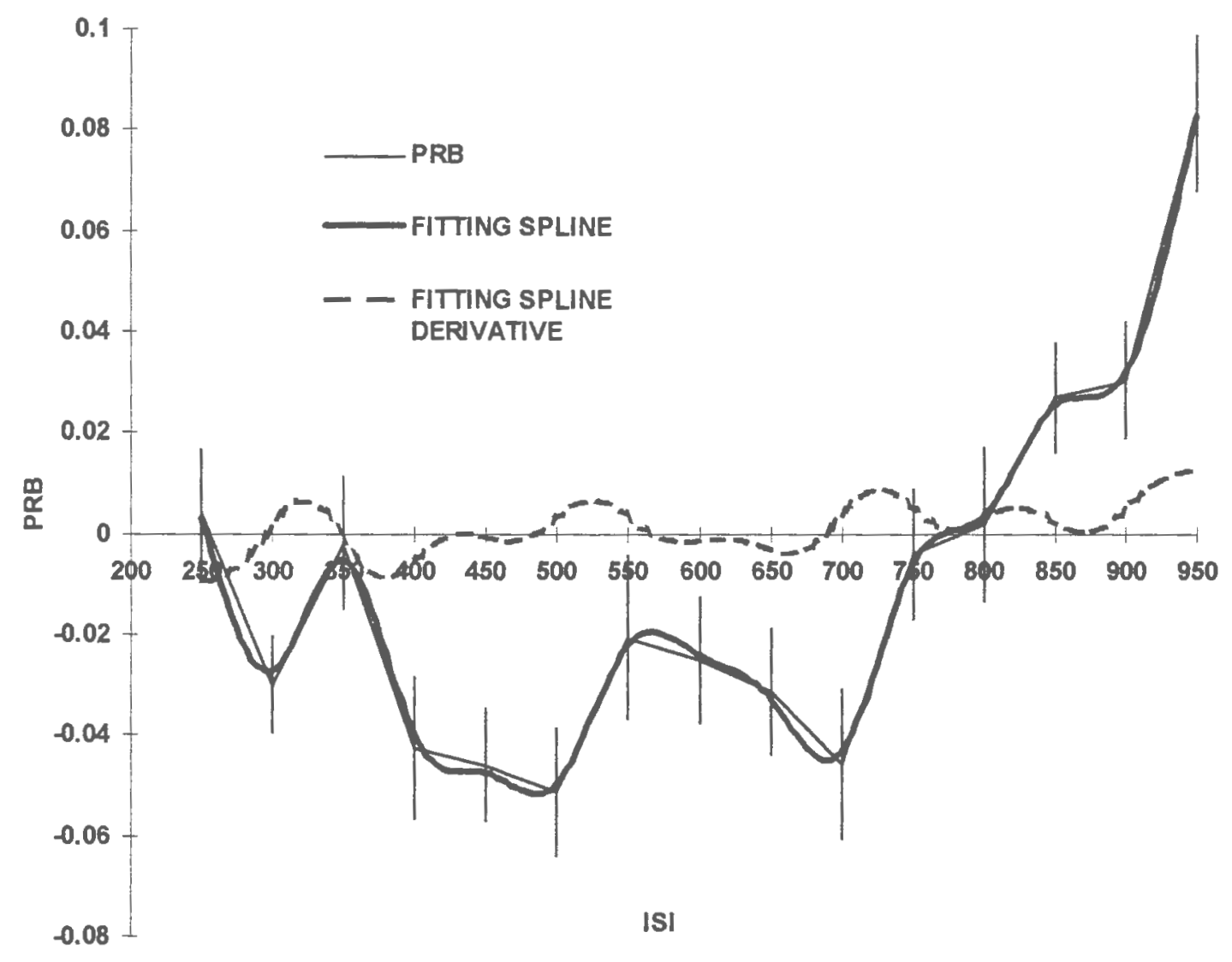

Figure XIV.10 Oscillator Signature (Sub.20)

PRB - Percent Residual Bias

ISI - Interstimulus Interval 


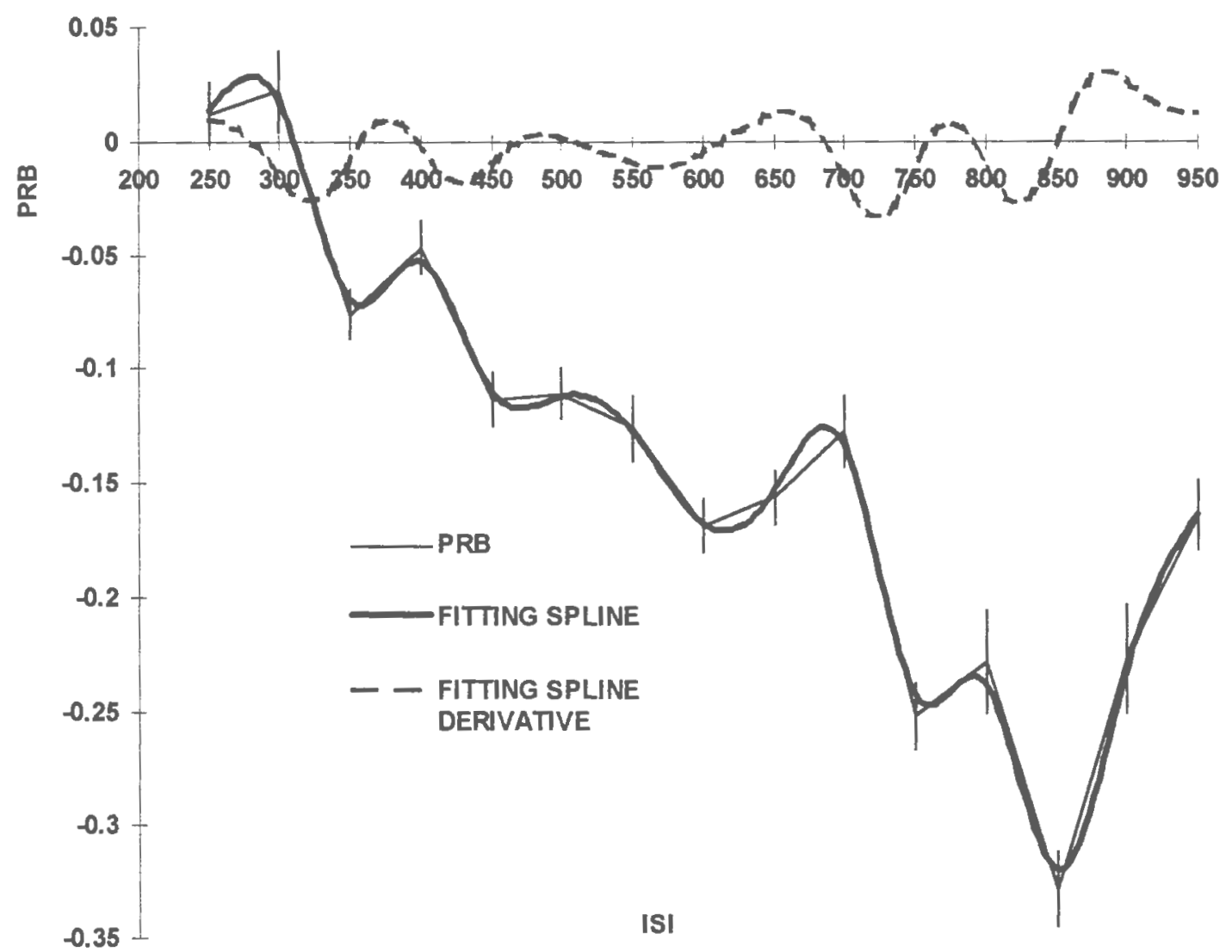

Figure XIV.11 Oscillator Signature (Sub.21)

PRB - Percent Residual Bias

ISI - Interstimulus Interval 


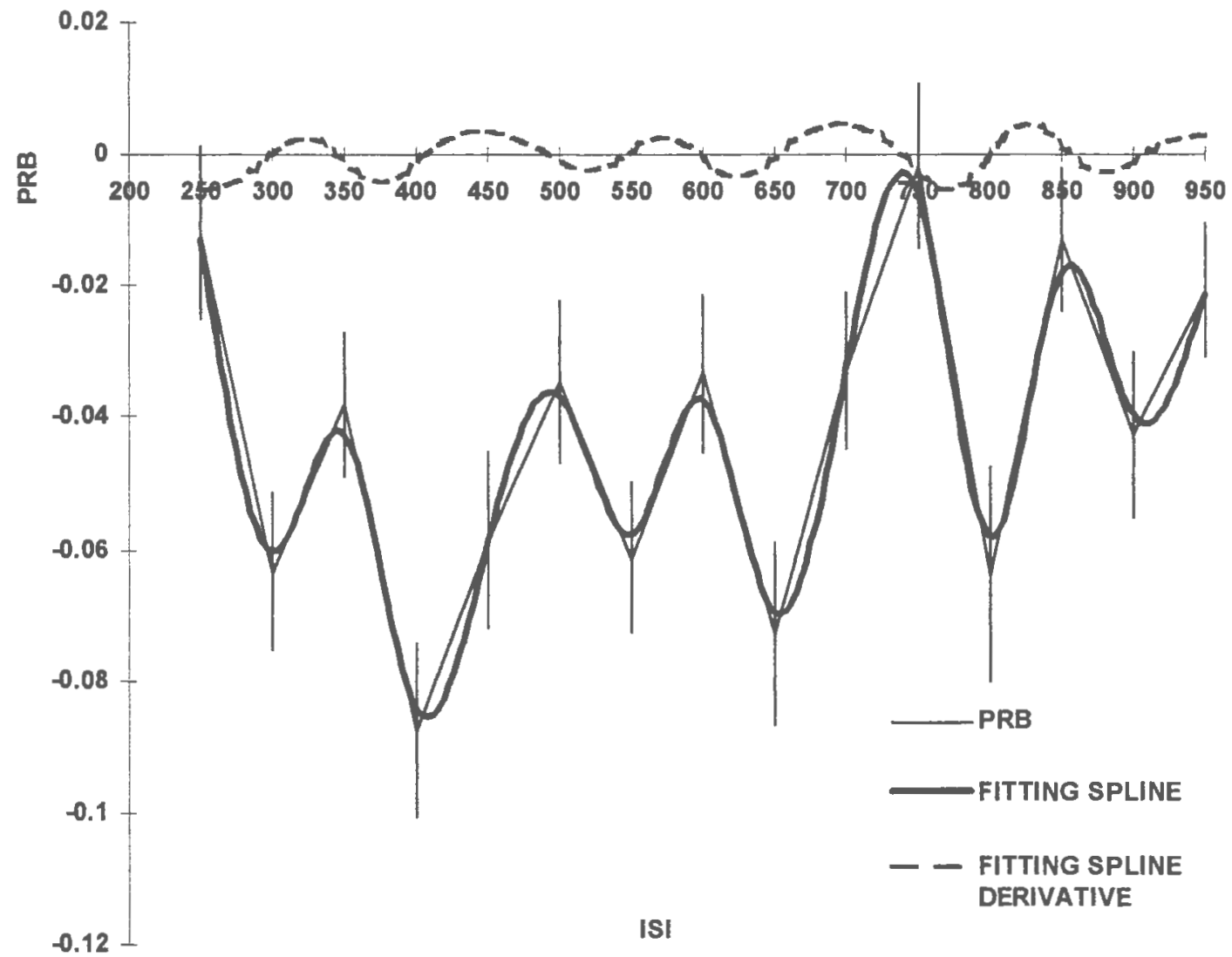

Figure XIV.12 Oscillator Signature (Sub.22)

PRB - Percent Residual Bias

ISI - Interstimulus Interval 


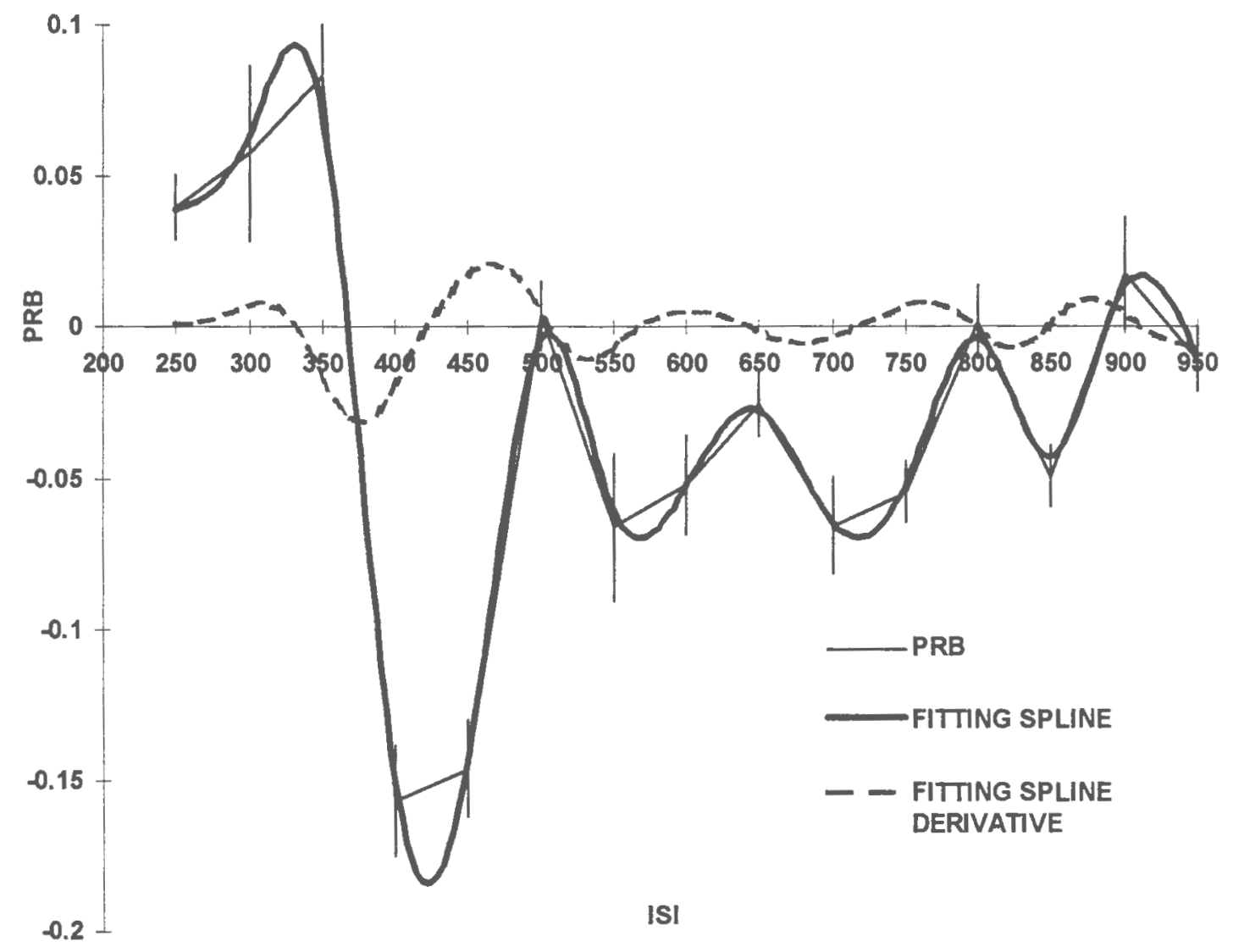

Figure XIV.13 Oscillator Signature (Sub.23)

PRB - Percent Residual Bias

ISI - Interstimulus Interval 


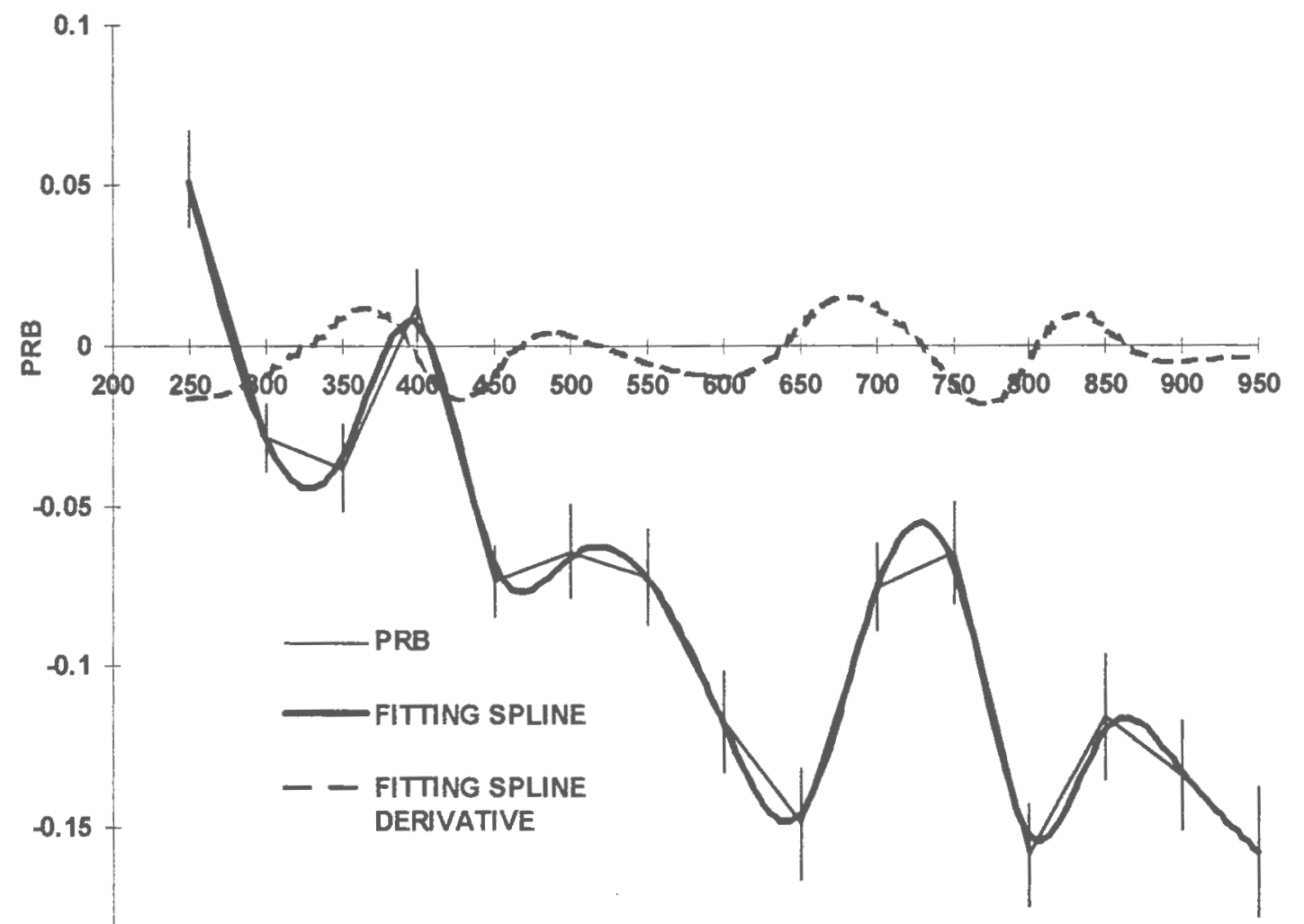

0.2

ISI

Figure XIV.14 Oscillator Signature (Sub.24)

PRB - Percent Residual Bias

ISI - Interstimulus Interval 


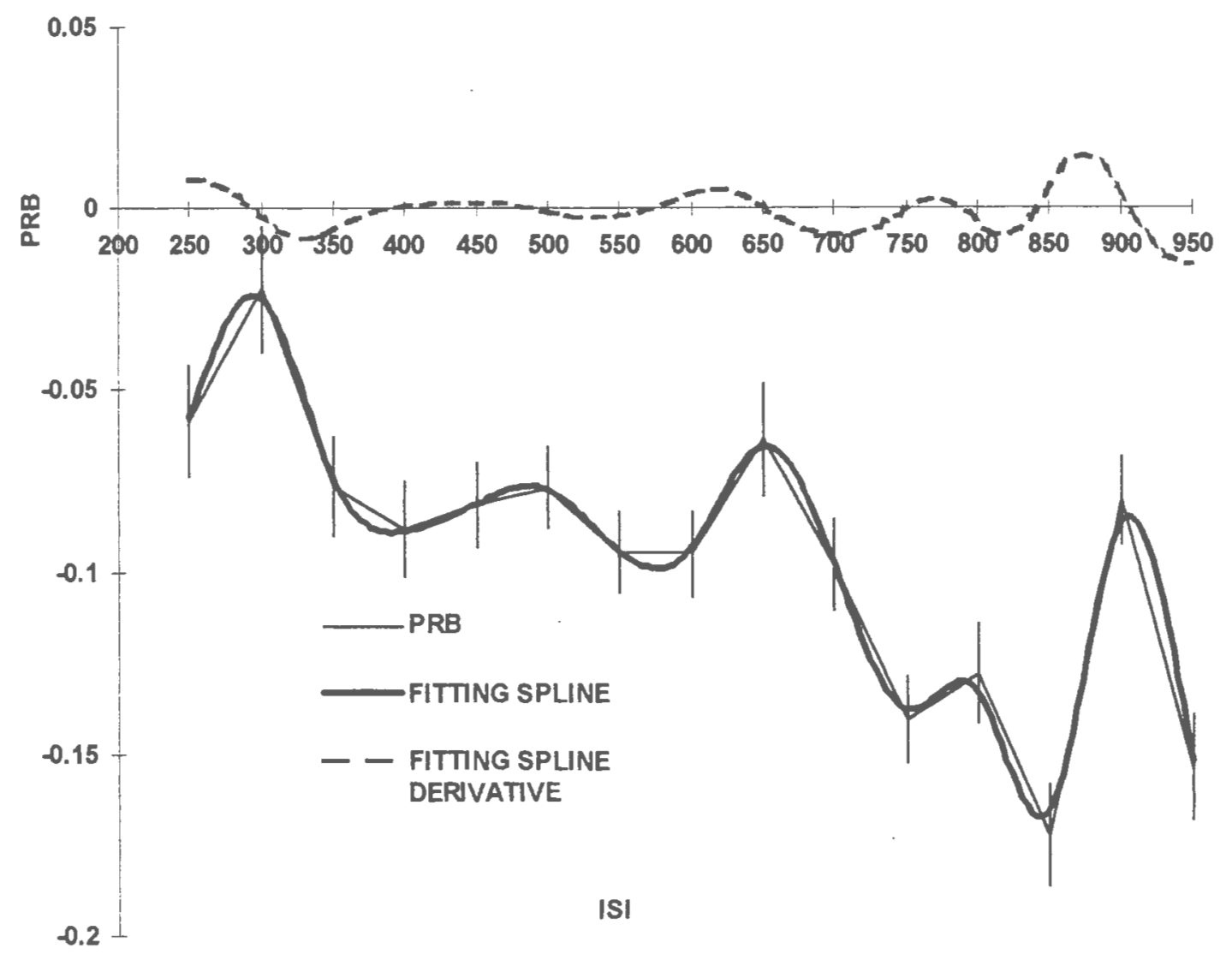

Figure XIV.15 Oscillator Signature (Sub.25)

PRB - Percent Residual Bias

ISI - Interstimulus Interval 


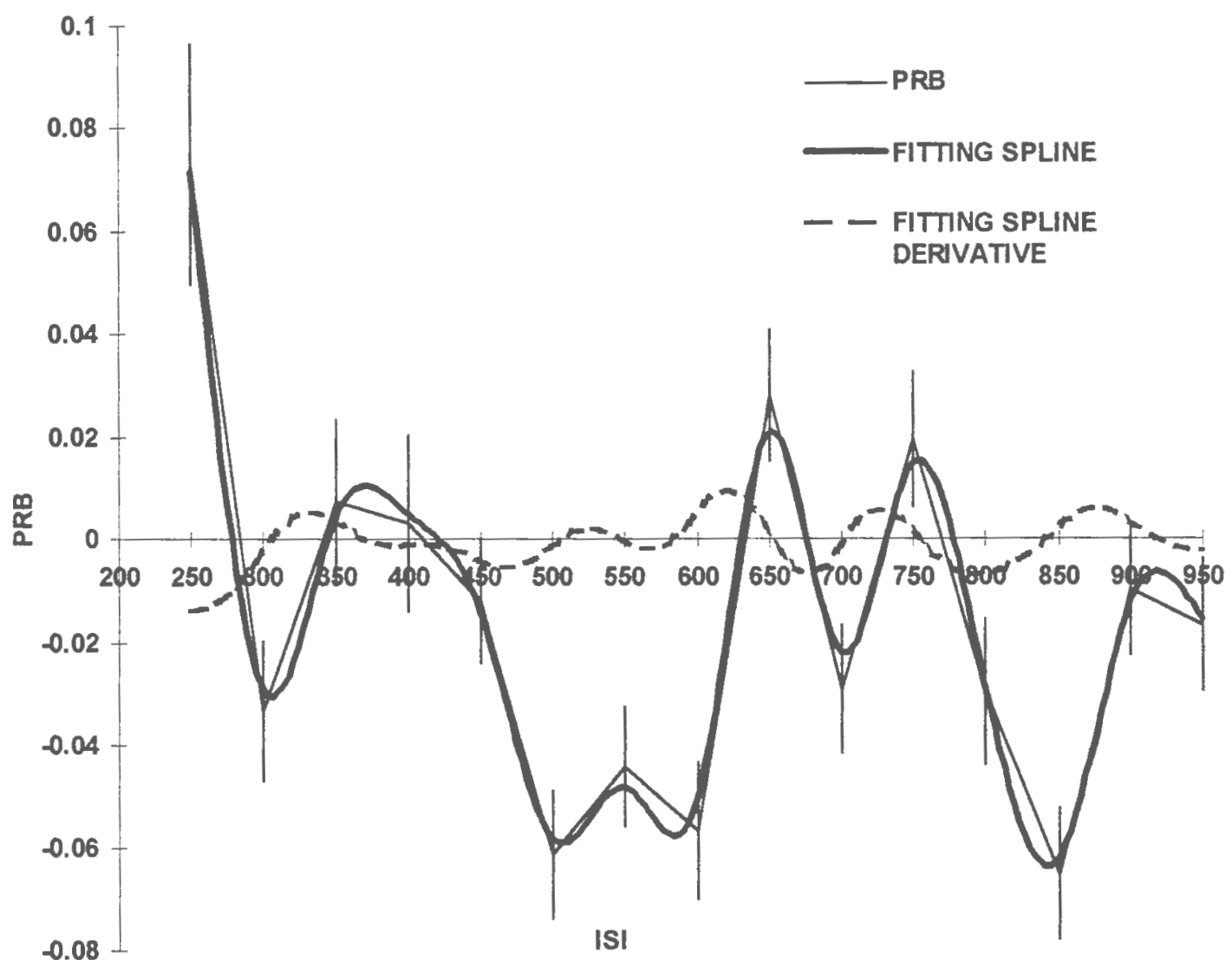

Figure XIV.16 Oscillator Signature (Sub.26)

PRB - Percent Residual Bias

ISI - Interstimulus Interval 


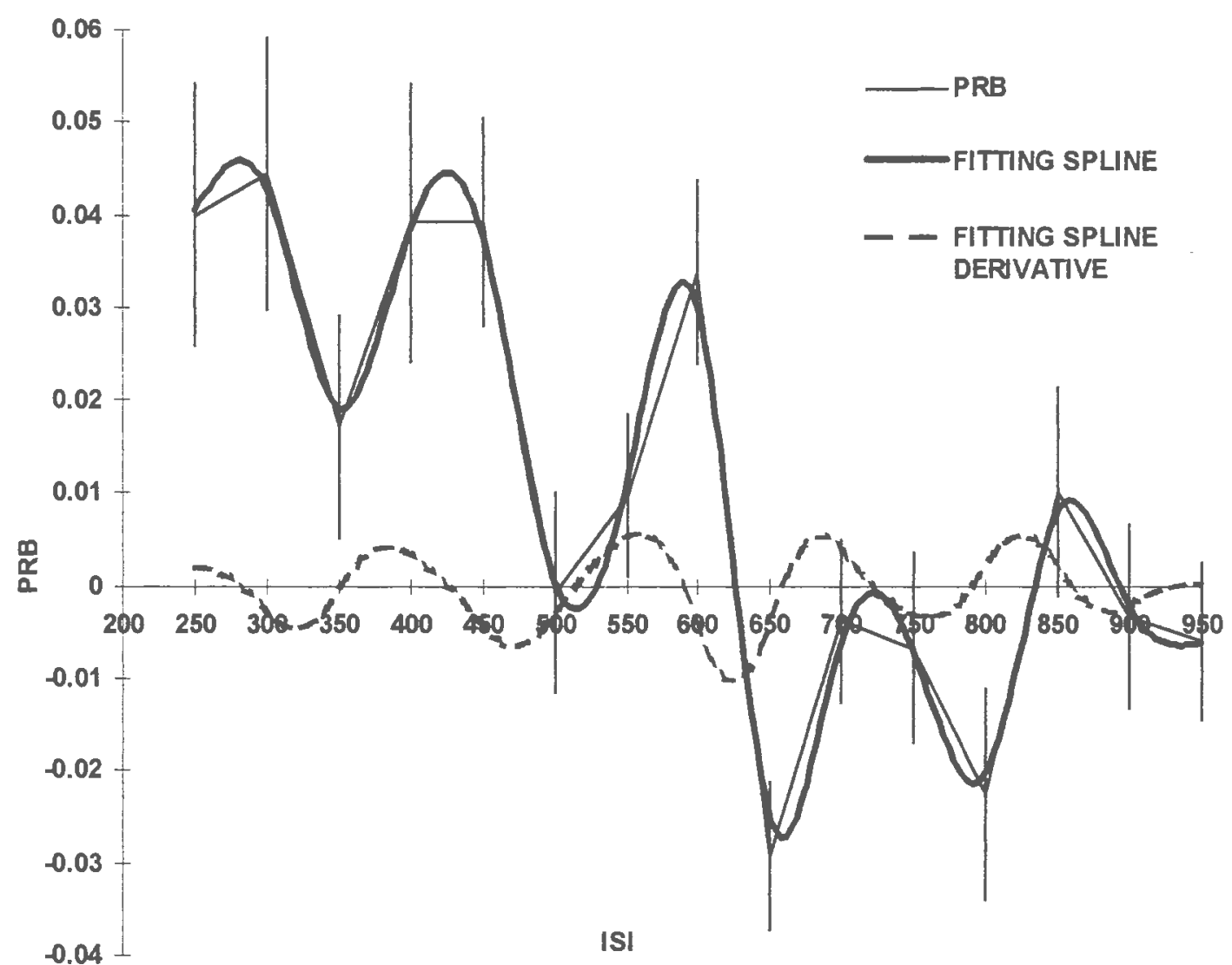

Figure XIV.17 Oscillator Signature (Sub.27)

PRB - Percent Residual Bias

ISI - Interstimulus Interval 


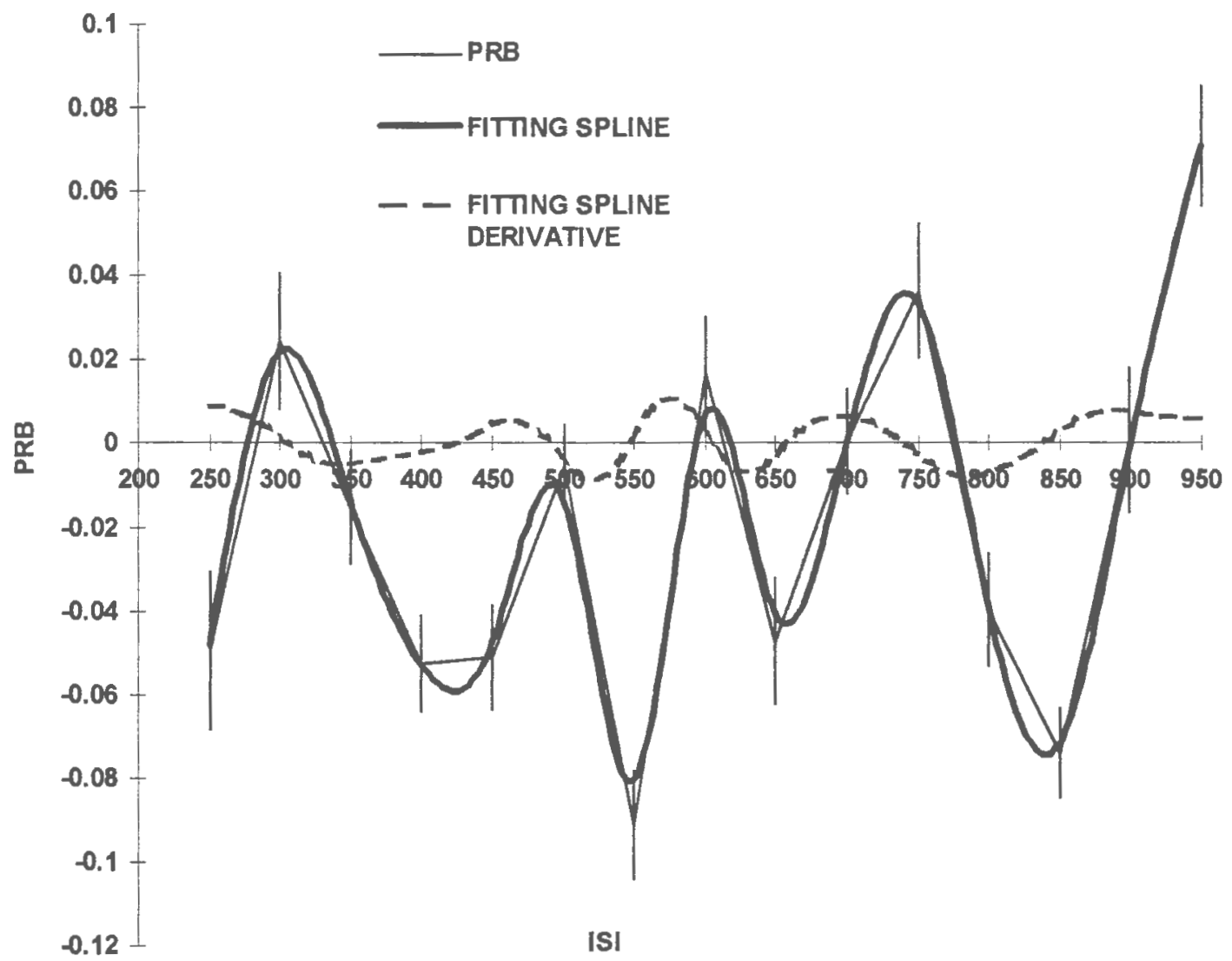

Figure XIV.18 Oscillator Signature (Sub.28)

PRB - Percent Residual Bias

ISI - Interstimulus Interval 


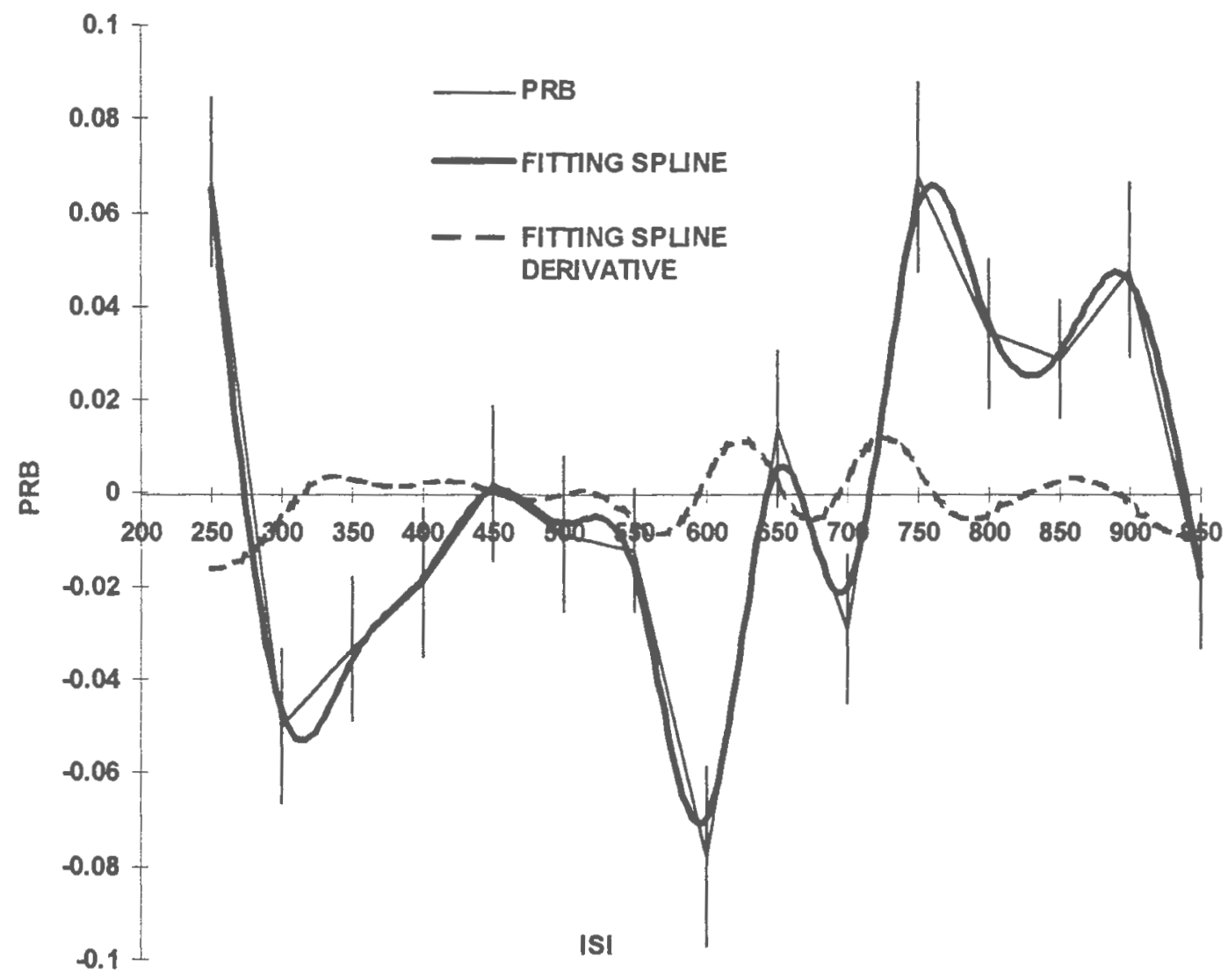

Figure XIV.19 Oscillator Signature (Sub.29)

PRB - Percent Residual Bias

ISI - Interstimulus Interval 


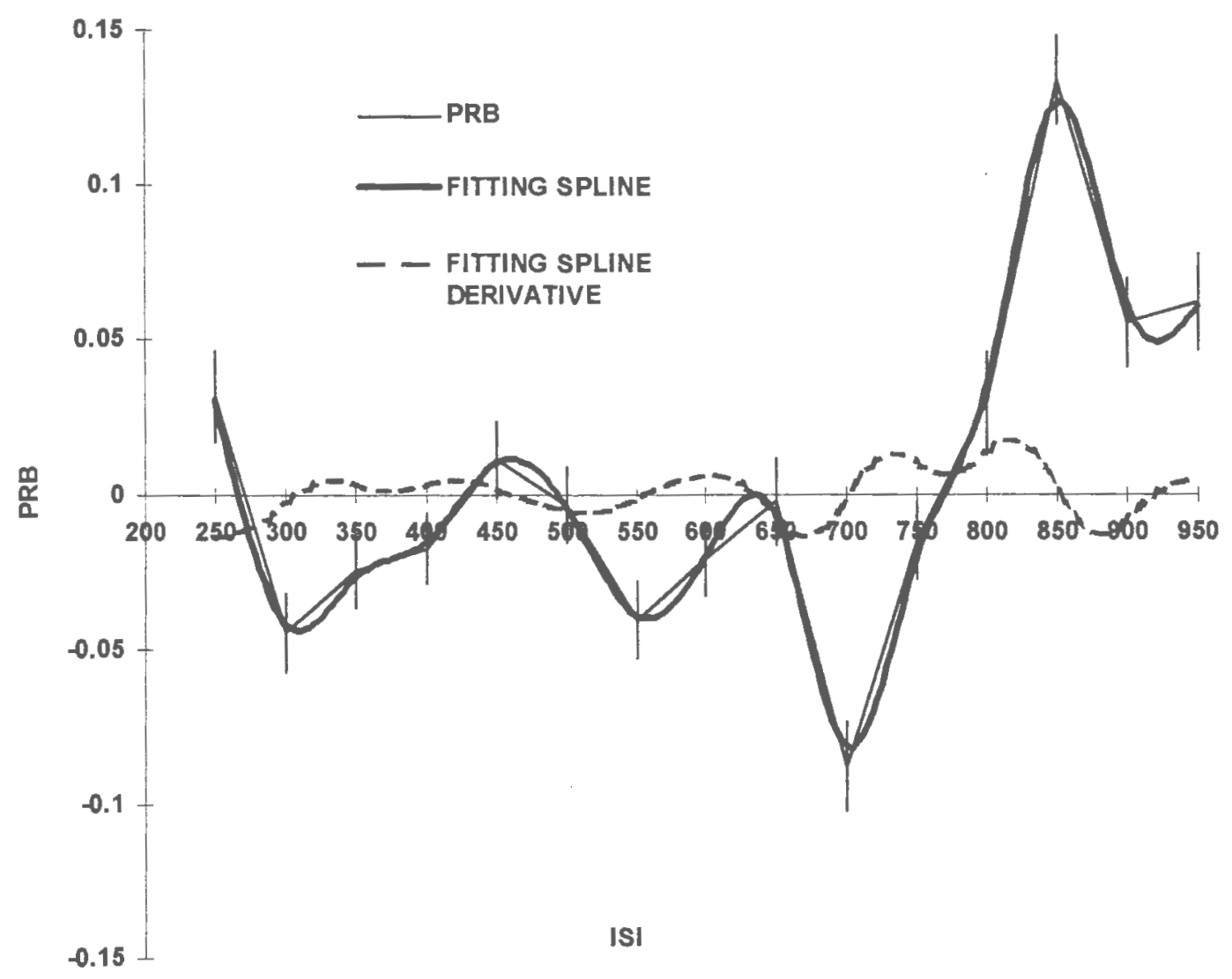

Figure XIV.20 Oscillator Signature (Sub.30)

PRB - Percent Residual Bias

ISI - Interstimulus Interval 


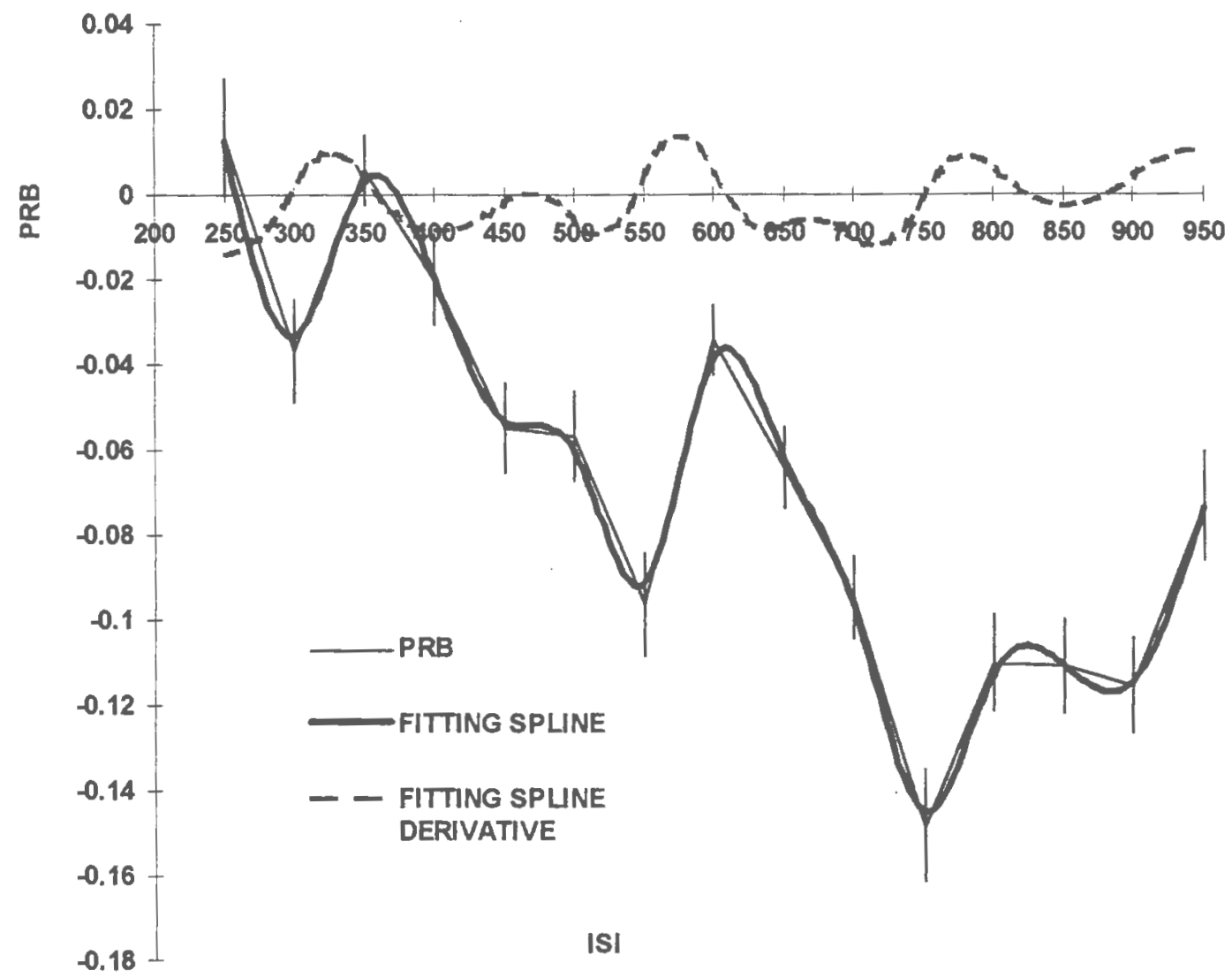

Figure XIV.21 Oscillator Signature (Sub.31)

PRB - Percent Residual Bias

ISI - Interstimulus Interval 


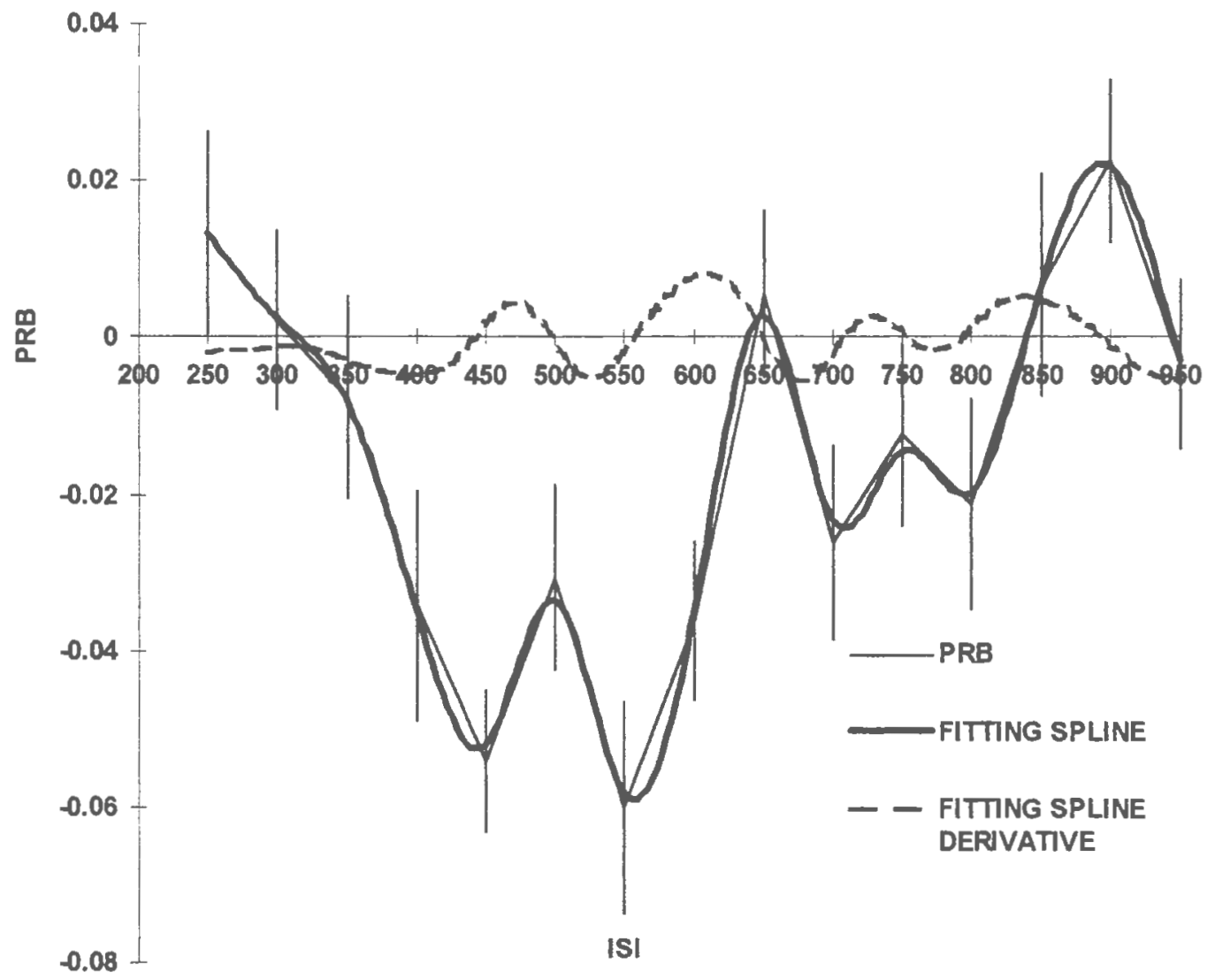

Figure XIV.22 Oscillator Signature (Sub.32)

PRB - Percent Residual Bias

ISI - Interstimulus Interval 


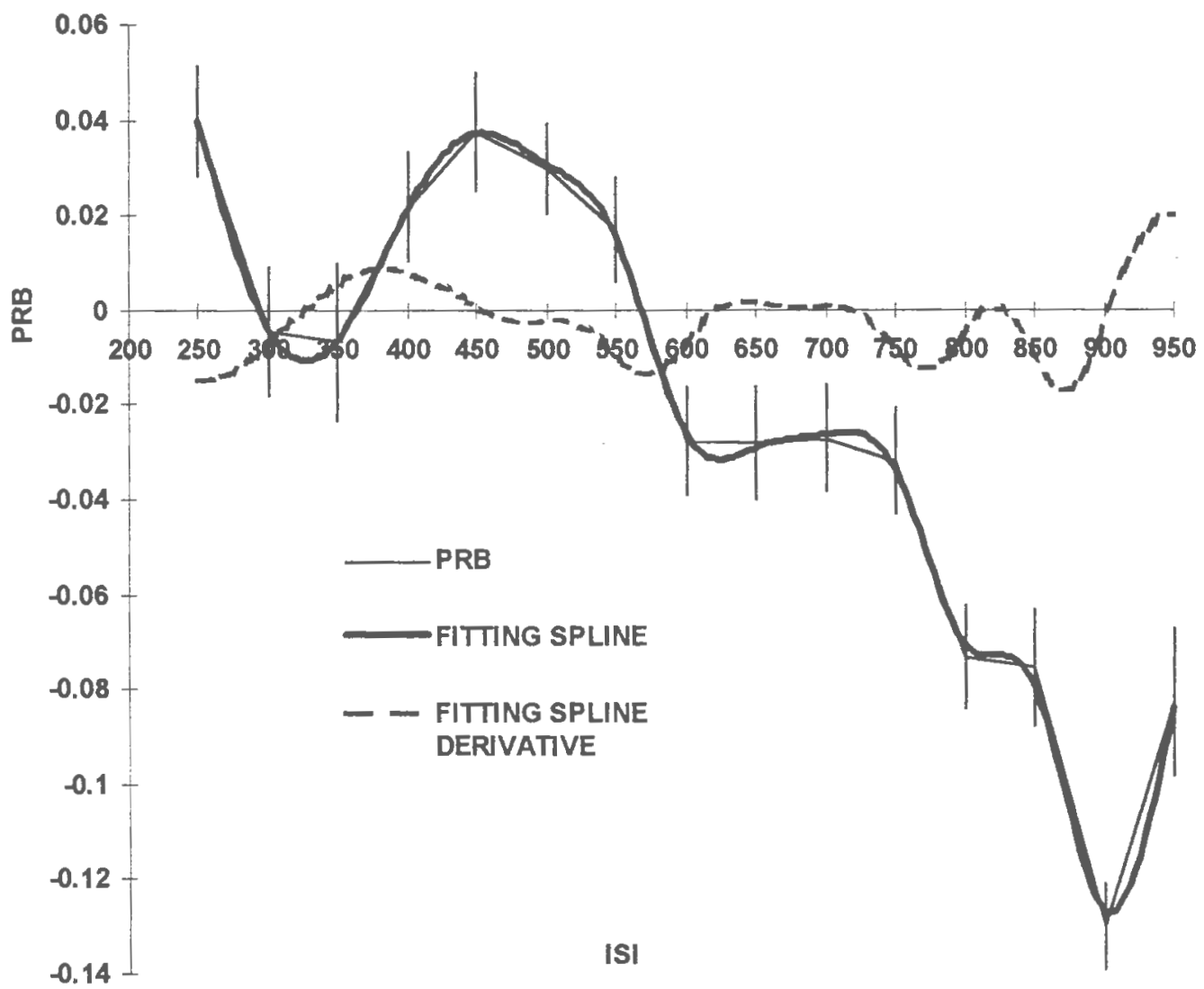

Figure XIV.23 Oscillator Signature (Sub.33)

PRB - Percent Residual Bias

ISI - Interstimulus Interval 


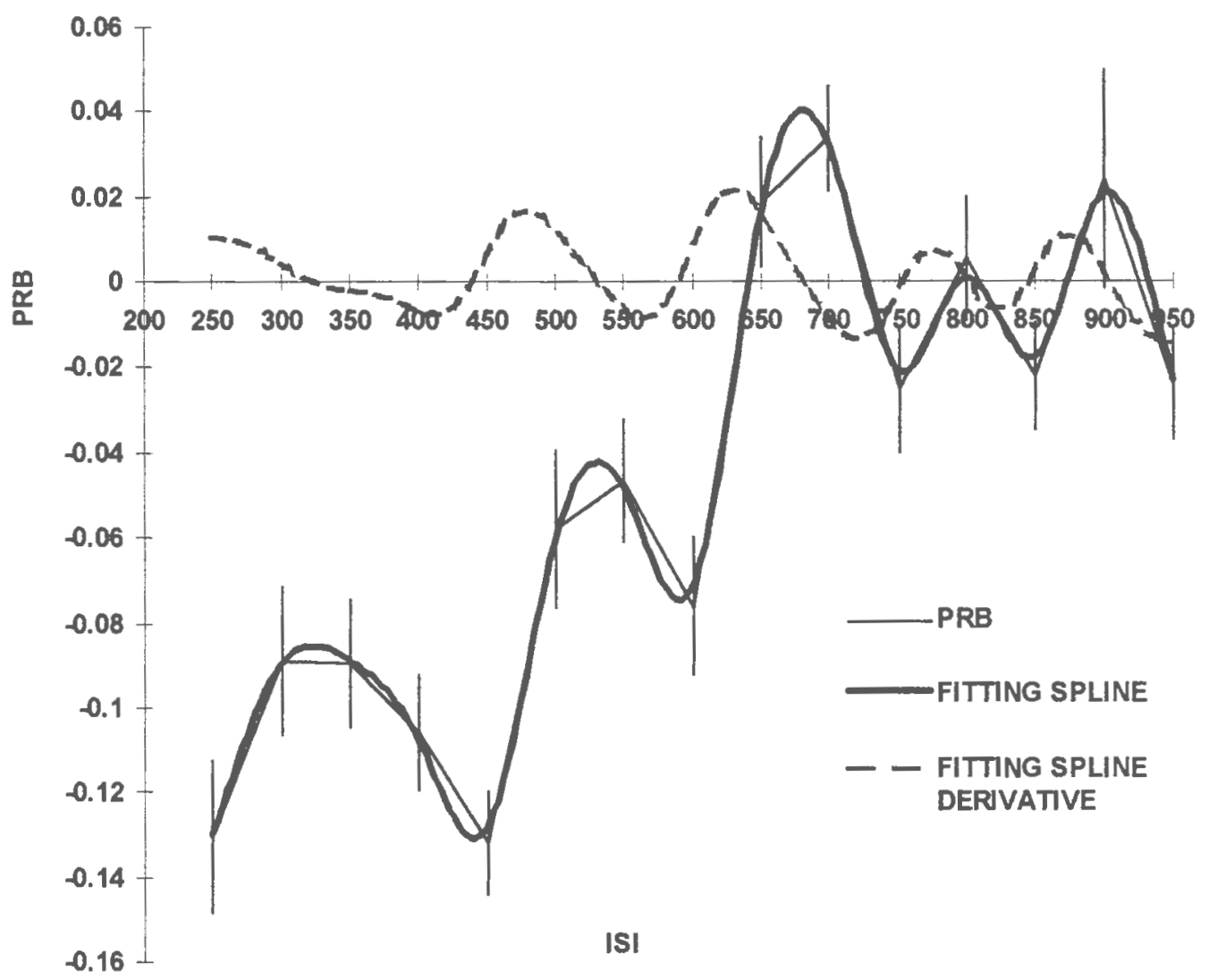

Figure XIV.24 Oscillator Signature (Sub.34)

PRB - Percent Residual Bias

ISI - Interstimulus Interval 


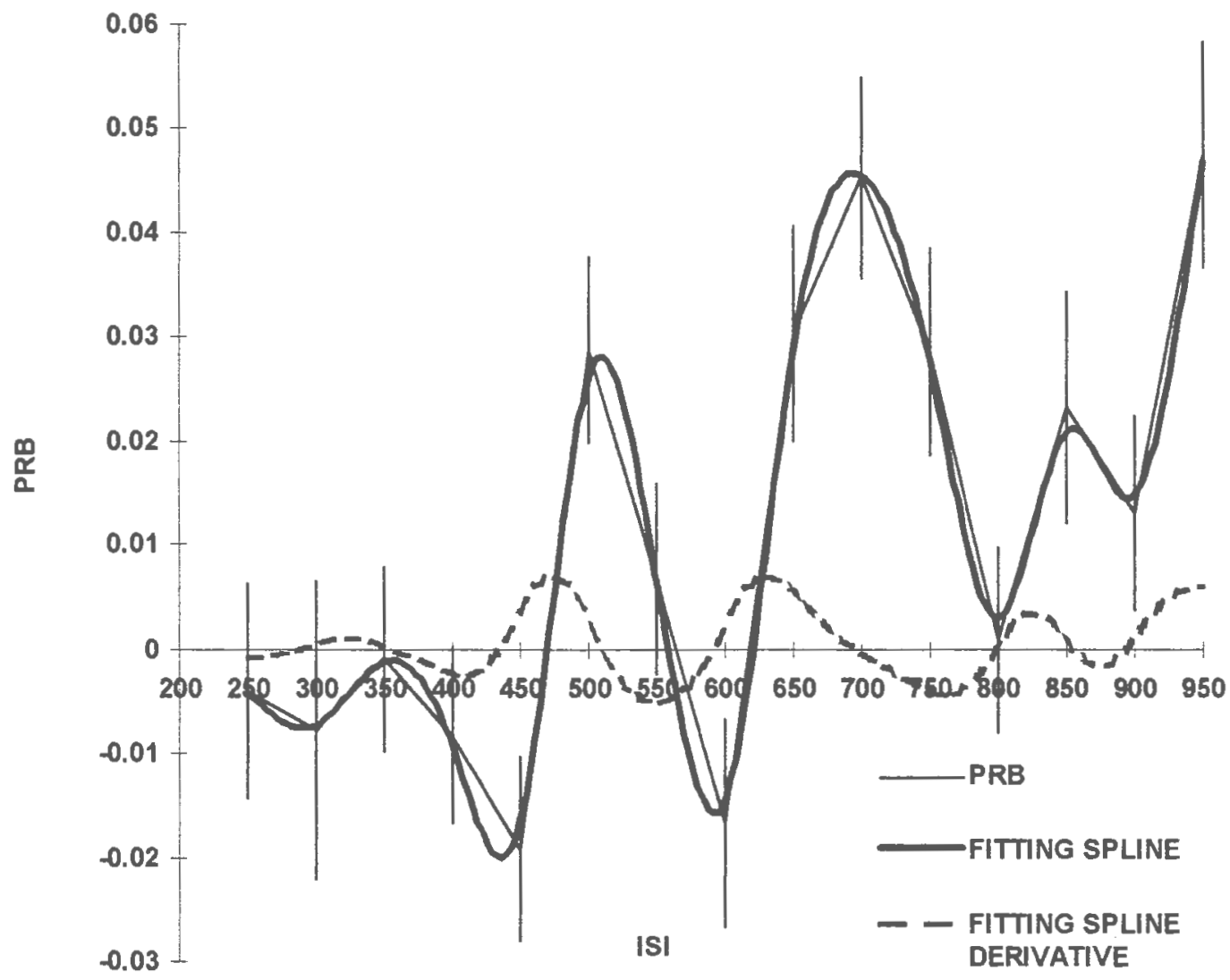

Figure XIV.25 Oscillator Signature (Sub.35)

PRB - Percent Residual Bias

ISI - Interstimulus Interval 


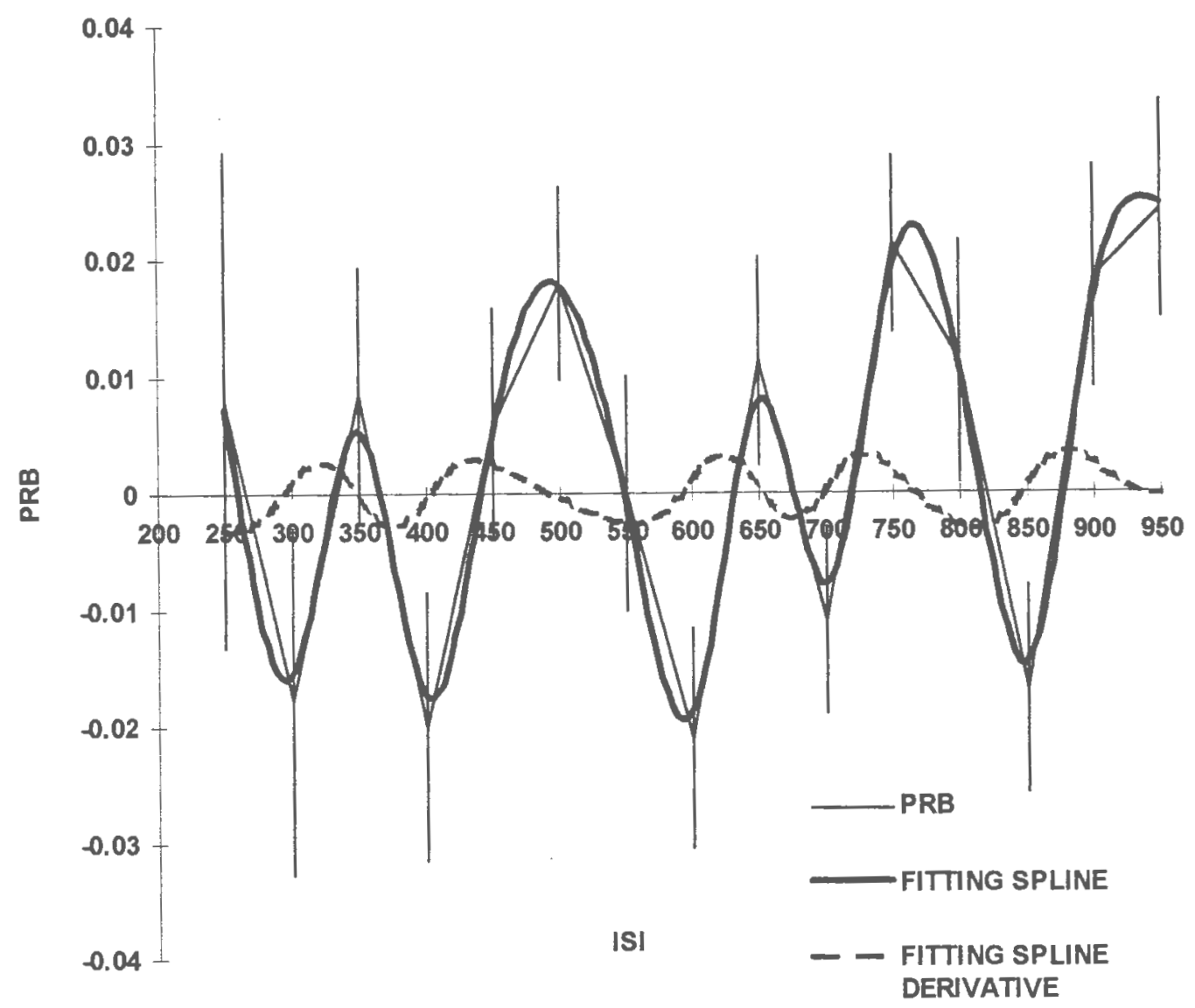

Figure XIV.26 Oscillator Signature (Sub.36)

PRB - Percent Residual Bias

ISI - Interstimulus Interval 


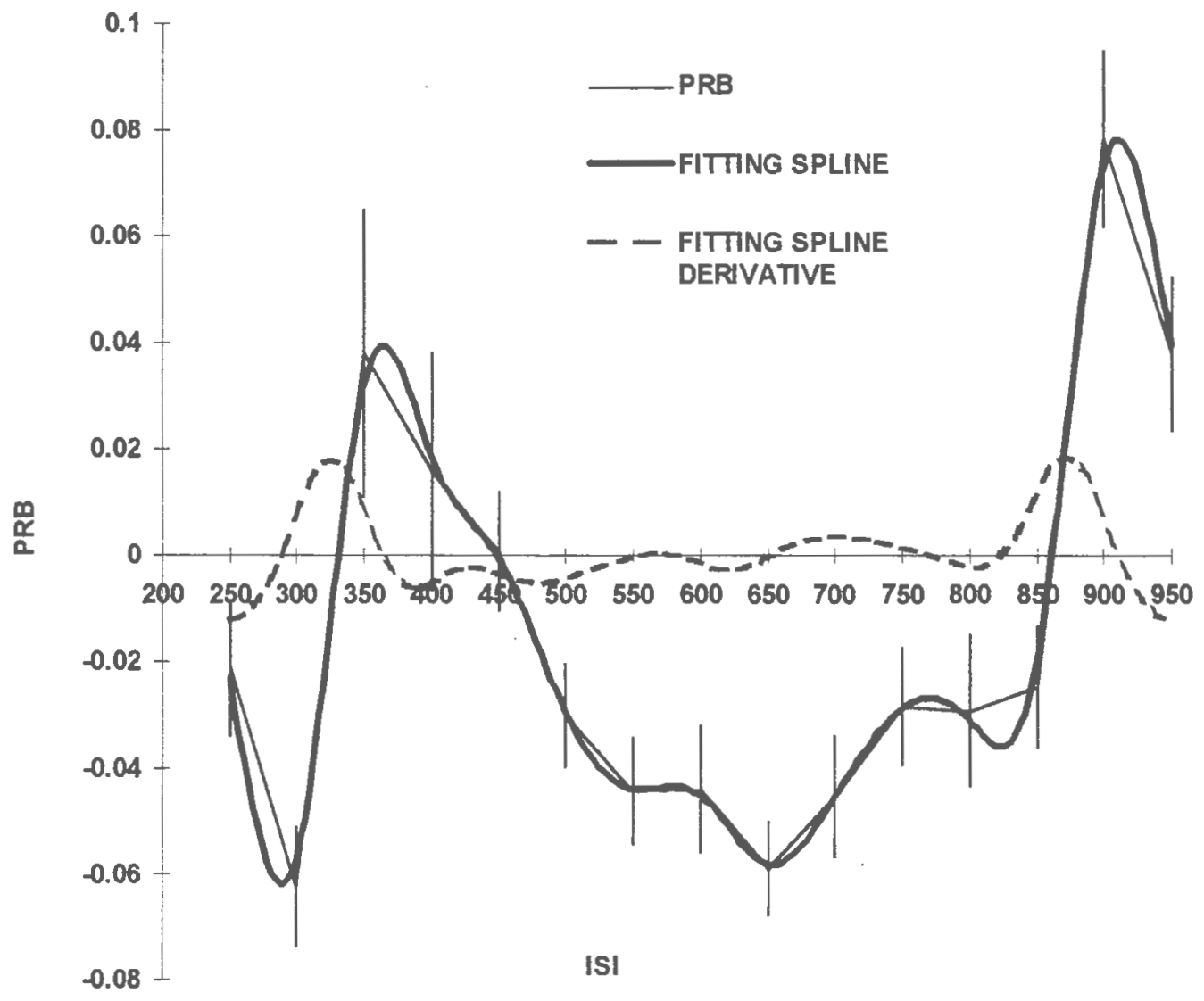

Figure XIV.27 Oscillator Signature (Sub.37)

PRB - Percent Residual Bias

ISI - Interstimulus Interval 


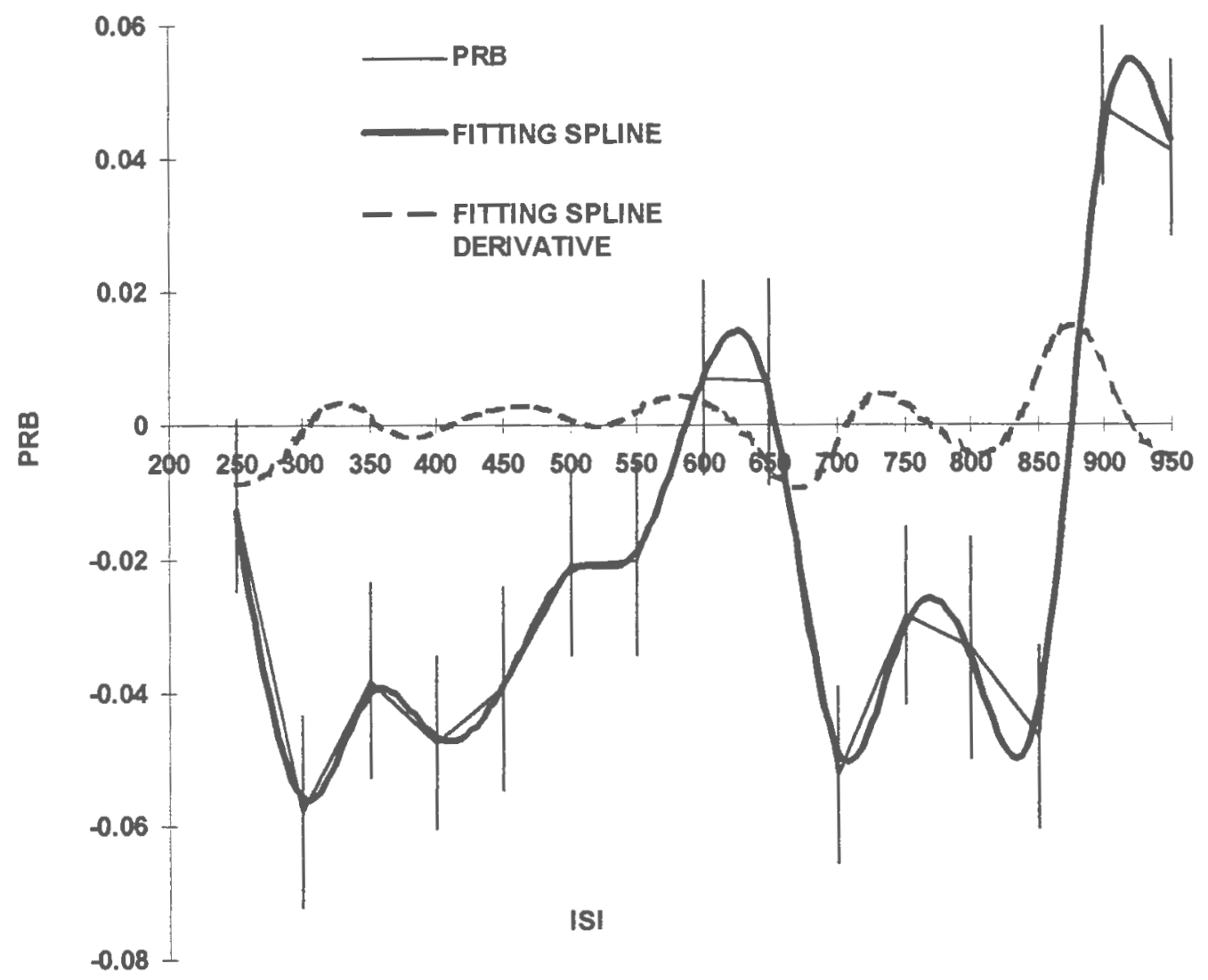

Figure XIV.28 Oscillator Signature (Sub.38)

PRB - Percent Residual Bias

ISI - Interstimulus Interval 


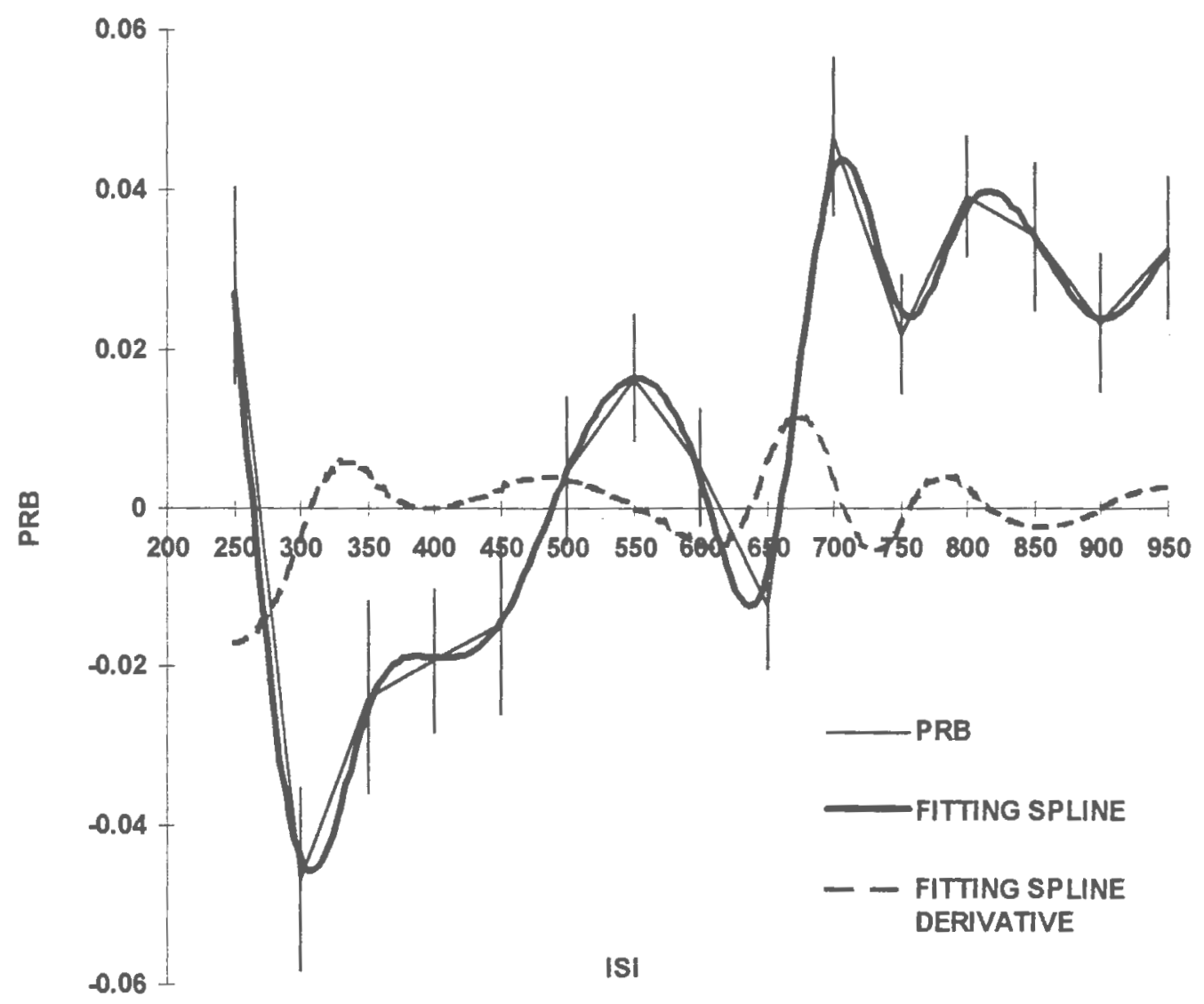

Figure XIV.29 Oscillator Signature (Sub.39)

PRB - Percent Residual Bias

ISI - Interstimulus Interval 


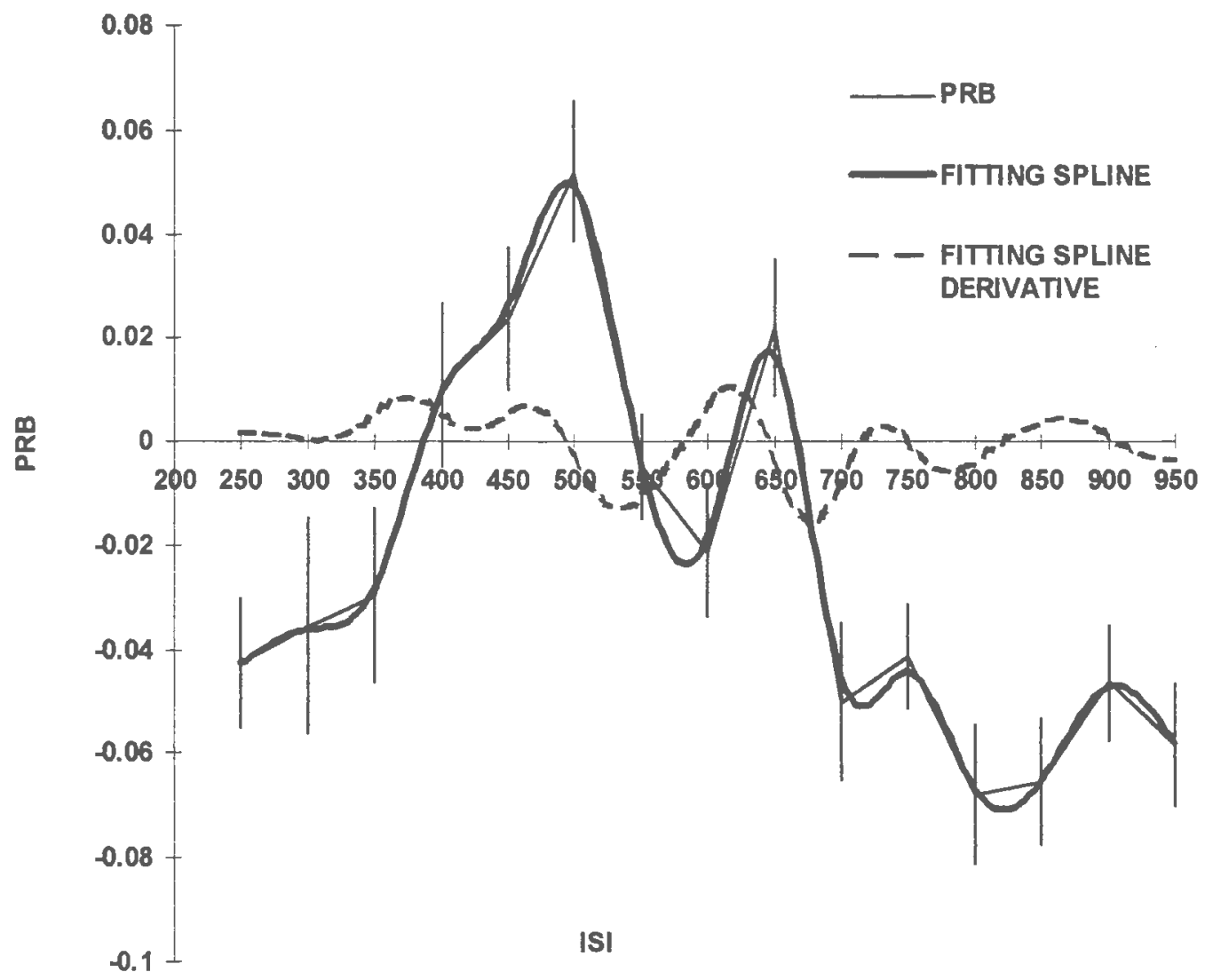

Figure XIV.30 Oscillator Signature (Sub.40)

PRB - Percent Residual Bias

ISI - Interstimulus Interval 


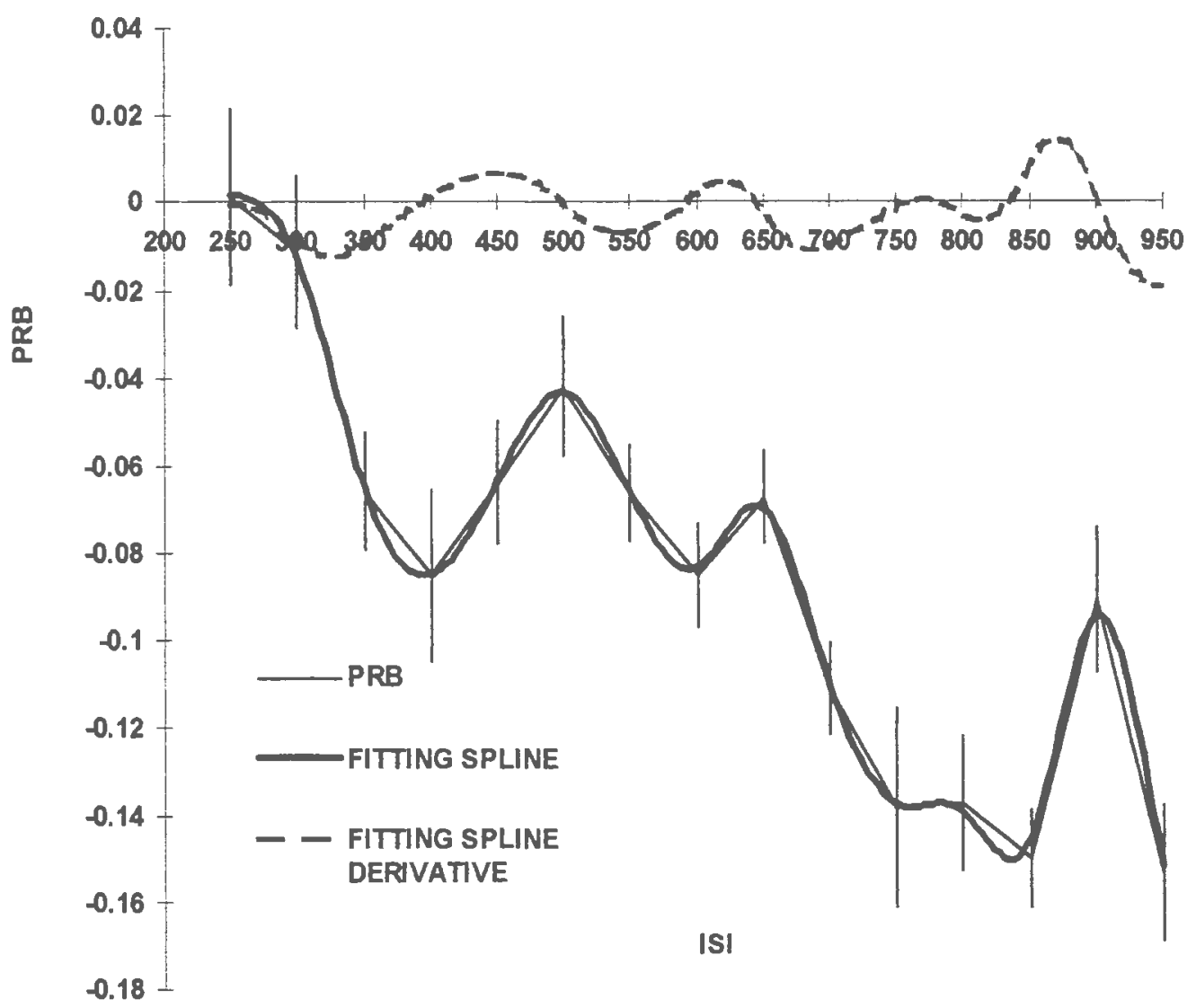

Figure XIV.31 Oscillator Signature (Sub.41)

PRB - Percent Residual Bias

ISI - Interstimulus Interval 


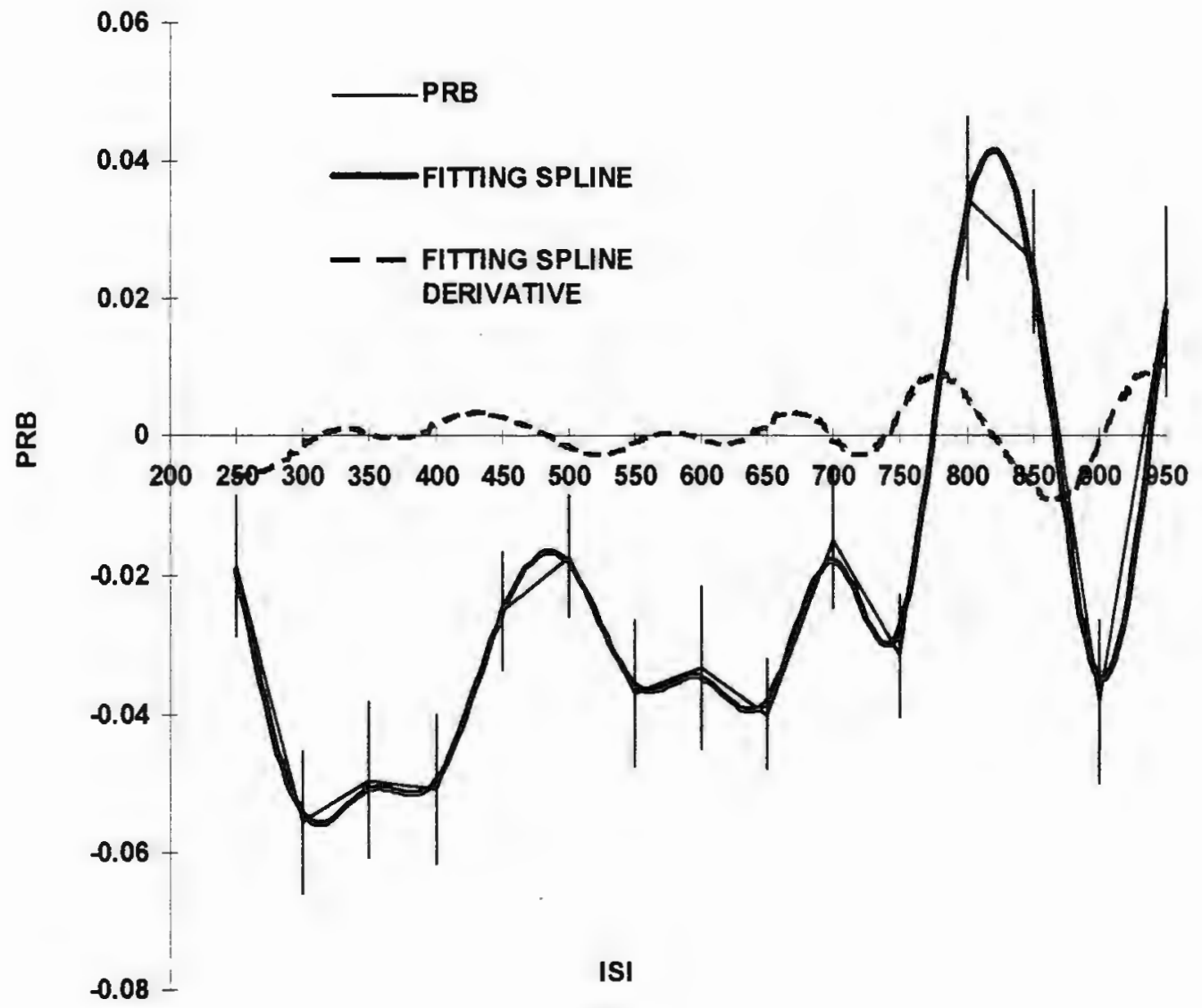

Figure XIV.32 Oscillator Signature (Sub.42)

PRB - Percent Residual Bias

ISI - Interstimulus Interval 


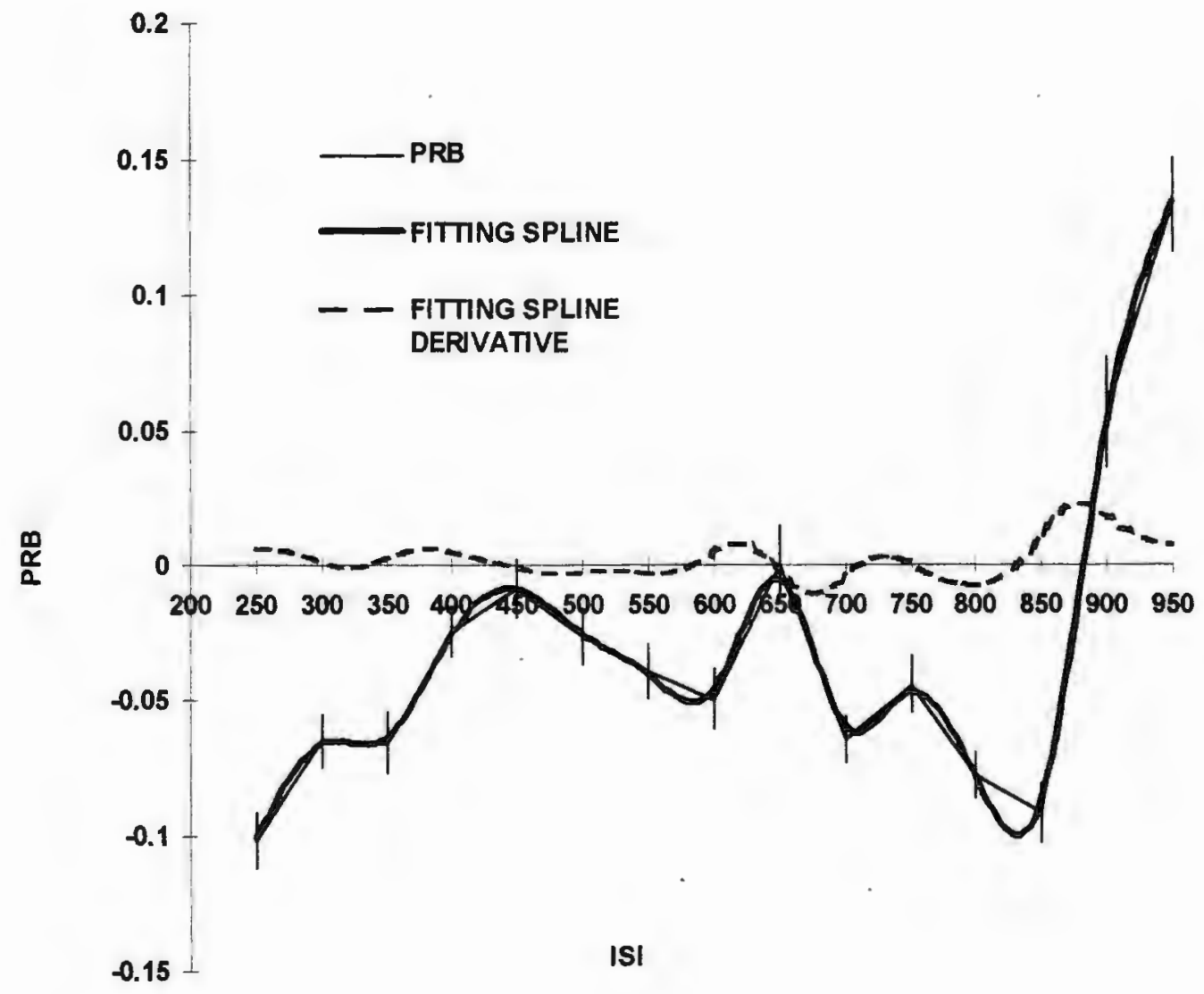

Figure XIV.33 Oscillator Signature (Sub.43)

PRB - Percent Residual Bias

ISI - Interstimulus Interval 


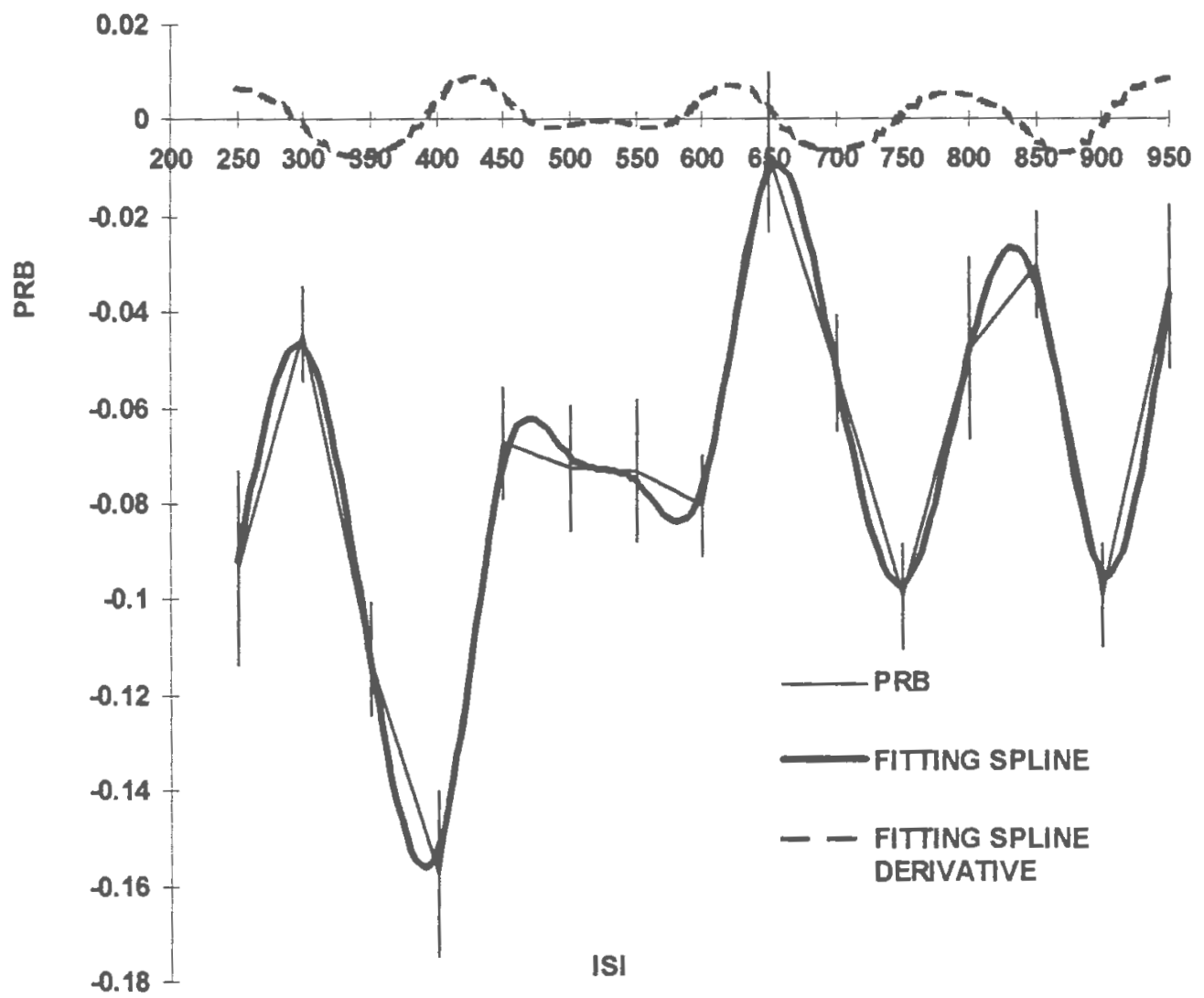

Figure XIV.34 Oscillator Signature (Sub.44)

PRB - Percent Residual Bias

ISI - Interstimulus Interval 


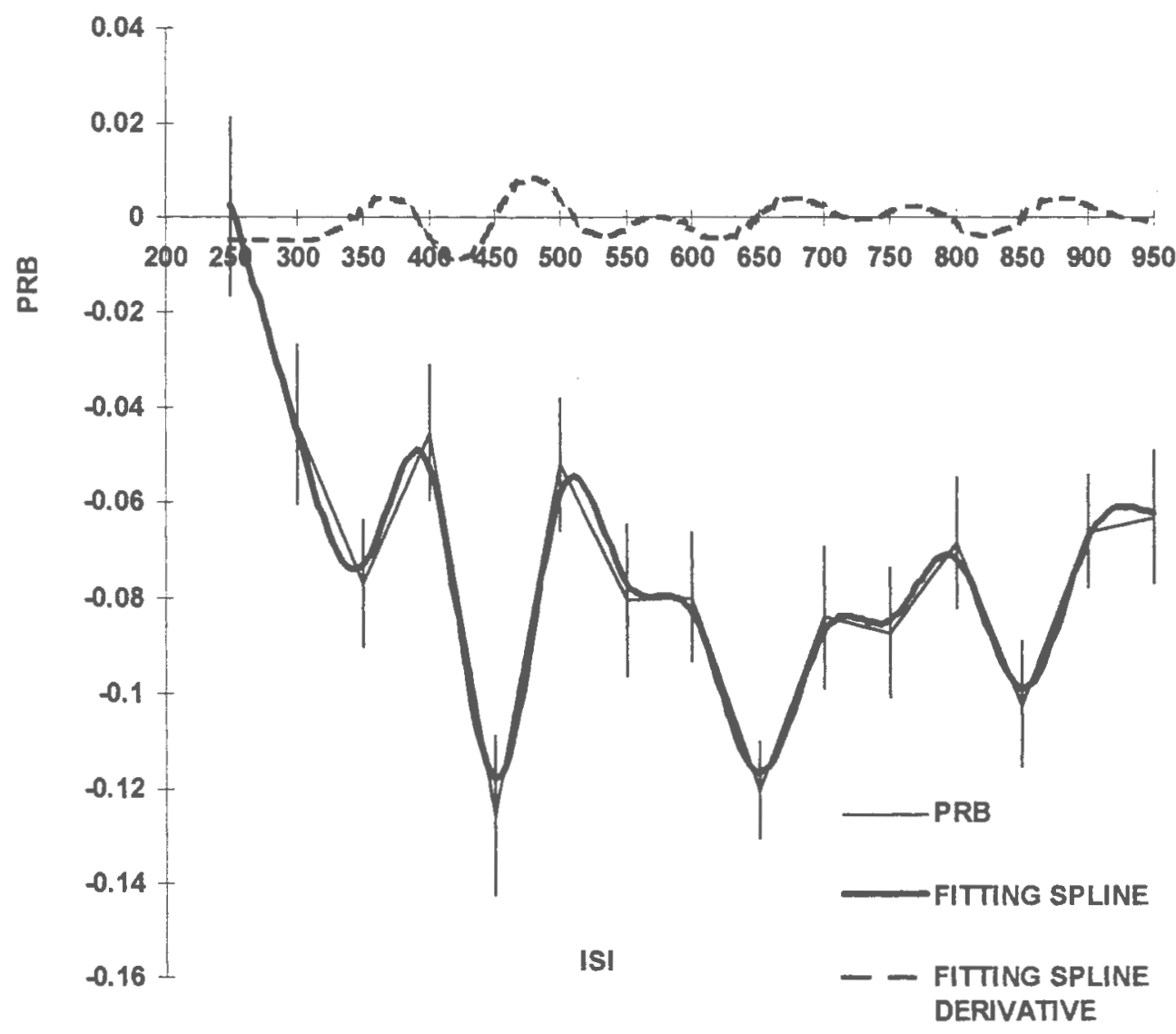

Figure XIV.35 Oscillator Signature (Sub.45)

PRB - Percent Residual Bias

ISI - Interstimulus Interval 


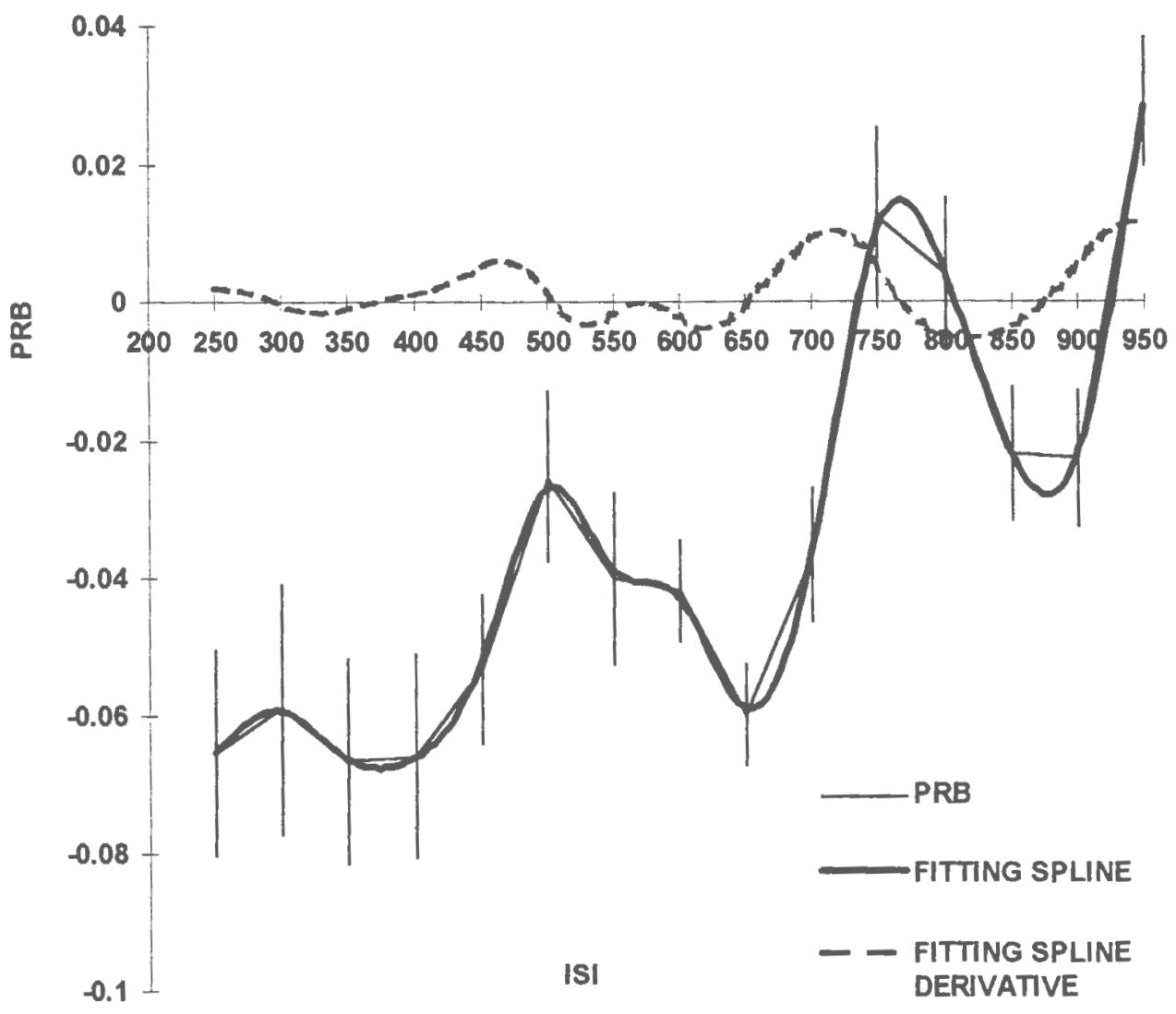

Figure XIV.36 Oscillator Signature (Sub.47)

PRB - Percent Residual Bias

ISI - Interstimulus Interval 


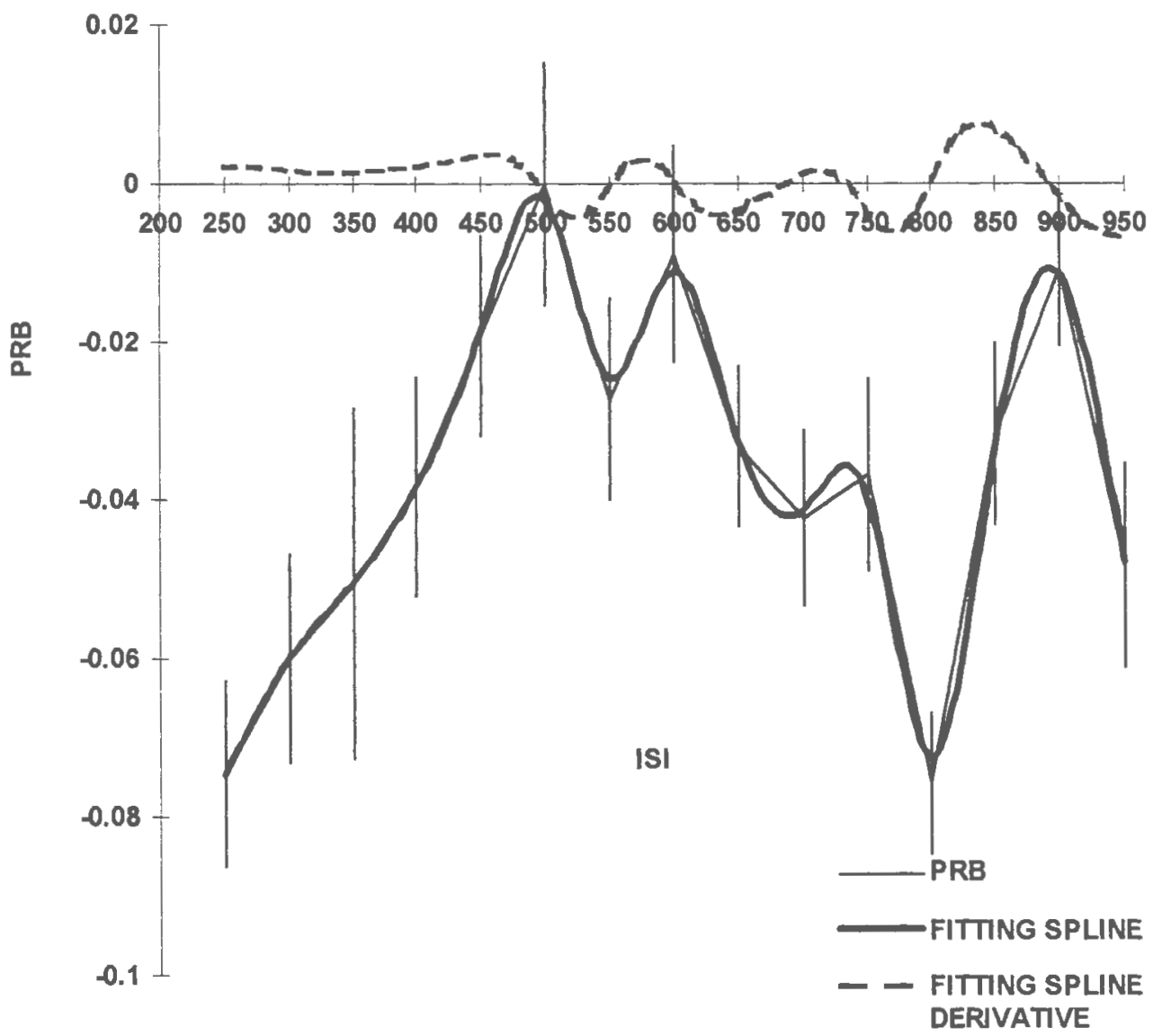

Figure XIV.37 Oscillator Signature (Sub.48)

PRB - Percent Residual Bias

ISI - Interstimulus Interval 


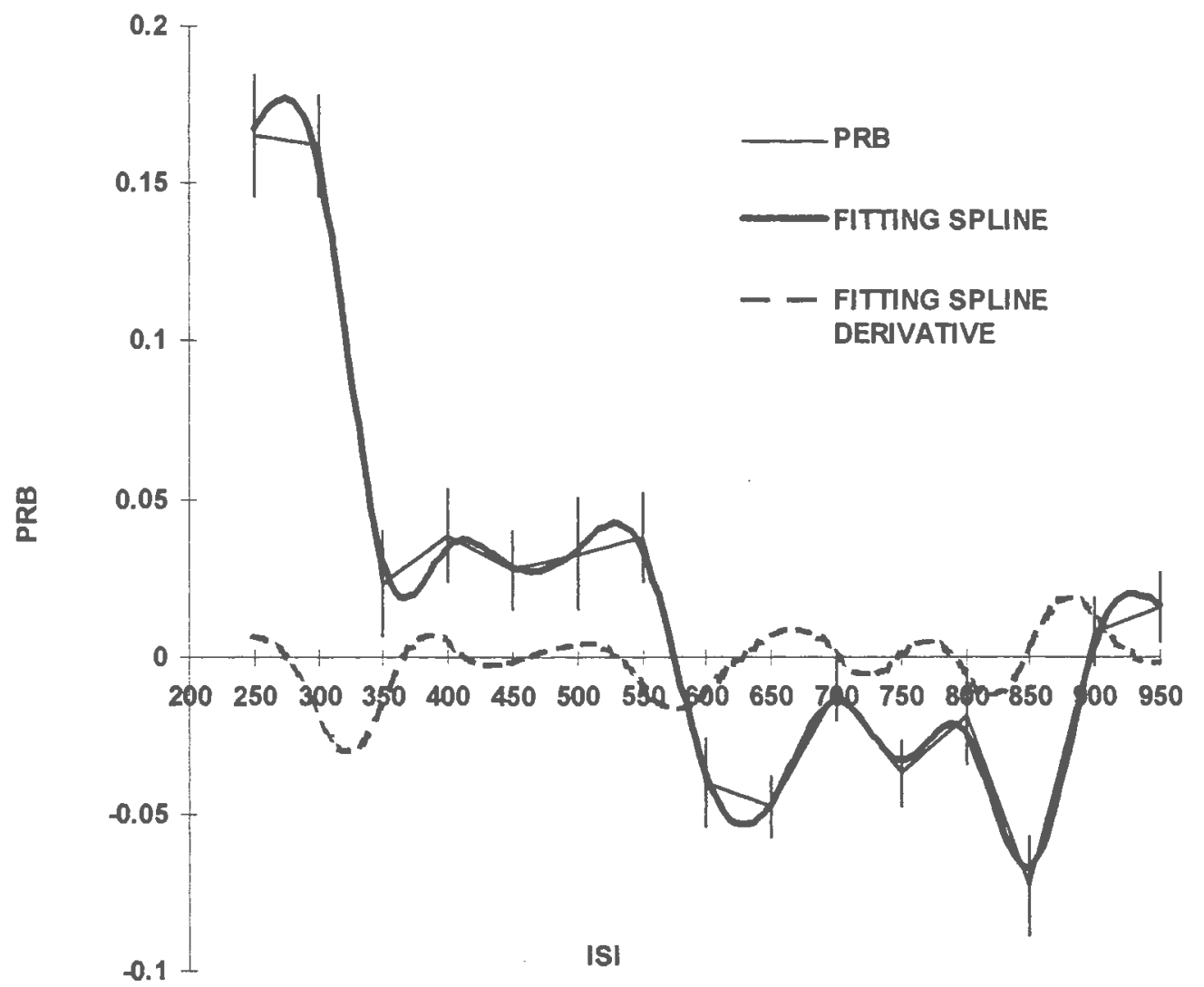

Figure XIV.38 Oscillator Signature (Sub.49)

PRB - Percent Residual Bias

ISI - Interstimulus Interval 


\section{APPENDIX XV}

Averaged first derivatives for each subject using

$$
1,3,6,9 \text {, and } 15 \text { random points }
$$

Subject

ID

Random points used

\begin{tabular}{|c|c|c|c|c|c|}
\hline 10 & $\frac{1}{-0.00137}$ & $\frac{3}{-0.00073}$ & $\frac{6}{-0.00062}$ & $\frac{9}{-0.00053}$ & $\frac{15}{-0.00035}$ \\
\hline 11 & 0.00092 & 0.00037 & 0.00005 & 0.00005 & 0.00004 \\
\hline 12 & 0.00016 & -0.00023 & -0.00032 & -0.00038 & -0.00018 \\
\hline 13 & -0.00048 & 0.00027 & 0.00011 & 0.00022 & -0.00008 \\
\hline 15 & -0.00049 & -0.00069 & -0.00133 & -0.00069 & -0.00080 \\
\hline 16 & -0.00045 & 0.00063 & -0.00016 & -0.00025 & -0.00003 \\
\hline 17 & -0.00004 & -0.00028 & 0.00017 & -0.00013 & -0.00009 \\
\hline 18 & -0.00115 & -0.00023 & 0.00003 & -0.00003 & -0.00006 \\
\hline 19 & 0.00043 & -0.00008 & 0.00009 & 0.00009 & 0.00023 \\
\hline 20 & -0.00018 & 0.00054 & 0.00063 & 0.00065 & 0.00031 \\
\hline 21 & 0.00023 & 0.00043 & 0.00028 & 0.00010 & -0.00022 \\
\hline 22 & 0.00003 & 0.00013 & 0.00039 & -0.00002 & -0.00018 \\
\hline 23 & 0.00038 & -0.00121 & -0.00025 & -0.00028 & -0.00026 \\
\hline 24 & -0.00054 & -0.00057 & -0.00017 & -0.00038 & -0.00031 \\
\hline 25 & 0.00064 & 0.00035 & -0.00002 & -0.00024 & -0.00022 \\
\hline 26 & 0.00088 & 0.00021 & 0.00042 & 0.00030 & 0.00011 \\
\hline 27 & -0.00043 & -0.00029 & -0.00020 & -0.00013 & -0.00008 \\
\hline 28 & 0.00158 & 0.00077 & 0.00102 & 0.00072 & 0.00047 \\
\hline 29 & 0.00199 & -0.00028 & -0.00002 & 0.00012 & -0.00029 \\
\hline 30 & 0.00054 & 0.00092 & 0.00001 & 0.00013 & 0.00015 \\
\hline 31 & 0.00075 & 0.00004 & -0.00026 & -0.00001 & -0.00011 \\
\hline 32 & 0.00050 & -0.00007 & -0.00007 & -0.00008 & -0.00004 \\
\hline 33 & -0.00020 & -0.00013 & -0.00014 & 0.00020 & -0.00004 \\
\hline 34 & 0.00189 & 0.00142 & 0.00058 & 0.00037 & 0.00017 \\
\hline 35 & 0.00012 & -0.00005 & 0.00015 & 0.00030 & 0.00032 \\
\hline 36 & 0.00048 & 0.00008 & 0.00005 & 0.00003 & 0.00009 \\
\hline 37 & 0.00012 & -0.00031 & -0.00008 & -0.00017 & 0.00008 \\
\hline 38 & 0.00039 & 0.00021 & 0.00020 & 0.00024 & 0.00011 \\
\hline 39 & -0.00057 & -0.00045 & 0.00007 & -0.00010 & -0.00015 \\
\hline 40 & 0.00017 & -0.00010 & -0.00028 & -0.00024 & -0.00021 \\
\hline 41 & -0.00009 & -0.00085 & -0.00004 & 0.00009 & 0.00008 \\
\hline 42 & 0.00026 & -0.00049 & -0.00010 & -0.00009 & -0.00014 \\
\hline 43 & 0.00307 & 0.00046 & 0.00052 & 0.00051 & 0.00037 \\
\hline 44 & 0.00136 & 0.00098 & 0.00109 & 0.00048 & 0.00058 \\
\hline 45 & -0.00073 & -0.00049 & -0.00021 & -0.00030 & -0.00016 \\
\hline 47 & 0.00063 & 0.00049 & 0.00053 & 0.00055 & 0.00030 \\
\hline 48 & 0.00025 & 0.00029 & 0.00001 & -0.00003 & 0.00005 \\
\hline 49 & -0.00108 & -0.00016 & -0.00008 & 0.00006 & 0.00017 \\
\hline
\end{tabular}




\section{APPENDIX XVI}

Variability of Raw Data for Preferred Muscular Relaxation

Time Test

\begin{tabular}{|c|c|c|c|c|}
\hline $\begin{array}{c}\text { Subject } \\
\text { ID }\end{array}$ & Mean & Median & $\begin{array}{l}\text { Standard } \\
\text { Deviation }\end{array}$ & $\begin{array}{l}\text { Percent } \\
\text { error }\end{array}$ \\
\hline 10 & 0.63600 & 0.62400 & 0.03025 & $5 \%$ \\
\hline 11 & 0.60800 & 0.60800 & 0.04131 & $7 \%$ \\
\hline 12 & 0.60600 & 0.62000 & 0.03774 & $6 \div$ \\
\hline 13 & 0.42200 & 0.40800 & 0.08349 & $20 \%$ \\
\hline 15 & 0.40480 & 0.40800 & 0.02806 & $7 \%$ \\
\hline 16 & 0.33400 & 0.33600 & 0.01007 & $3 \%$ \\
\hline 17 & 0.65867 & 0.66400 & 0.01665 & $3 \%$ \\
\hline 18 & 0.30080 & 0.30400 & 0.00716 & $2 \%$ \\
\hline 19 & 0.70133 & 0.71200 & 0.05676 & $8 \%$ \\
\hline 20 & 0.44160 & 0.44000 & 0.02220 & $5 \%$ \\
\hline 21 & 0.44200 & 0.44400 & 0.03659 & $8 \%$ \\
\hline 22 & 0.51600 & 0.51200 & 0.04165 & $8 \%$ \\
\hline 23 & 0.43200 & 0.43200 & 0.04440 & $10 \%$ \\
\hline 24 & 0.52640 & 0.53600 & 0.02907 & $6 \%$ \\
\hline 25 & 0.54400 & 0.60000 & 0.08890 & $16 \%$ \\
\hline 26 & 0.62400 & 0.63200 & 0.03622 & $6 \%$ \\
\hline 28 & 0.49600 & 0.50400 & 0.07505 & $15 \%$ \\
\hline 29 & 0.61400 & 0.61200 & 0.03659 & $6 \%$ \\
\hline 30 & 0.79400 & 0.80800 & 0.04727 & $6 \%$ \\
\hline 31 & 0.47067 & 0.47200 & 0.02551 & $5 \%$ \\
\hline 32 & 0.61333 & 0.63200 & 0.09341 & $15 \%$ \\
\hline 33 & 0.74800 & 0.74400 & 0.01386 & $2 \frac{\circ}{0}$ \\
\hline 34 & 0.64667 & 0.63600 & 0.09592 & $15 \%$ \\
\hline 35 & 0.72340 & 0.75500 & 0.05088 & $7 \%$ \\
\hline 36 & 0.55600 & 0.54400 & 0.06677 & $12 \%$ \\
\hline 37 & 0.71520 & 0.70400 & 0.03469 & $5 \%$ \\
\hline 38 & 0.67800 & 0.71600 & 0.11131 & $16 \%$ \\
\hline 39 & 0.47200 & 0.46800 & 0.03318 & $7 \%$ \\
\hline 40 & 0.96260 & 0.99900 & 0.07754 & $8 \%$ \\
\hline 41 & 0.68075 & 0.67600 & 0.03752 & $6 \%$ \\
\hline 42 & 0.58533 & 0.56800 & 0.05996 & 10 음 \\
\hline 43 & 0.55867 & 0.56400 & 0.12844 & $23 \%$ \\
\hline 44 & 0.56000 & 0.57600 & 0.08764 & $16 \%$ \\
\hline 45 & 0.55886 & 0.54400 & 0.05415 & $10 \%$ \\
\hline 46 & 0.40720 & 0.42400 & 0.04291 & $11 \%$ \\
\hline 47 & 0.58044 & 0.59200 & 0.02746 & $5 \%$ \\
\hline 48 & 0.53440 & 0.52000 & 0.02427 & $5 \%$ \\
\hline 49 & 0.98160 & 0.99900 & 0.03891 & $4 \%$ \\
\hline
\end{tabular}


APPENDIX XVII

Variability of Raw Data for Fast Muscular Relaxation Time Test

\begin{tabular}{|c|c|c|c|c|}
\hline Subject ID & Mean & Median & $\begin{array}{c}\text { Standard } \\
\text { Deviation }\end{array}$ & Percent error \\
\hline 10 & 0.35200 & 0.35200 & 0.03394 & 108 \\
\hline 11 & 0.37333 & 0.38400 & 0.01848 & 58 \\
\hline 12 & 0.37600 & 0.38400 & 0.01386 & 48 \\
\hline 13 & 0.31800 & 0.32000 & 0.01649 & 58 \\
\hline 15 & 0.30800 & 0.30800 & 0.01697 & 68 \\
\hline 16 & 0.30133 & 0.30400 & 0.02013 & 78 \\
\hline 17 & 0.38560 & 0.37600 & 0.03459 & 98 \\
\hline 18 & 0.25800 & 0.26000 & 0.00766 & 38 \\
\hline 19 & 0.40800 & 0.43200 & 0.12573 & $31 z$ \\
\hline 20 & 0.31000 & 0.31200 & 0.04099 & 138 \\
\hline 22 & 0.34800 & 0.34400 & 0.01532 & 48 \\
\hline 23 & 0.38240 & 0.37600 & 0.04210 & $11 \%$ \\
\hline 24 & 0.37200 & 0.37600 & 0.00800 & $2 \frac{8}{3}$ \\
\hline 25 & 0.53600 & 0.52800 & 0.02653 & $5 q$ \\
\hline 26 & 0.31360 & 0.31200 & 0.01043 & $3 \delta$ \\
\hline 27 & 0.35040 & 0.36000 & 0.02851 & 88 \\
\hline 28 & 0.43000 & 0.42800 & 0.03479 & 88 \\
\hline 29 & 0.43200 & 0.43200 & 0.04800 & $11 \%$ \\
\hline 30 & 0.50400 & 0.52800 & 0.05987 & $12 \delta$ \\
\hline 31 & 0.31480 & 0.32800 & 0.05161 & 168 \\
\hline 32 & 0.48160 & 0.50400 & 0.05166 & 118 \\
\hline 33 & 0.49800 & 0.50800 & 0.03479 & 78 \\
\hline 34 & 0.56000 & 0.56800 & 0.07673 & 148 \\
\hline 35 & 0.36000 & 0.35200 & 0.01876 & 58 \\
\hline 36 & 0.40600 & 0.40000 & 0.02389 & 68 \\
\hline 37 & 0.42933 & 0.40800 & 0.03695 & 98 \\
\hline 38 & 0.42400 & 0.39600 & 0.07005 & $17 \%$ \\
\hline 39 & 0.39600 & 0.39600 & 0.01665 & 48 \\
\hline 40 & 0.65600 & 0.62400 & 0.06248 & 108 \\
\hline 41 & 0.37867 & 0.39200 & 0.06897 & $18 \varepsilon$ \\
\hline 42 & 0.38800 & 0.39200 & 0.06959 & 188 \\
\hline 43 & 0.44800 & 0.44400 & 0.04572 & 108 \\
\hline 44 & 0.39400 & 0.40400 & 0.04099 & $10 \%$ \\
\hline 45 & 0.40200 & 0.41200 & 0.03600 & 98 \\
\hline 46 & 0.54533 & 0.55600 & 0.03867 & 78 \\
\hline 47 & 0.50400 & 0.51600 & 0.04183 & 88 \\
\hline 48 & 0.37800 & 0.37200 & 0.02298 & 68 \\
\hline 49 & 0.49067 & 0.49600 & 0.08812 & 188 \\
\hline
\end{tabular}


APPENDIX XVIII

Variability of Raw Data for Critical Fusion Flicker Threshold test

\begin{tabular}{|c|c|c|c|c|}
\hline Subject ID & Mean & Median & $\begin{array}{c}\text { Standard } \\
\text { Deviation } \\
\end{array}$ & $\begin{array}{c}\text { Percent } \\
\text { error }\end{array}$ \\
\hline 10 & 2032.1 & 2004.5 & 69.4 & $3 \frac{0}{0}$ \\
\hline 11 & 2095.7 & 2106.0 & 67.1 & $3 \frac{\circ}{0}$ \\
\hline 12 & 2436.1 & 2427.0 & 39.5 & $2 \%$ \\
\hline 13 & 2352.6 & 2359.5 & 19.4 & $1 \%$ \\
\hline 15 & 1822.0 & 1825.5 & 39.2 & $2 \%$ \\
\hline 16 & 2235.6 & 2238.0 & 51.4 & $2 \%$ \\
\hline 17 & 2080.4 & 2093.5 & 45.7 & $2 \%$ \\
\hline 18 & 2255.8 & 2243.0 & 44.3 & $2 \%$ \\
\hline 19 & 2061.8 & 2060.0 & 33.3 & $2 \%$ \\
\hline 20 & 2245.0 & 2224.5 & 73.2 & $3 \%$ \\
\hline 21 & 2125.9 & 2130.5 & 55.5 & $3 \%$ \\
\hline 22 & 2425.4 & 2437.0 & 37.9 & $2 \%$ \\
\hline 23 & 2106.3 & 2102.5 & 35.9 & $2 \%$ \\
\hline 24 & 2074.0 & 2066.0 & 56.1 & $3 \%$ \\
\hline 25 & 2274.4 & 2282.0 & 28.2 & $1 \%$ \\
\hline 26 & 2187.4 & 2196.5 & 48.4 & $2 \%$ \\
\hline 27 & 2232.8 & 2228.0 & 50.5 & $2 \%$ \\
\hline 28 & 2341.9 & 2341.5 & 36.2 & $2 \%$ \\
\hline 29 & 2142.2 & 2133.0 & 49.1 & $2 \%$ \\
\hline 32 & 2349.9 & 2347.5 & 50.3 & $2 \%$ \\
\hline 33 & 2078.4 & 2069.5 & 46.8 & $2 \frac{\circ}{0}$ \\
\hline 34 & 2203.0 & 2200.0 & 9.7 & $0 \%$ \\
\hline 35 & 2286.0 & 2289.5 & 37.4 & $2 \%$ \\
\hline 36 & 2428.3 & 2433.5 & 37.0 & $2 \%$ \\
\hline 37 & 2403.4 & 2414.5 & 36.2 & $2 \%$ \\
\hline 38 & 2284.9 & 2285.5 & 47.9 & $2 \%$ \\
\hline 39 & 2371.7 & 2365.0 & 27.9 & $1 \%$ \\
\hline 41 & 2093.8 & 2095.5 & 62.3 & $3 \%$ \\
\hline 42 & 2312.8 & 2323.0 & 22.7 & $1 \%$ \\
\hline 43 & 2228.3 & 2227.5 & 27.3 & $1 \%$ \\
\hline 41 & 2330.1 & 2335.5 & 41.0 & $2 \%$ \\
\hline 45 & 2164.3 & 2170.0 & 35.1 & $2 \%$ \\
\hline 46 & 2274.5 & 2254.0 & 46.4 & $2 \%$ \\
\hline 47 & 2034.8 & 2043.0 & 44.1 & $2 \%$ \\
\hline 48 & 2117.1 & 2099.5 & 42.6 & $2 \frac{\circ}{0}$ \\
\hline 49 & 2266.8 & 2262.5 & 51.4 & $2 \%$ \\
\hline
\end{tabular}


Appendix XIX

An example of data acquisition function for Fast Muscular Relaxation Time.

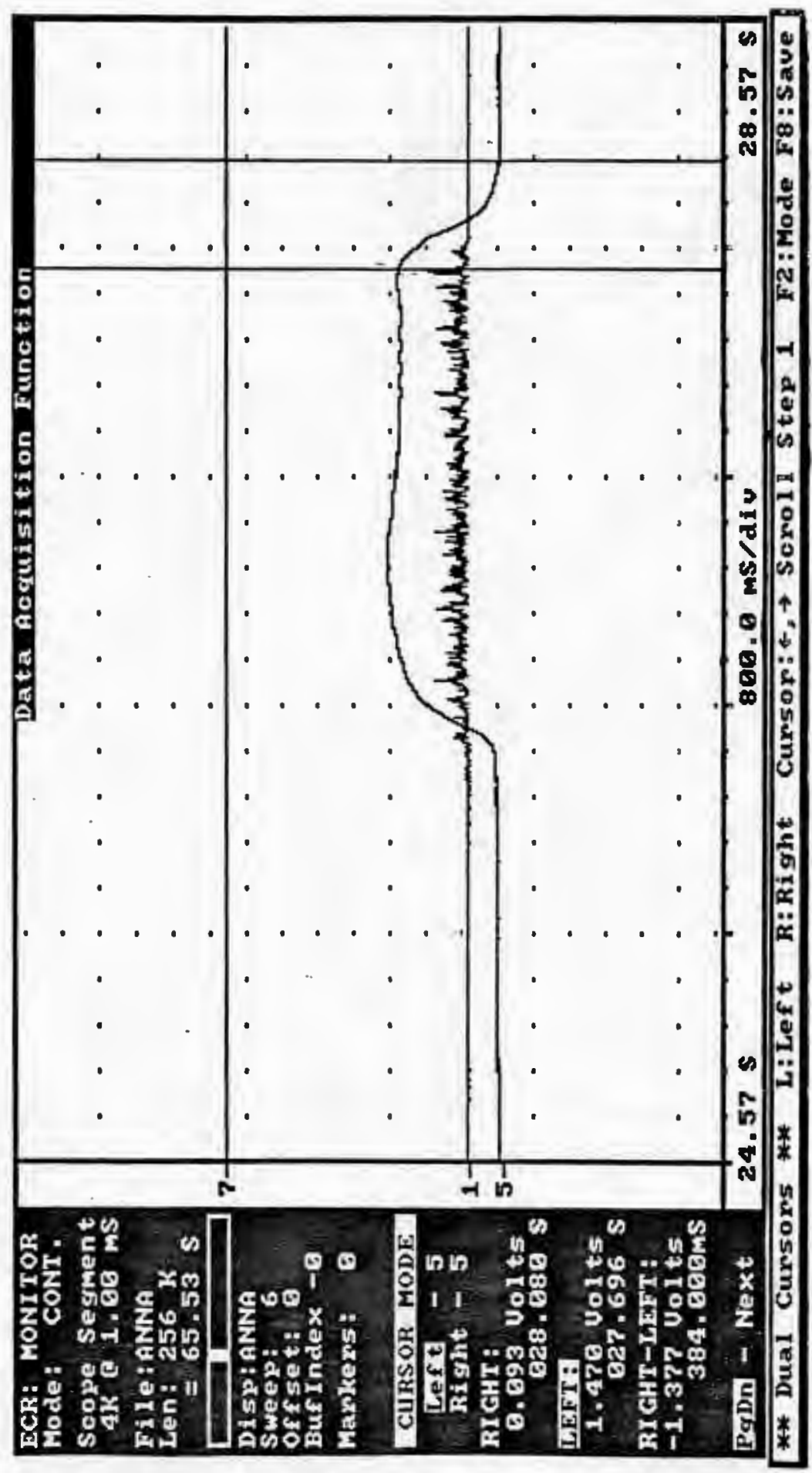


Appendix XX

An example of data acquisition function for Preferred Muscular Relaxation Time.

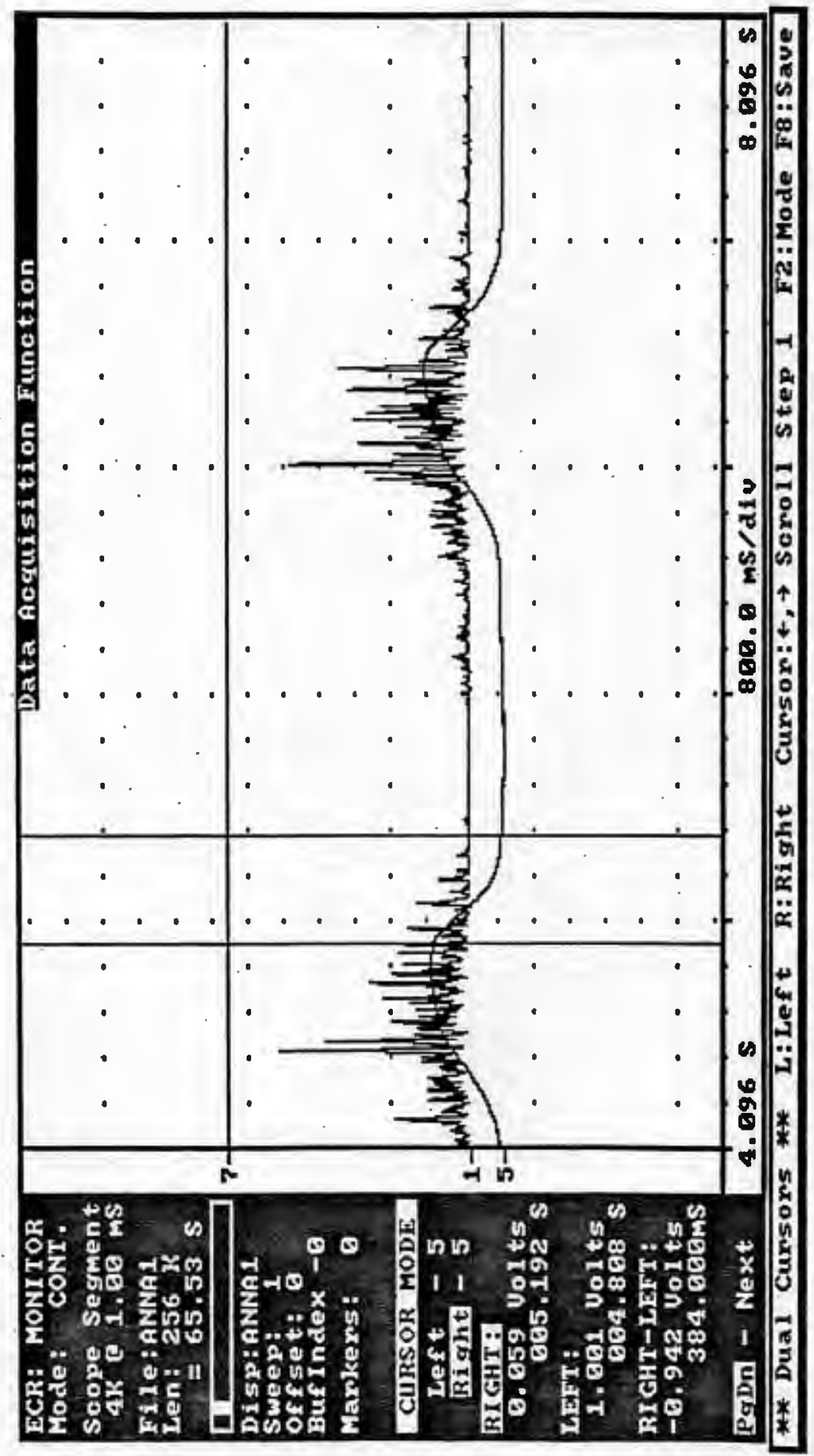




\section{BIBLIOGRAPHY}

Akimova, M.P. (1974). Development of speedy motion in regards to individual characteristic such as force and lability of the nervous system. In B.Merlin (Ed.), Psychophysiological Peculiarities of Professional Growth, Moscow: Soviet Russia, 23-57.

Ali, M.R. and Amir, T. (1989). Effects of fasting on visual flicker fusion. Perceptual and Motor skills, $69(2), 627-631$.

Azhichshenko, A., and Vysochin, U. (1985). Coordination of movements and muscular relaxation in young gymnasts. Physical Training Advancement in Young and Adult Athletes, Leningrad, Lesgaft Institute, 3-15.

Bartley, S. and Simonson, E. (1976). Use of visual methods for measurement of general fatigue. In Simonson, E. and Queiser P., (Eds.), Psychological Aspects and Physiological Correlates of Work and Fatigue, Springfield, IL: Thomas, 176-190.

Baschera, P. and Grandjean, E. (1979). Effects of repetitive tasks with different degrees of difficulty on 
critical fusion frequency (CFF) and subjective state. Ergonomics, $22(4), 377-385$.

Benson H. (1989). The Relaxation Response, N.Y.

Benson, H. (1990). Three case reports of the metabolic and electroencephalographic changes during advanced Buddhist meditation techniques. Behavioral Medicine, 16, 2,90-95.

Boff, K.R., Kaufman, L., and Thomas, J.P. (Eds), (1986). Handbook of Perception and Human Performance. John Willey and Sons, New-York.

Brand, N., Wijk, A., and Hijman R., (1990). In Drenth, P., Sergeant, J., and Takens R. (Eds), European Perspectives in Psychology. Vol.2. John Willey and Sons, New-York.

Brand, N. and Jolles, J. (1985). Compatibility effects in initiation time and movement time: a test to assess Motor dysfunctions. In J.A. Sergeant \& A.F. Kalverboer (Eds.), Proceedings of the Congress 'Hyperactivity as a scientific Challenge'. Groningen.

Brand, N., Wijk, A., and Hijman, R (1990). Motor planning in neurological and psychiatric patients. In 
Drenth, P., Sergeant, J., and Takens R. (Eds), European Perspectives in Psychology, Vol.2. John willey and Sons, New-York.

Byrne, D.G., (1976). Choice reaction times in depressive states. British Journal of Social and Clinical Psychology, 15, 149-156.

Cattell, R.B. (1972). The interrelation of Pavlov's typology, and the Arousal Concept, in replicated Trait and State Factors. In: Biological Bases of Individual Behavior. Nebylitsyn and Gray (Eds), New York, New York: Academic Press, Inc.

Collyer, C.E., Broadbent, H.A., and Church, R.M. (1990). Preferred rates of repetitive tapping are not strongly determined by physical dynamics. Paper presented at the American Psychological Society convention, June 1990.

Collyer, C.E., Broadbent, H.A., \& Church, R.M. (1992). Categorical time production: Evidence for discrete timing in motor control. Perception and Psychophysics, 51(2), 134-144.

Collyer, C.E., Broadbent, H.A., \& Church, R.M. (1994). Preferred rates of repetitive tapping and categorical time 
production. Perception and Psychophysics, 55(4), 443-453.

Debus, G., and Borgens. (1988). Two experimental approaches to specifying drug effects: Physiological and Subjective state vs. information processing. In Hindmarch I., Aufdembrinke, B., and Ott, H., (Eds), Psychopharmacology and Reaction Time. John Willey and Sons, New-York.

Donders, F.C. (1969). On the speed of mental process. In W.G. Koster (Ed.\&Trans.), Attention and Performance, Vol.2 (pp. 412-431). Amsterdam: North Holland Press. (Original work published 1869).

Elkin, D.G., (1962). Time perception and feedback principle. Voprosy Psichologii, 2, 151-155.

Evarts, E.V., Teravainen, H., and Calne, D.B. (1981). Reaction Time in Parkinson's Disease. Brain, 104, 167-186.

Eysenck, H.J. (1990). Biological dimensions of personality. In L.A. Pervin (Ed.), Handbook of Personality: Theory and Research. New York: Guilford.

Eysenck, H.J. (1987). Speed of Information Processing, Reaction Time, and the Theory of Intelligence. In Vernon, P. 
(Ed), Speed of Information Processing and Intelligence. Ablex Publishing Corporation, New-Jersey.

Fraisse P., (1963). The psychology of time. Harper and Row, New York, Evanston and London.

Frewer, L.J., and Hindmarch, I. (1988). The Effects of Time of day, Age, and Anxiety on a Choice Reaction Task. In Hindmarch, I., Aufdembrinke, B., and Ott, H. (Eds), Psychopharmacology and Reaction Time. John willey and Sons, New-York.

Gallistel, C.R.(1993). The organization of learning. First MIT Press paperback edition.

Gibbon, J. (1977). Scalar expectancy theory and Weber's law in animal timing. Psychological Review, 84, 279-325.

Gibbon, J., and Church, R.M. (1984). Sources of variance in an information processing theory of timing. In H.L. Roitblat, T.G. Bever, and H.S. Terrace (Eds.), Animal Cognition (pp.465-488). Hillsdale, NJ: Lawrence Erbaum Associates.

Glueck, B., and Stroebel, C. (1975). Biofeedback and 
meditation in the treatment of psychiatric illnesses. Biofeedback and Self-Control. Chicago, Aldine Publishing, $58-77$.

Goldstein, I. (1964a). Physiological responses in anxious women patients. Archives of General Psychiatry, 10.

Goldstein, I.(1964b). Role of muscle tension in personality theory. Psychological Bulletin, 61, 6 .

Gray, J.A. (1964). Pavlov's Typology. Mac Millan, New York.

Grozier, W.J. and Wolf, E. (1941). Flash duration and critical intensity for response to flicker. Journal of General Physiology, 24, 635-654.

Jensen, A., (1987). Individual Differences in the Hick Paradigm.In Vernon, P. (Ed), Speed of Information Processing and Intelligence. Ablex Publishing Corporation, New-Jersey.

Kelly, D.H. and Wilson, H.R.(1978). Human flicker sensitivity: two stages of retinal diffusion. Science, 202, 896-899. 
Grundstrom, R., et al. (1978). Degree of sedation obtained with various doses of diazepam and nitrazepam. Acta Pharmacologica et Toxicologica, 43(1), 13-18.

Hick, W.E. (1952). On the rate of gain of information processing. Quarterly Journal of Experimental Psychology, 4, $11-26$.

Hindmarch, I., Subhan, Z., Stoker, M. (1983). The effects of zimeldine and amitriptyline on car driving and psychomotor performance. Acta Psychiartica Scandinavica, 68 (suppl. 308), 141-146.

Hindmarch, I., Coleston, D., Kerr, J (1991). Psychopharmacological effects of pyritinol in normal volunteers. Neuropsychobiology, 24(3), 159-164.

Hoagland, H. (1933). The Physiological control of Judgments of Duration: Evidence for a Chemical Clock. Journal of General Psychology, 9, 267-287.

Holubar, J.(1969. The Sense of Time: an Electrophysiological Strudy of its Mechanism in Man. Cambridge, Mass. 
James, William. (1948). Psychology. Fine editions press, Cleveland.

Jacob, R.,G. and Chesney, M.A. (1984). Stress management for cardiovascular reactivity. Behavioral Medicine Update, 6,4 .

Keele, S.W., Pokorny, R.A., Corcos, D.M., \& Ivry R. (1985). Do perception and motor production share common timing mechanisms: A correlational analysis. Acta Psychologica, 60, 173-191.

Keele, s.w. (1987). Sequencing and timing in skilled perception and action: An overview. In A. Allport, D. Mackay, w. Prinz, \& Scheerer (Eds.), Language Perception and Production (463-487), London: Academic Press.

Keele, S.W., \& Ivry, R.I. (1987). Modular analysis of timing in motor skill. In G.H. Bower (Ed.), The Psychology of Learning and Motivation, Vol. 21, (pp. 183-228). San Diego: Academic Press, 21, 183-228.

King, D.,J., etal. (1991). A preliminary study of the effects of flosequinan on psychomotor function in healthy volunteers. International Clinical Psychopharmacology, 
$6(3), 155-168$.

Kleinknecht, R., and Donaldson D. (1975). A review of the effects of diazepam on cognitive and psychomotor performance. Journal of Nervous and Mental Disease, $161(6)$, $399-411$.

Kleinman, K. and Goldman, H. (1977). Relationship between essential hypertension and cognitive functioning II: Effects of Biofeedback training generalized to nonlaboratory environment. Psychophysiology, 14,2,192-197.

Klevak, A. and Boldirev, U. (1987). Relationship between skeletal muscular relaxation and some psychophysiological measures (1987). In Systemic Reactions of Organism and Adaptive Factors, Vysochin (Ed), Lesgaft Institute, Leningrad.

Kusnetsova, G., and Ostroumova, M., (1987). Relationship between functional condition of the neuromuscular system, and neuroendocrine and metabolic status at rest in athletes. In systemic reactions of organism and adaptive factors, Vysochin (Ed), Leningrad, Lesgaft Institute. 
Lagergren, K., and Levander, S. (1975). Effects of changes in heart rate in different body positions upon critical flicker fusion threshold and reaction time performance in patients with artificial pacemakers. Journal of Psychiatric Research, 12(4), 257-264.

Leigh, G. (1982). The combined effects of alcohol consumption and cigarette smoking on critical flicker frequency. Addictive Behaviors, 7, 251-259.

MacNab, M., Foltz, E., Sweitzer, J. (1985). Evaluation of signal detection theory on the effects of psychotropic drugs on critical flicker-fusion frequency in normal subjects. Psychopharmacology, 85(4), 431-435.

Malmo, R.B. (1975) . On emotions, needs and our archaic brain. New York, Holt, Rinehart and Winston.

Meyer, D.E., Osman, A.M., Irwin, D.E. and Yantis, S. (1990). Modern mental chronometry. Biological Psychology, $26,3-67$.

Moiseeva, N.(1985). Time Perception in Sport, Tashkent, Medicine, 72-115. 
Musumeci, M. and Misiak, H. (1974). Circadian variation of critical flicker frequency among children. Perceptual and Motor Skills, 38, 751-754.

Nebylitsyn, V.D.(1972). Fundamental Properties of the Human Nervous System, New York-London, Plenum Press.

Nebylitsyn, V.D. and Gray, J.A. (Eds), (1972). Biological Bases of Individual Behavior. New York, New York: Academic Press, Inc.

Ogura, C., et al. (1987). Comparative study of the effects of antidepressants on several physiological parameters in healthy volunteers. Neuropsychobiology, 17 (3), $139-144$

O'Hanlon, J., McGrath, J. et-al (1984). Body temperature and temporal acuity. Journal of Experimental Psychology, $102(5), 788-794$.

Patel, C. (1975). Twelve months follow-up of yoga and biofeedback in the management of hypertension. Biofeedback and Self-Control, Aldine Publishing, Chicago, 90-96.

Pathy, M.S., Bayer, A.J., and Stoker, M.J. (1986). A 
double blind comparison of chlormethiazole and temazepam in elderly patients with sleep disturbances. Acta Psychiatrica Scandinavica, 73, 99-103.

Powel, R. (1983). Flicker fusion as a typological index of nervous system reactivity. Perceptual and Motor Skills, $57(3), 701-702$.

Payne, J. (1982). Flicker fusion threshold and mental arousal. Perceptual and Motor Skills, 55(3), 995-1001.

Rosenbaum, D.A. (1991). Human Motor Control. Academic Press, Inc. Harcourt Brace Jovanovich Publishers: San Diego, New York, Boston, London.

Sainsbury, P. and Gibson, J. (1954). Symptoms of anxiety and tension and the accompanying psychological changes in the muscular system. Journal of Neurological Neurosurgical Psychiatry, 17, 216-224.

Schafer, E., \& Marcus, M. (1973). Self-stimulation alters human memory brain responses. Science, 181,175-177.

Schwin, R., Hill, S., Goodwin, D., Powell, B. (1974). Marijuana and critical flicker fusion: Evidence for 
perceptual sharpening. Journal of Nervous and Mental Disease, $158(2), 142-144$.

Shipman, w. (1964). Study in physiology of muscle tension. Archives of General Psychiatry, 11.

Smith, J.M. and Misiak, H. (1976). Critical flicker frequency and psychotropic drugs in normal human subjects a review. Psychopharmacology, 47, 175-182.

Stevens, L.T. (1886). On the time-sense. Mind, 11, 393404.

Swantantra J. (1981). Anxiety in relation to task complexity. Indian Journal of Clinical Psychology, 8,147149.

Teplov, B.M. (1963). New data for the study of nervous system properties in man. In Teplov B.M. (Ed), . Typological Features of Higher Nervous Activity in Man, Vol.3, Moscow, Academy of Pedagogical Sciences, RSFSR.

Teplov, B.M. (1972). The problem of types of human higher nervous activity and methods of determining them. In Nebylitsyn, V.D. and Gray (Eds.), Biological Bases of 
Individual Behavior, New York and London: Academic Press (111).

Tsukanov, B.I. (1985). Estimation of Error of Perceived Duration. Voprosy Psychologii, 3, 149-153.

Urgelles, L., and Luis A. (1982). Fatigue. Revista del Hospital Psiquiatrico de la Habana (English abstract), 23, $423-426$.

Verigna, F. (1963). Phase shifts in the human retina. Nature, 197, 998-999.

Volle, M., Brisson G., Perusse, M., Tanaka, M., Doyon, Y.(1979). Compressed work week: psychophysiological and psychological repercussions. Ergonomics, 22(9), 1001-1010.

Volle, M., Brisson G. (1980). Critical fusion frequency and fatigue measurement: A review, Travail-Humain, 43(1), 65-86.

Vysochin, U. (1978). Polymyography - method of evaluation of the functional condition of the muscular system in athletes. Theory and Practice of Physical Culture, 6, 26-29. 
Warrington, S.J., Ankier, S., Turner, P. (1986). Evaluation of possible interactions between ethanol and trazodone or amitriptyline. Neuropsychobiology, 15 (supp 1), $31-37$.

Weber, A., Fussler, C., O'Hanlon, J., Gierer, R., Granjean, E. (1980). Psychophysiological effects of repetitive tasks. Ergonomics, 23(11), 1033-1046.

Weber, A., Jermini, C., Grandjean, E. (1975). Relationship between objective and subjective assessment of experimentally induced fatigue. Ergonomics, 18(2), 151-156.

Wenger, M. (1938). Some relationships between muscular processes and personality and their factorial analysis. Child Development, 9, 261-276.

Wenger, M. (1943). An attempt to appraise individual differences in level of muscular tension. Journal of Experimental Psychology, 32, 213-235.

Wilson, A., Housberger, etal (1975). Transcendental meditation and asthma. Biofeedback and Self-control, Chicago, Aldine Publishing, 83-88. 
Wing, A. W. (1980) The long and short timing in response sequences. Tutorials in Motor Behavior, 469-486.

Wing, A.M., \& Kristofferson, A.B. (1973). Response delays and the timing of discrete motor responses. Perception and Psychophysics, 14,5-12.

Wing, A.W., Keele, S., \& Margolin, D.I. (1984). Motor disorder and the timing of repetitive movements. Annals New York Academy of Sciences, 423, 183-192.

Woodrow, H. (1930). The reproduction of temporal intervals. Journal of Experimental Psychology, 13, 473-499.

Woodrow, H. (1934). The temporal indifference interval determined by the method of mean error. Journal of Experimental Psychology, 17, 167-188.

Woodworth, R.S. (1938). Experimental Psychology. New York: Holt.

Woodworth, R.S., Schlosberg, H. (1954). Experimental Psychology, (2nd ed.), New York: Holt.

Woolfolk, R. (1975). Psychophysiological correlates of meditation. Archives of General Psychiatry, 32,1326-1333. 